Supporting Information for

\title{
Bicyclic-capped Histone Deacetylase 6 Inhibitors with Improved Activity in a Model of Axonal Charcot-Marie-Tooth Disease
}

Sida Shen, ${ }^{\dagger, /}$ Veronick Benoy, ${ }^{\ddagger}, "$ Joel A. Bergman, ${ }^{\dagger, /}$ Jay H. Kalin, ${ }^{\dagger}$ Mariana Frojuello, ${ }^{\dagger}$ Giulio Vistoli, ${ }^{\S}$ Wanda Haeck, ${ }^{*}$ Ludo Van Den Bosch, ${ }^{*}$, and Alan P. Kozikowski* ${ }^{*}$

${ }^{\dagger}$ Drug Discovery Program, University of Illinois at Chicago, $833 \mathrm{~S}$ Wood St, Chicago, IL, 60612, United States

${ }^{\ddagger}$ Laboratory of Neurobiology, Vesalius Research Center (VIB) and Leuven Research Institute for Neuroscience and Disease (LIND), KU Leuven, O\&N4 Herestraat 49, B3000 Leuven, Belgium.

${ }^{\S}$ Dipartimento di Scienze Farmaceutiche, Università degli Studi di Milano, Via Mangiagalli 25, 20133 Milano, Italy.

"These authors contributed equally to this work.

${ }^{*}$ Corresponding authors:

*L.v.d.B., Email: ludo.vandenbosch@vib-kuleuven.be. Phone: (+32)016 3306 81;

*A.P.K., Email: kozikowa@uic.edu. Phone: (+1)312 996 7577;

\section{Contents}

NMR spectra 
${ }^{1} \mathrm{H}$ NMR (400 MHz, $\mathrm{CDCl}_{3}$ ) and ${ }^{13} \mathrm{C} \mathrm{NMR}\left(100 \mathrm{MHz}, \mathrm{CDCl}_{3}\right)$ spectra for ester intermediate of compound $\mathbf{1}$.
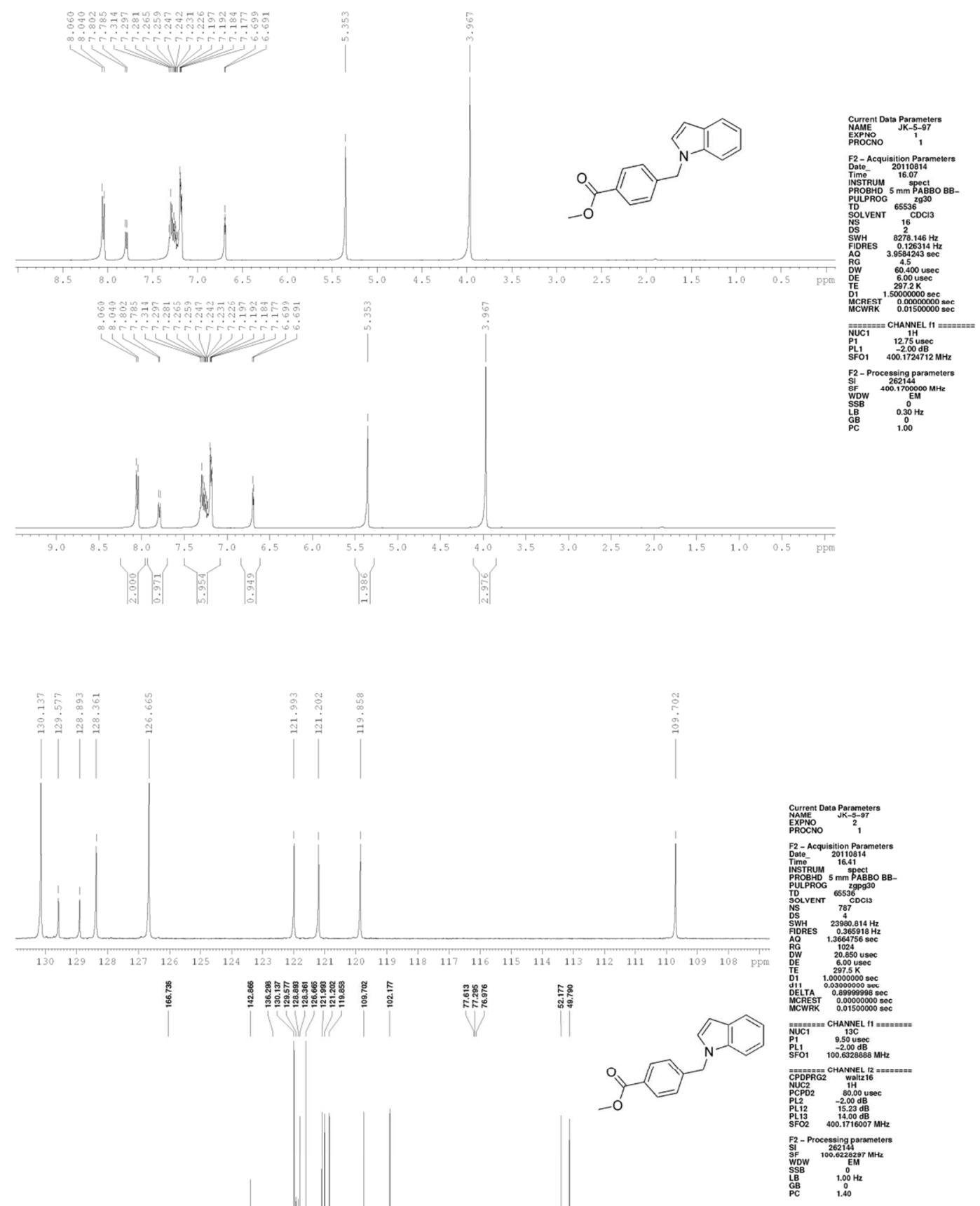
${ }^{1} \mathrm{H}$ NMR (400 MHz, DMSO- $d_{6}$ ) and ${ }^{13} \mathrm{C}$ NMR (100 MHz, DMSO- $d_{6}$ ) spectra for compound 4-(1-indolylmethyl)- $N$-hydroxybenzamide (1).
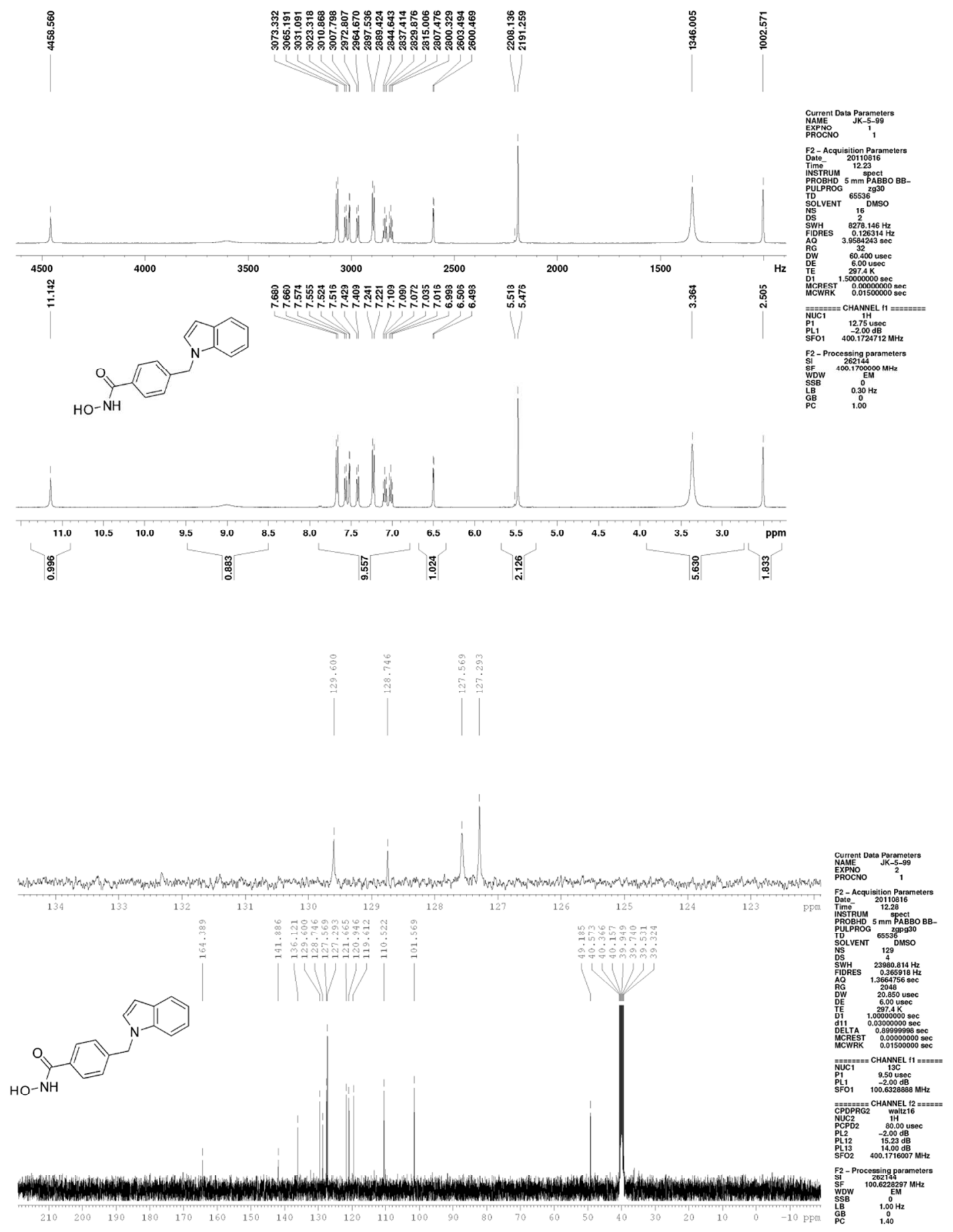
${ }^{1} \mathrm{H}$ NMR $\left(400 \mathrm{MHz}, \mathrm{CDCl}_{3}\right)$ and ${ }^{13} \mathrm{C}$ NMR $\left(100 \mathrm{MHz}, \mathrm{CDCl}_{3}\right)$ spectra for ester intermediate of compound 2
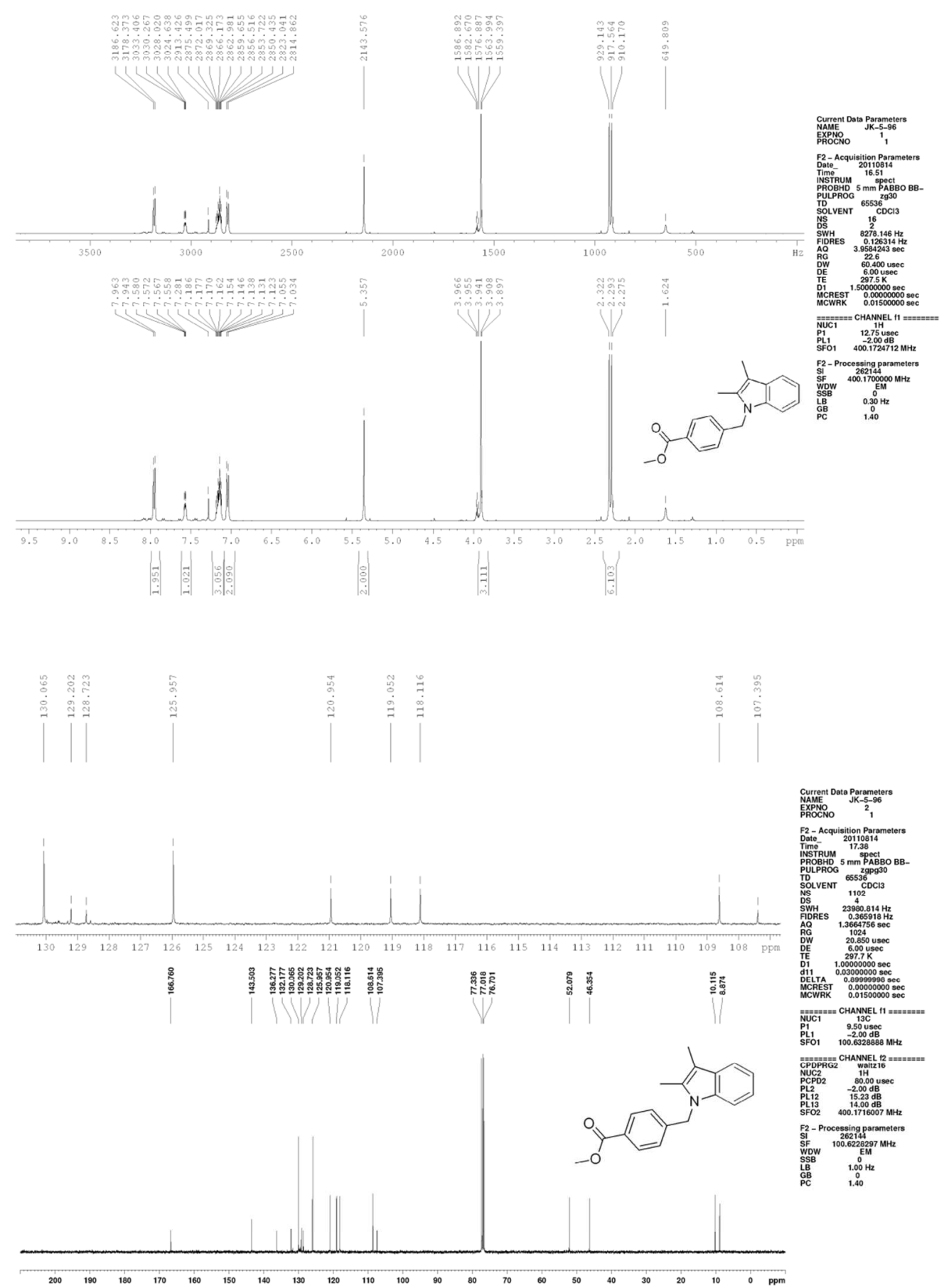
${ }^{1} \mathrm{H}$ NMR (400 MHz, DMSO- $d_{6}$ ) and ${ }^{13} \mathrm{C}$ NMR (100 MHz, DMSO- $d_{6}$ ) spectra for compound 4-[(2,3-dimethyl-1-indolyl)methyl]- $N$-hydroxybenzamide (2).
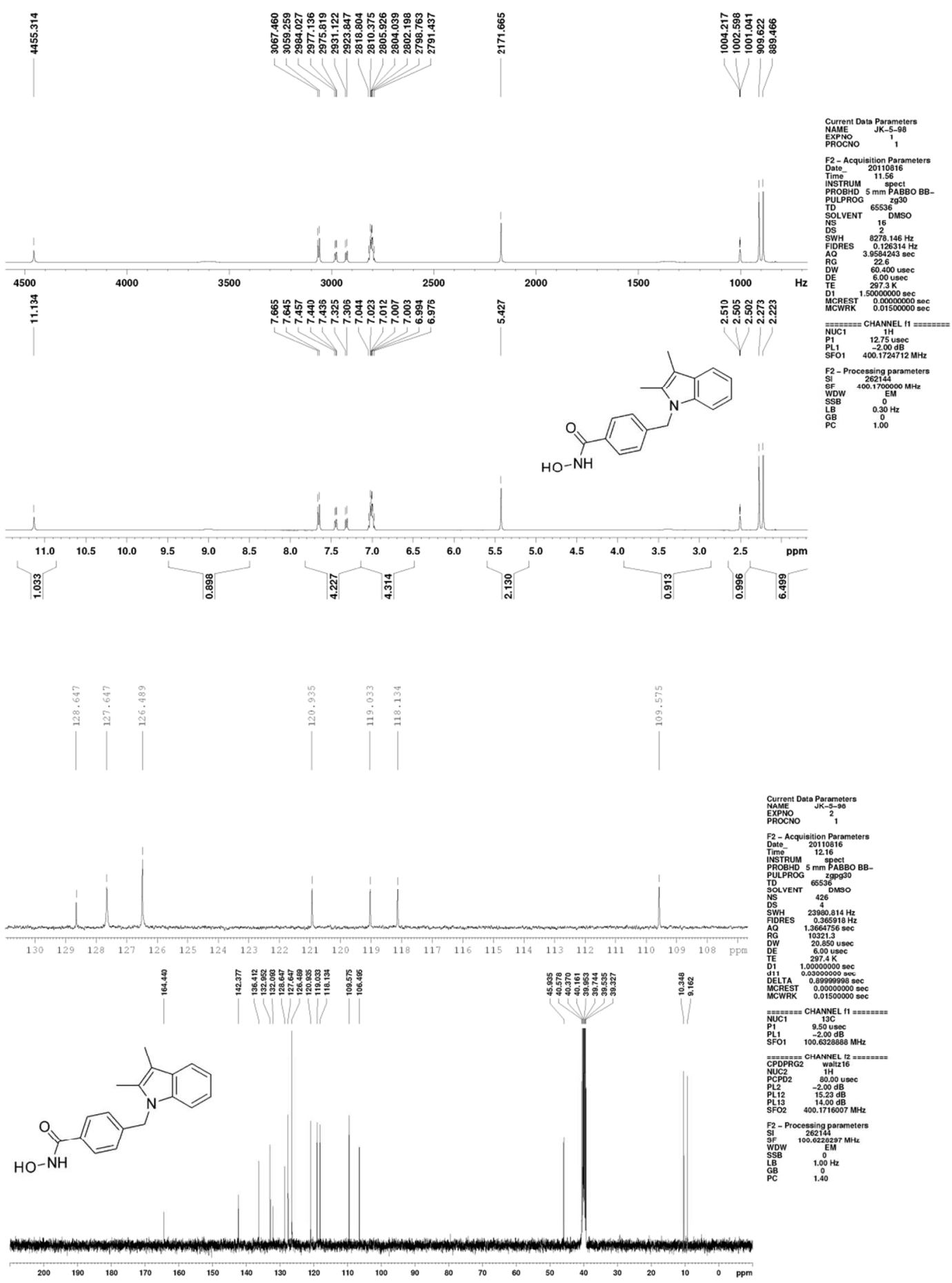
${ }^{1} \mathrm{H}$ NMR $\left(400 \mathrm{MHz}, \mathrm{CDCl}_{3}\right)$ and ${ }^{13} \mathrm{C} \mathrm{NMR}\left(100 \mathrm{MHz}, \mathrm{CDCl}_{3}\right)$ spectra for ester intermediate of compound $\mathbf{3}$
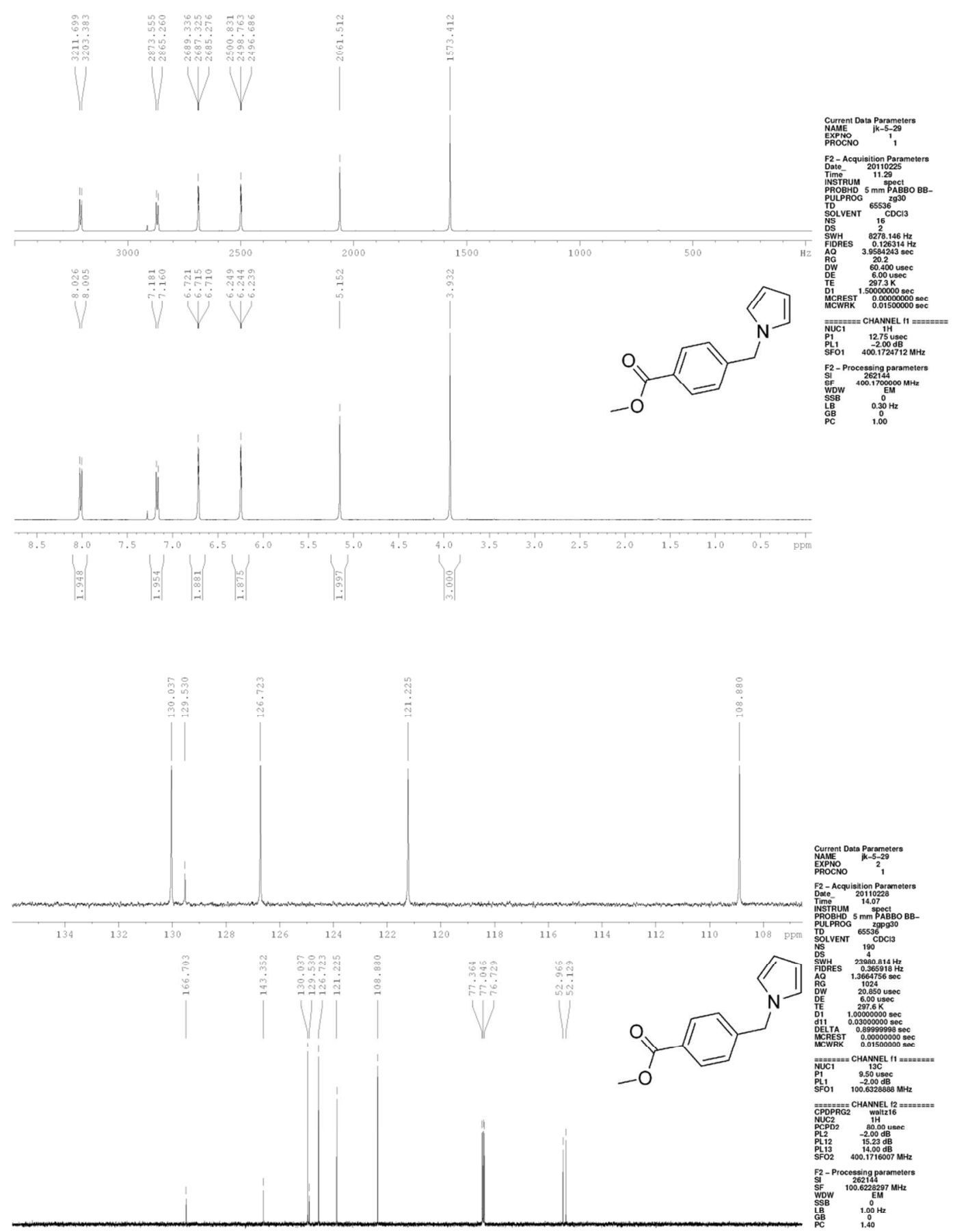
${ }^{1} \mathrm{H}$ NMR (400 MHz, CD $\left.\mathrm{CD}_{3} \mathrm{O}\right)$ and ${ }^{13} \mathrm{C}$ NMR (100 MHz, $\left.\mathrm{CD}_{3} \mathrm{OD}\right)$ spectra for compound 4-(1-pyrrolylmethyl)- $N$-hydroxybenzamide (3).
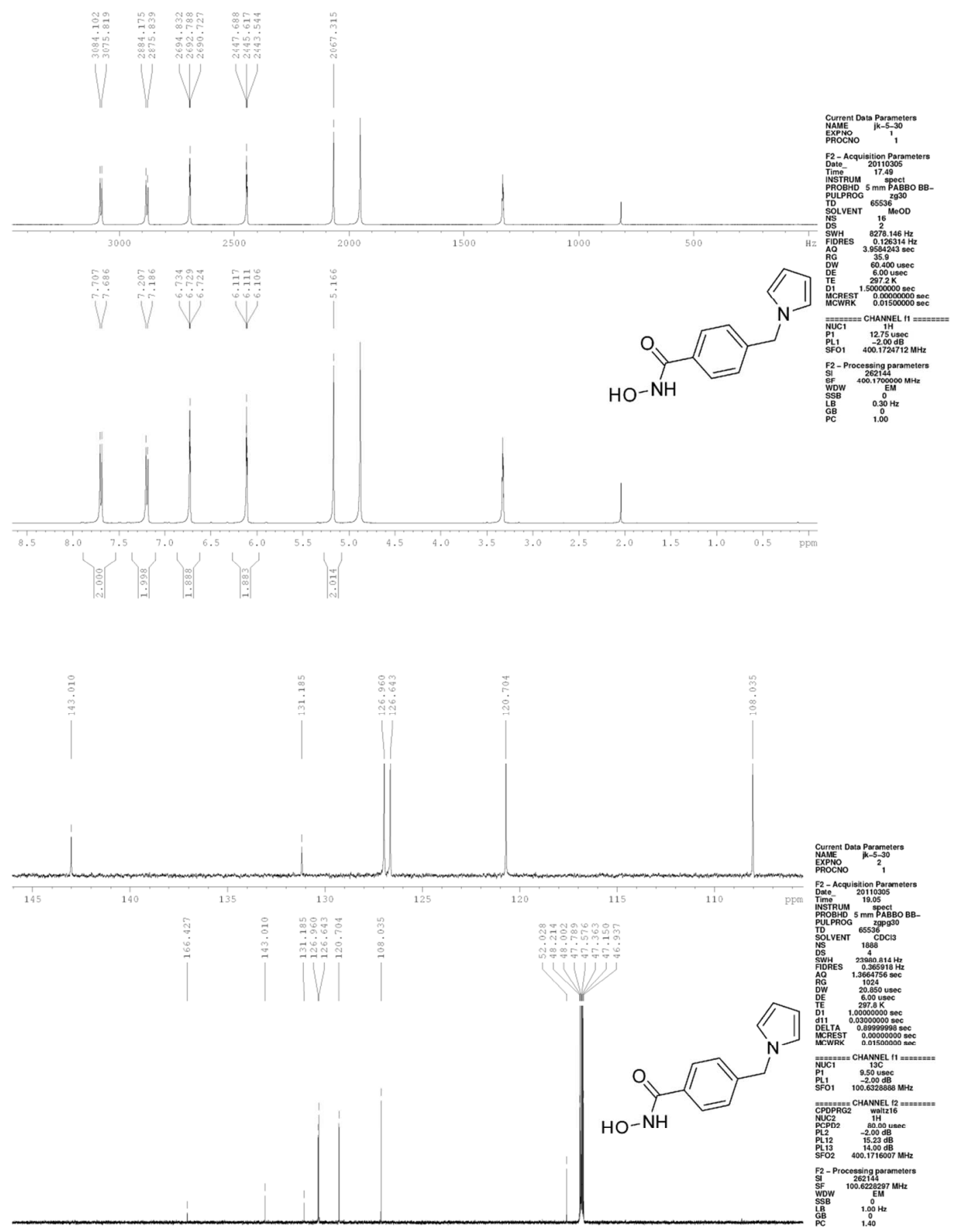
${ }^{1} \mathrm{H}$ NMR (400 MHz, $\mathrm{CDCl}_{3}$ ) and ${ }^{13} \mathrm{C} \mathrm{NMR}\left(100 \mathrm{MHz}, \mathrm{CDCl}_{3}\right)$ spectra for ester intermediate of compound 4
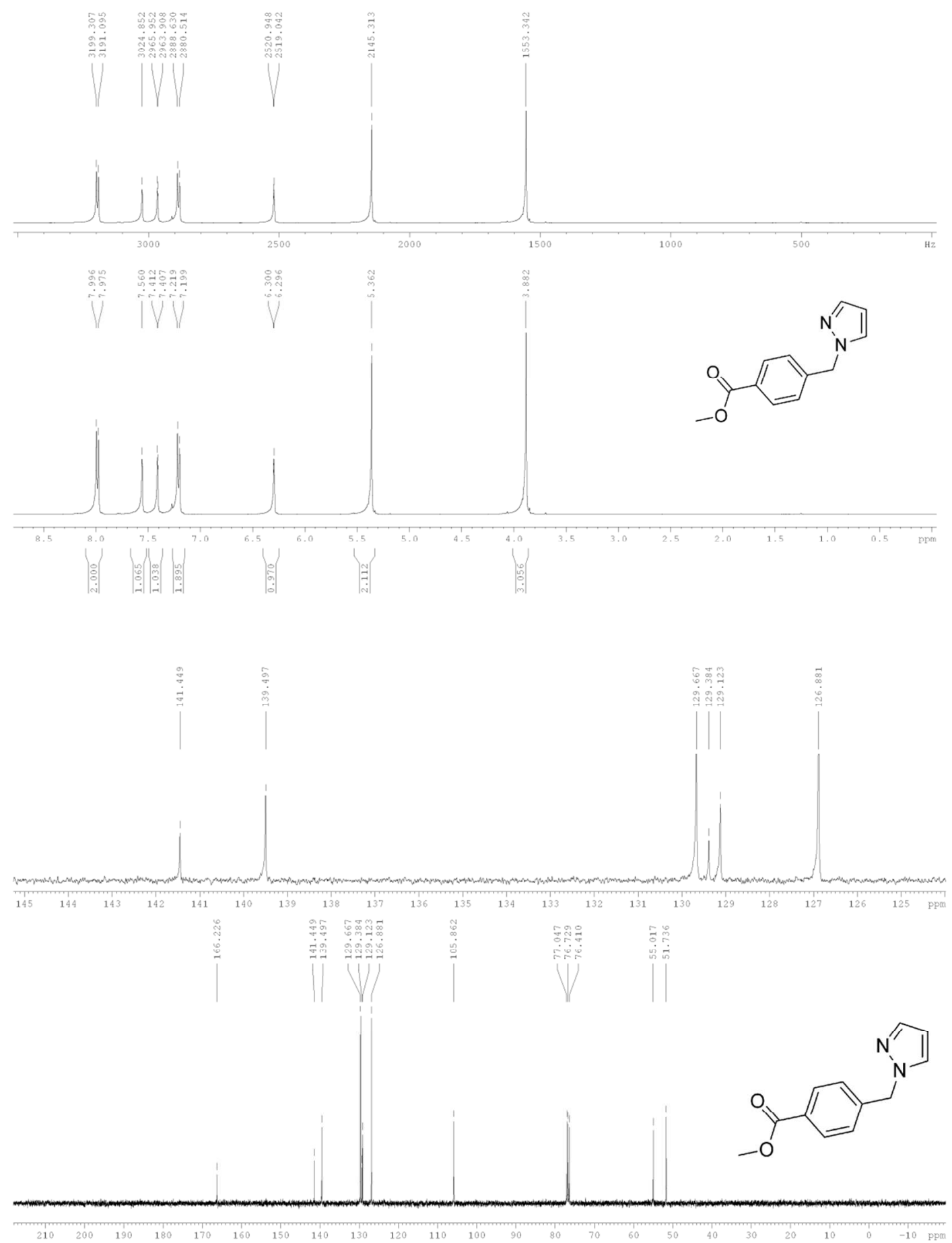
${ }^{1} \mathrm{H}$ NMR (400 MHz, $\left.\mathrm{CD}_{3} \mathrm{OD}\right)$ and ${ }^{13} \mathrm{C}$ NMR (100 MHz, $\left.\mathrm{CD}_{3} \mathrm{OD}\right)$ spectra for compound 4-(1-pyrazolylmethyl)- $N$-hydroxybenzamide (4).
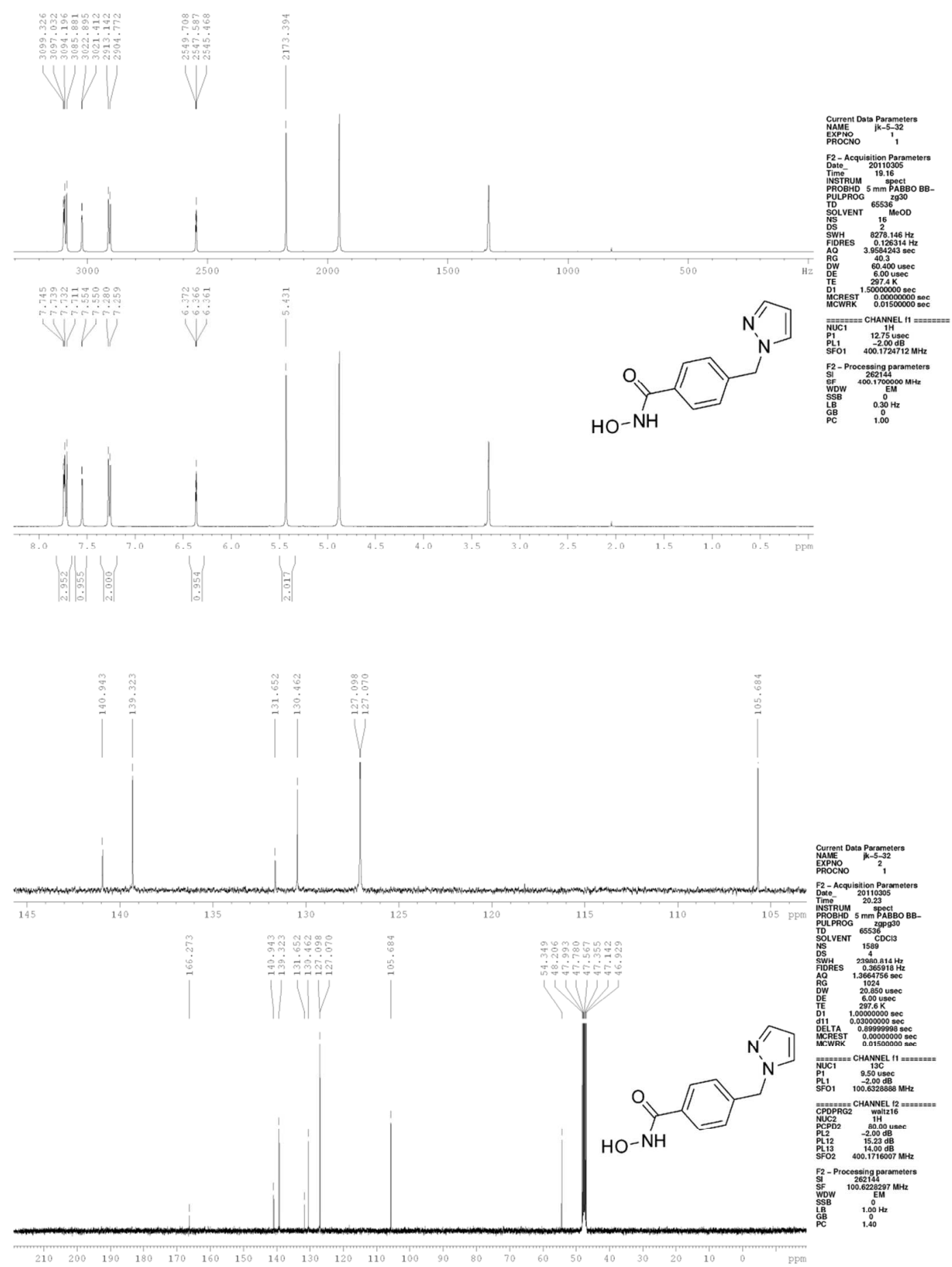
${ }^{1} \mathrm{H}$ NMR $\left(400 \mathrm{MHz}, \mathrm{CDCl}_{3}\right)$ and ${ }^{13} \mathrm{C} \mathrm{NMR}\left(100 \mathrm{MHz}, \mathrm{CDCl}_{3}\right)$ spectra for ester intermediate of compound 5.
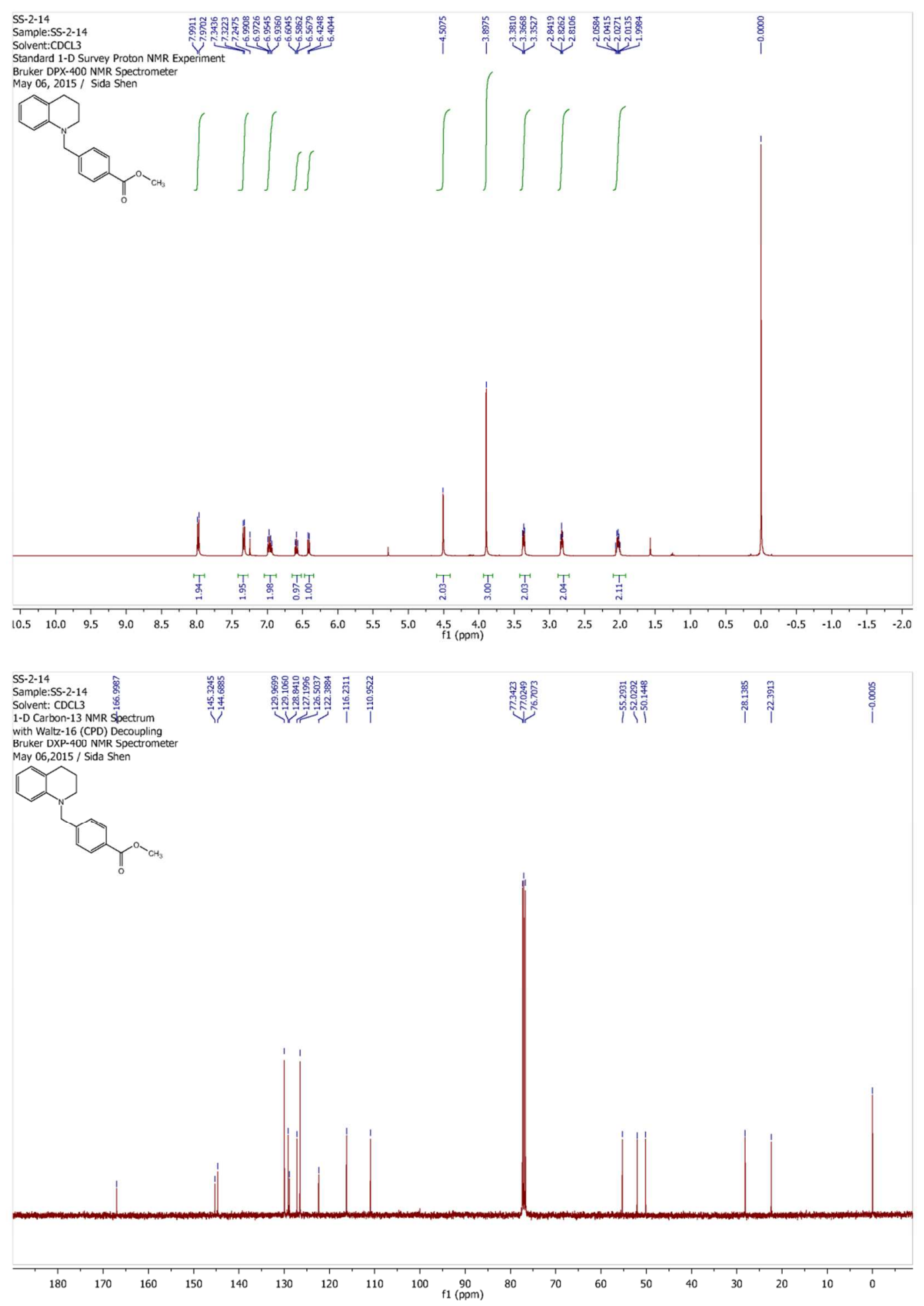
${ }^{1} \mathrm{H}$ NMR (400 MHz, DMSO- $d_{6}$ ) and ${ }^{13} \mathrm{C}$ NMR (100 MHz, DMSO- $d_{6}$ ) spectra for compound 4-[(1,2,3,4-tetrahydro-1-quinolyl)methyl]- $N$-hydroxybenzamide (5).

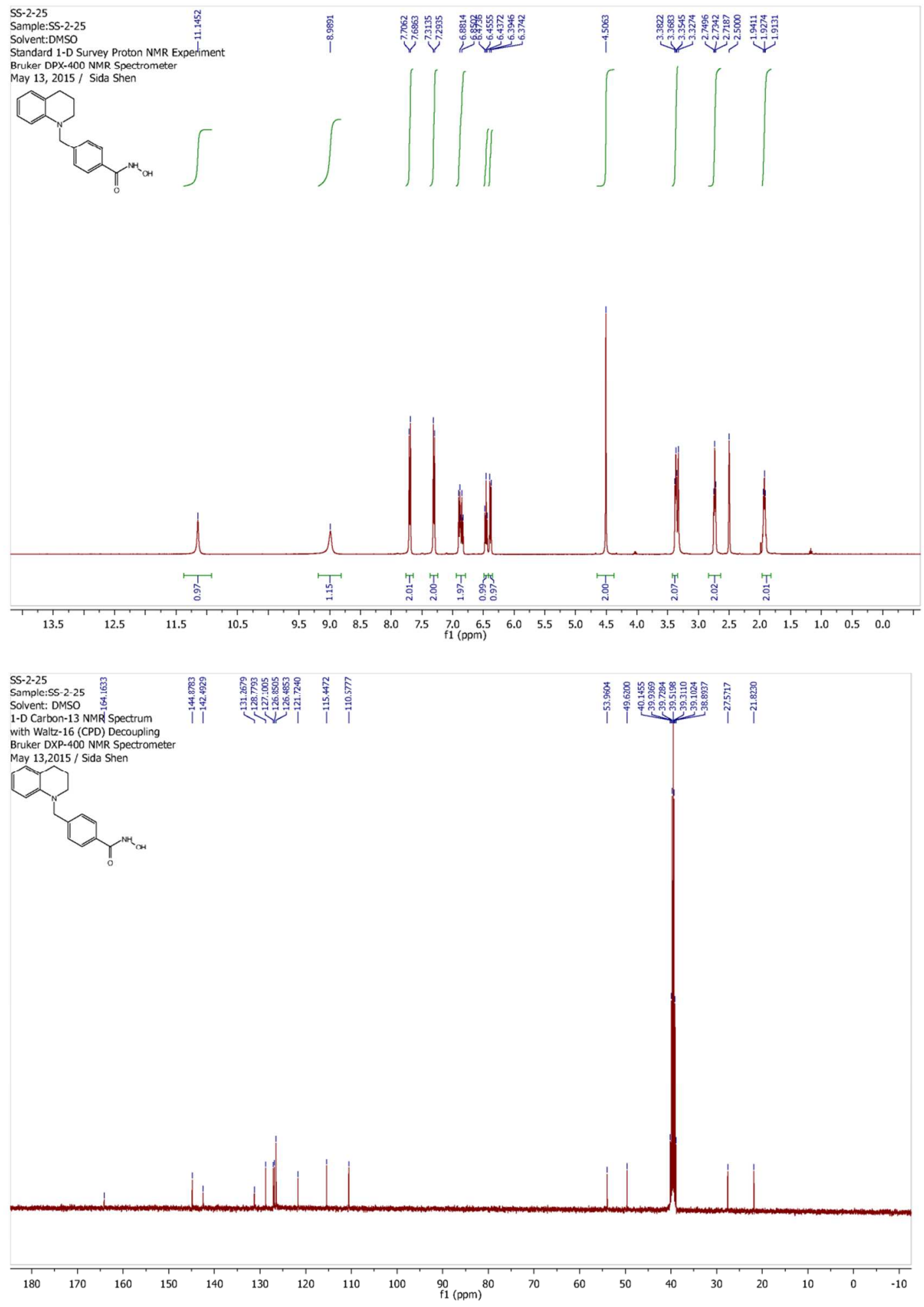


${ }^{1} \mathrm{H}$ NMR (400 MHz, $\left.\mathrm{CD}_{3} \mathrm{OD}\right)$ and ${ }^{13} \mathrm{C}$ NMR $\left(100 \mathrm{MHz}, \mathrm{CD}_{3} \mathrm{OD}\right)$ spectra for ester intermediate of compound 6 .
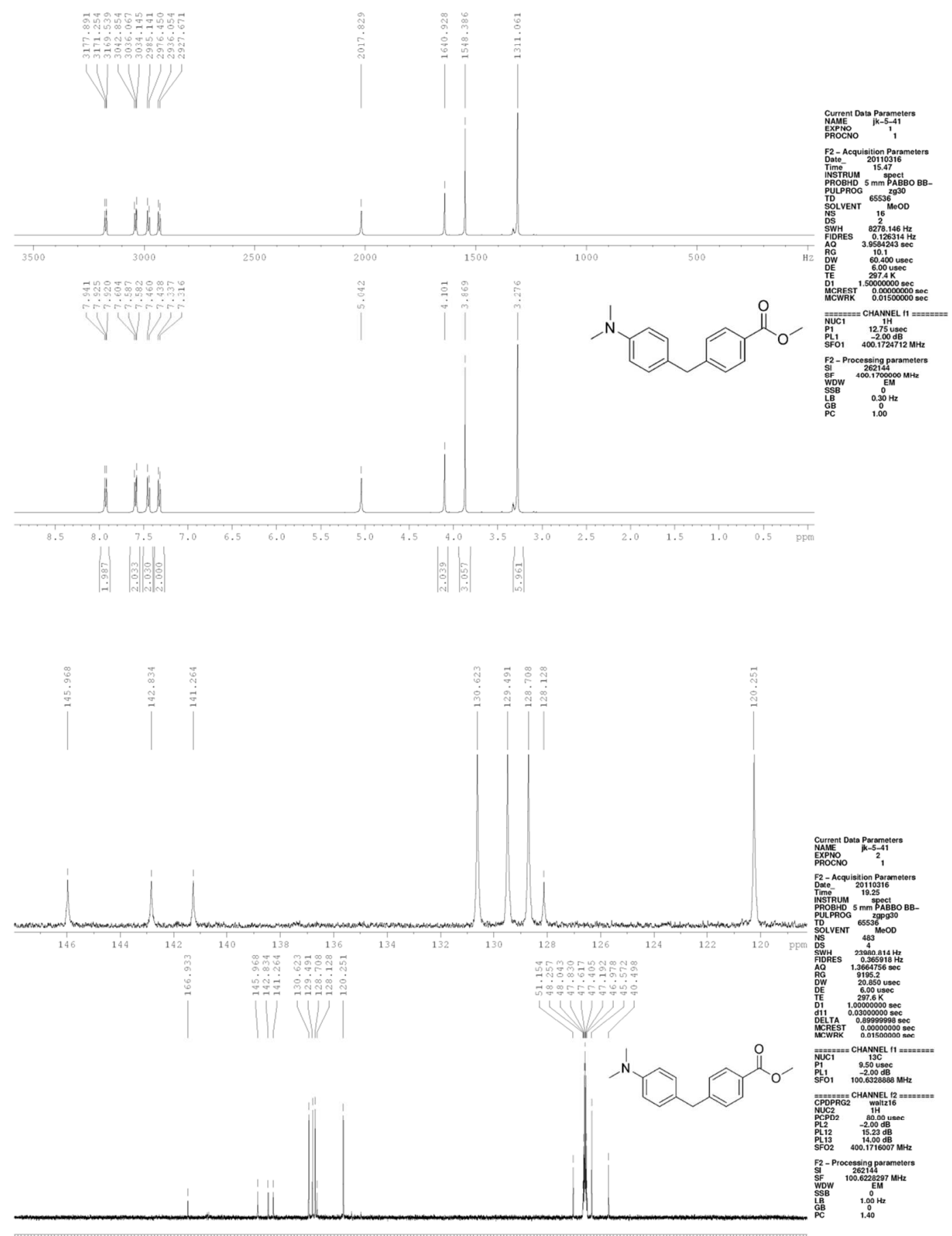
${ }^{1} \mathrm{H}$ NMR (400 MHz, CD $\left.\mathrm{CD}_{3} \mathrm{O}\right)$ and ${ }^{13} \mathrm{C}$ NMR (100 MHz, CD $\left.3 \mathrm{OD}\right)$ spectra for compound 4-[4-(dimethylamino)benzyl]- $N$-hydroxybenzamide (6).
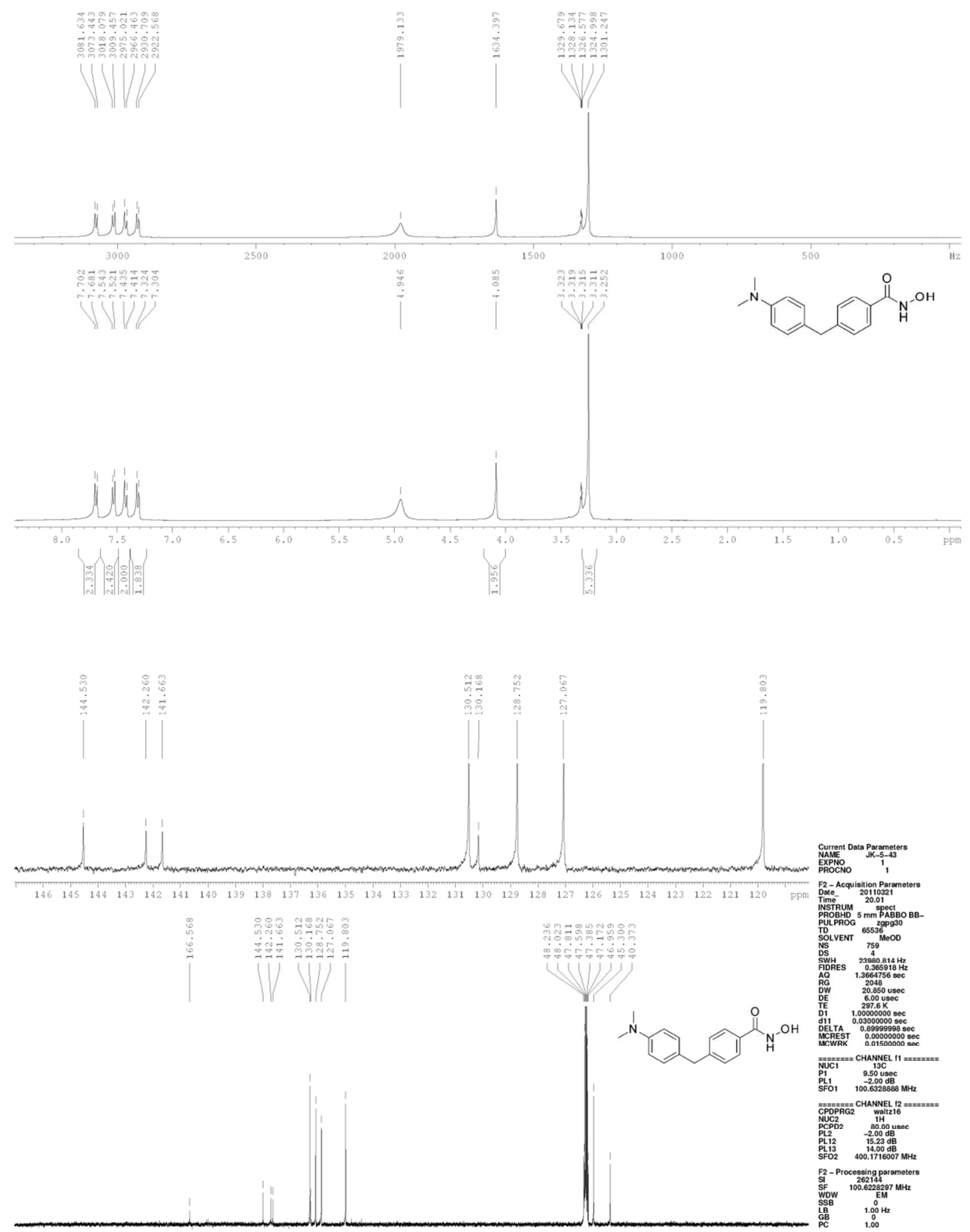
${ }^{1} \mathrm{H}$ NMR $\left(400 \mathrm{MHz}, \mathrm{CDCl}_{3}\right)$ and ${ }^{13} \mathrm{C} \mathrm{NMR}\left(100 \mathrm{MHz}, \mathrm{CDCl}_{3}\right)$ spectra for ester intermediate of compound 7.
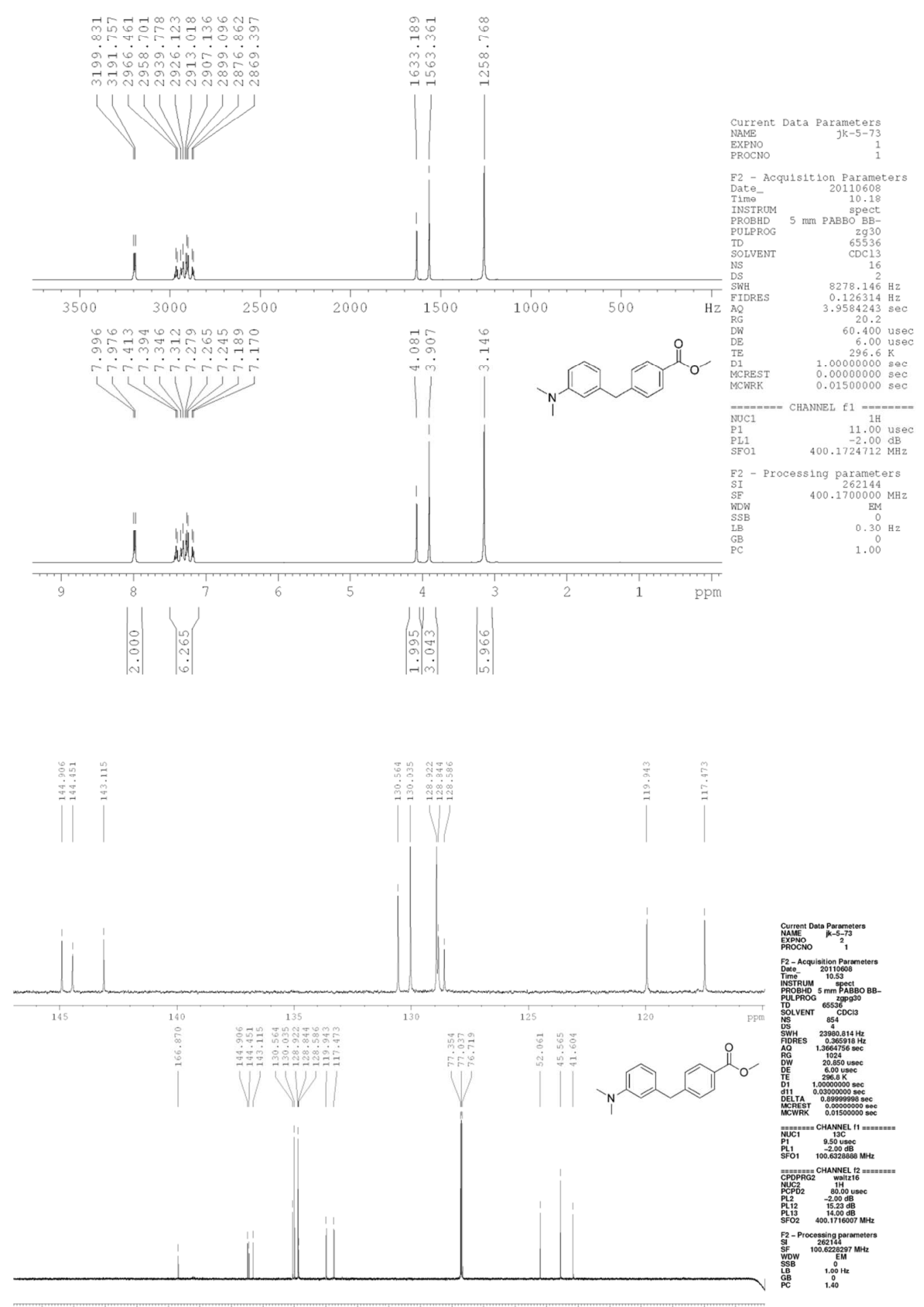
${ }^{1} \mathrm{H}$ NMR (400 MHz, CD $\left.\mathrm{CD}_{3} \mathrm{O}\right)$ and ${ }^{13} \mathrm{C}$ NMR (100 MHz, $\left.\mathrm{CD}_{3} \mathrm{OD}\right)$ spectra for compound 4-[3-(dimethylamino)benzyl]- $N$-hydroxybenzamide (7).

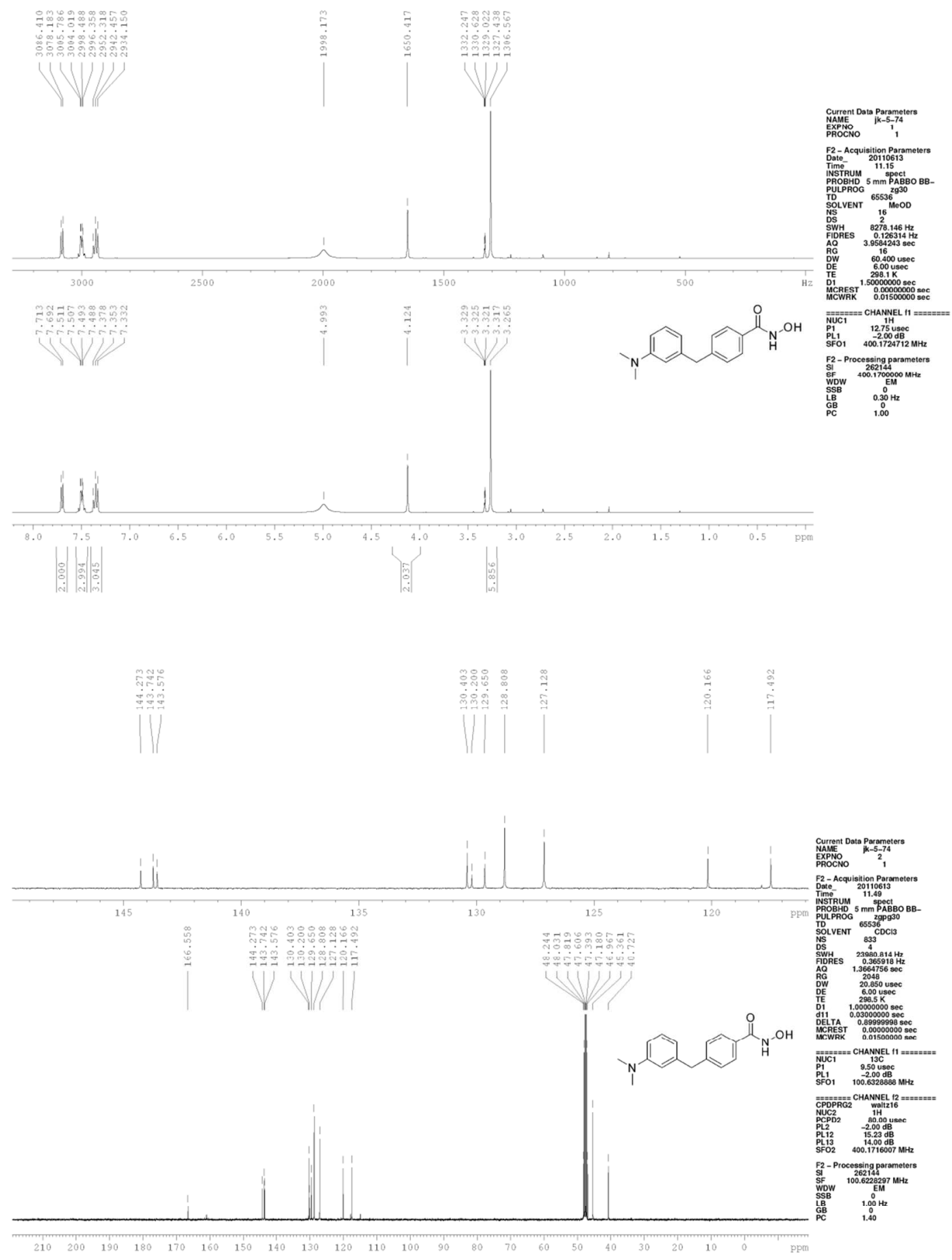


${ }^{1} \mathrm{H}$ NMR (400 MHz, $\mathrm{CDCl}_{3}$ ) and ${ }^{13} \mathrm{C} \mathrm{NMR}\left(100 \mathrm{MHz}, \mathrm{CDCl}_{3}\right)$ spectra for ester intermediate of compound 8.
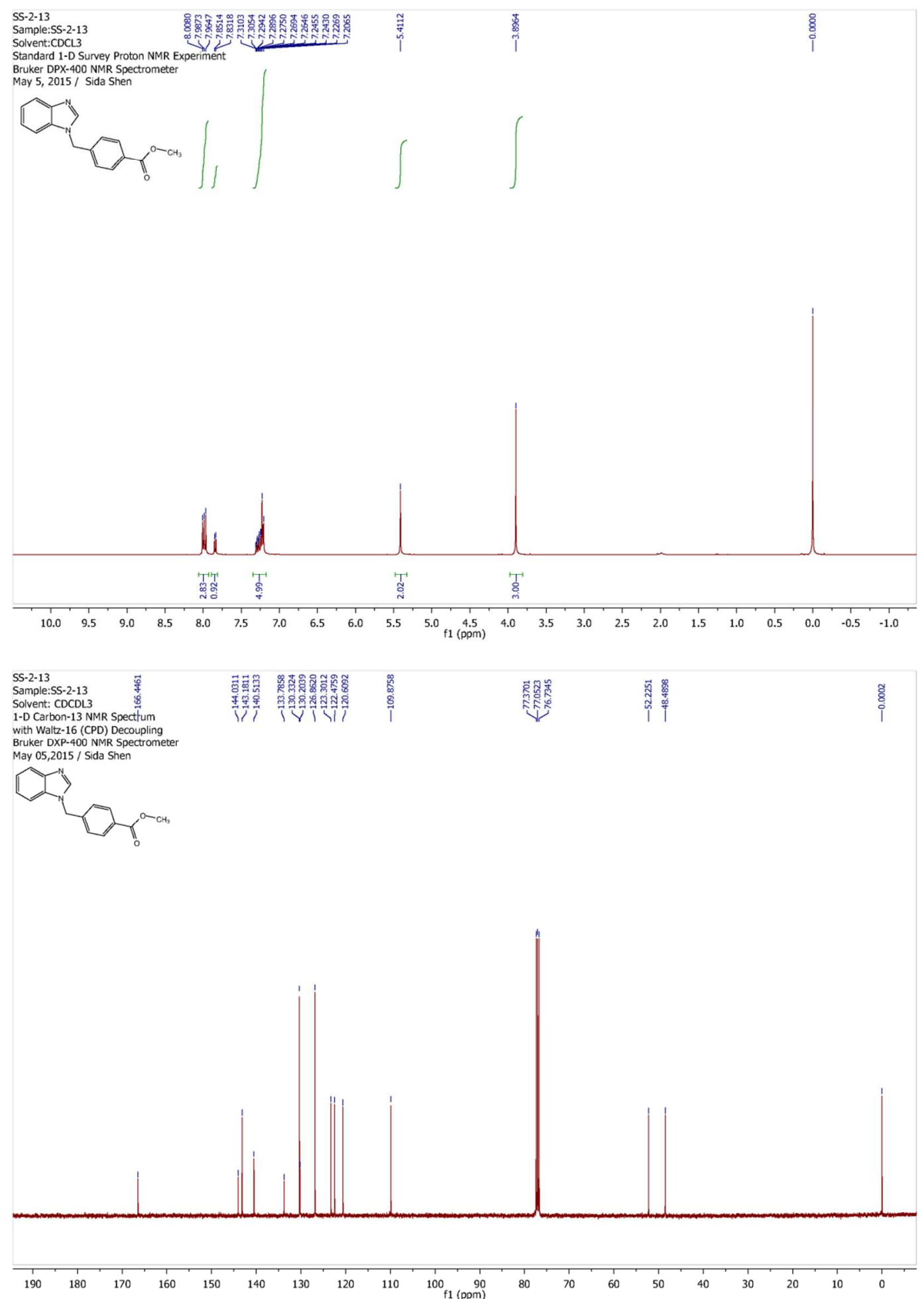
${ }^{1} \mathrm{H}$ NMR (400 MHz, DMSO- $d_{6}$ ) and ${ }^{13} \mathrm{C}$ NMR (100 MHz, DMSO- $d_{6}$ ) spectra for compound 4-(1-benzimidazolylmethyl)- $N$-hydroxybenzamide TFA Salt (8).

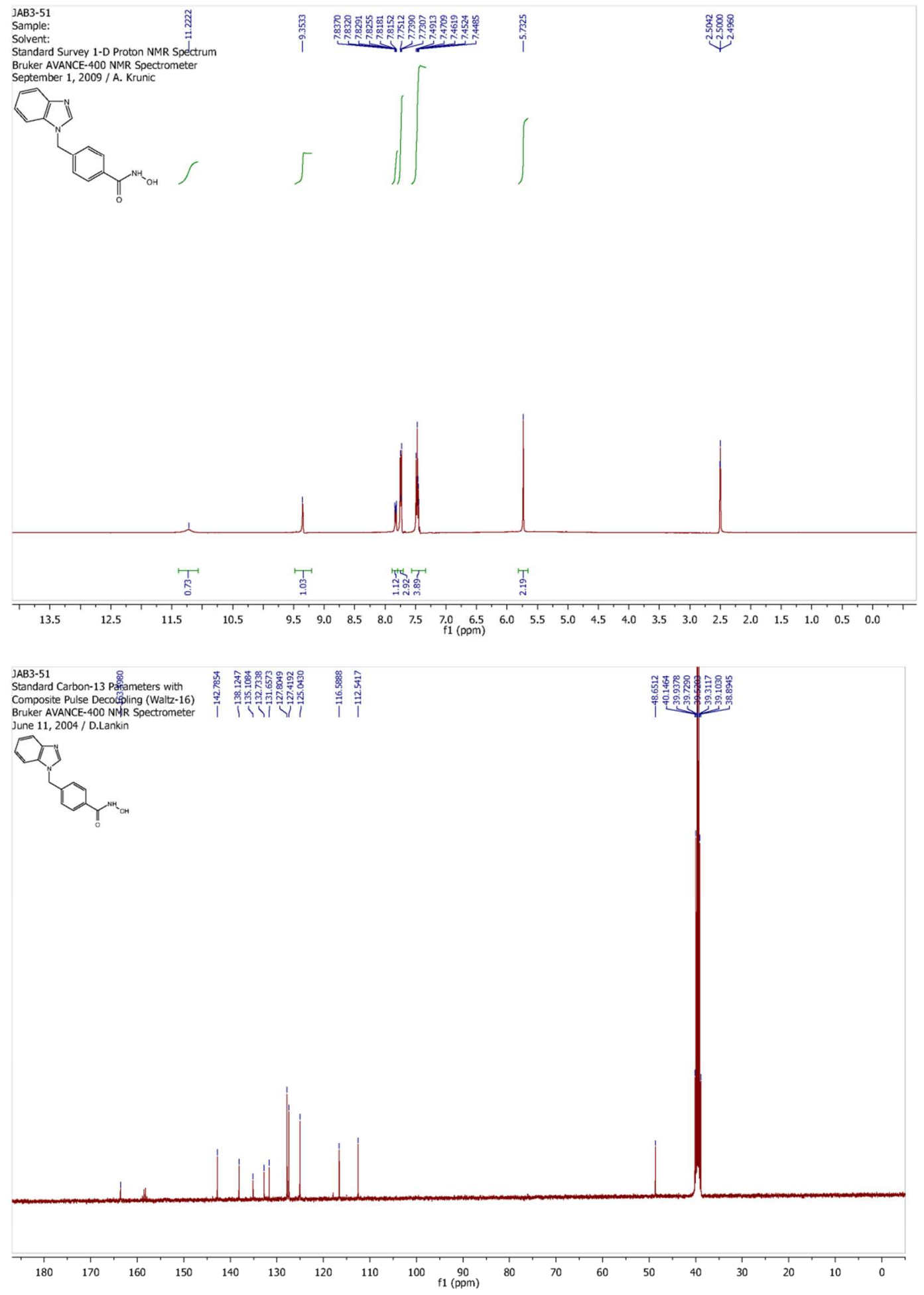


${ }^{1} \mathrm{H}$ NMR $\left(400 \mathrm{MHz}, \mathrm{CDCl}_{3}\right)$ and ${ }^{13} \mathrm{C} \mathrm{NMR}\left(100 \mathrm{MHz}, \mathrm{CDCl}_{3}\right)$ spectra for compound methyl 4-[(2-methyl-1-benzimidazolyl)methyl]benzoate (11a).

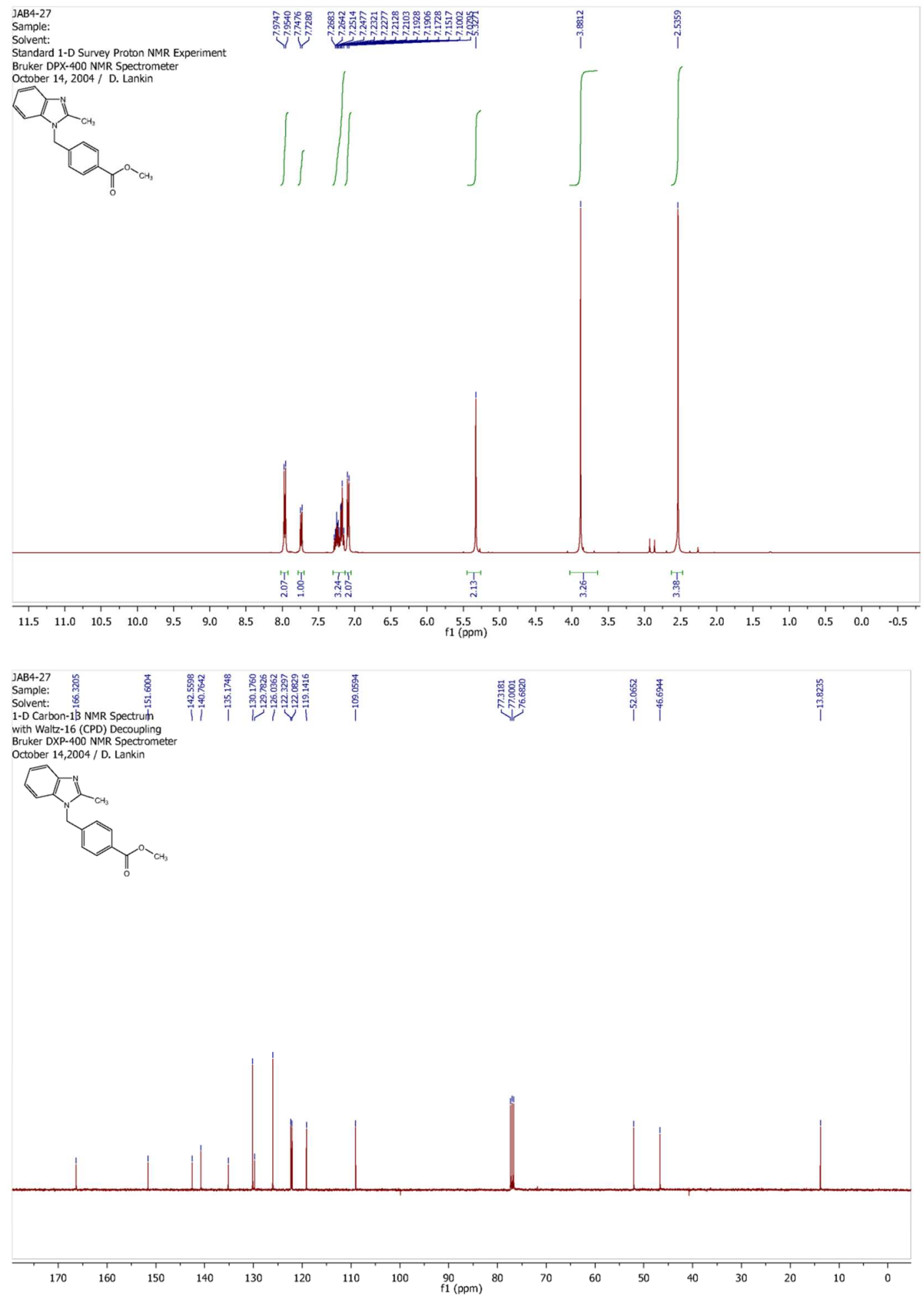


${ }^{1} \mathrm{H}$ NMR $\left(400 \mathrm{MHz}, \mathrm{CDCl}_{3}\right)$ and ${ }^{13} \mathrm{C} \mathrm{NMR}\left(100 \mathrm{MHz}, \mathrm{CDCl}_{3}\right)$ spectra for compound methyl 4-[(2-Isopropyl-1-benzimidazolyl)methyl]benzoate (11b).
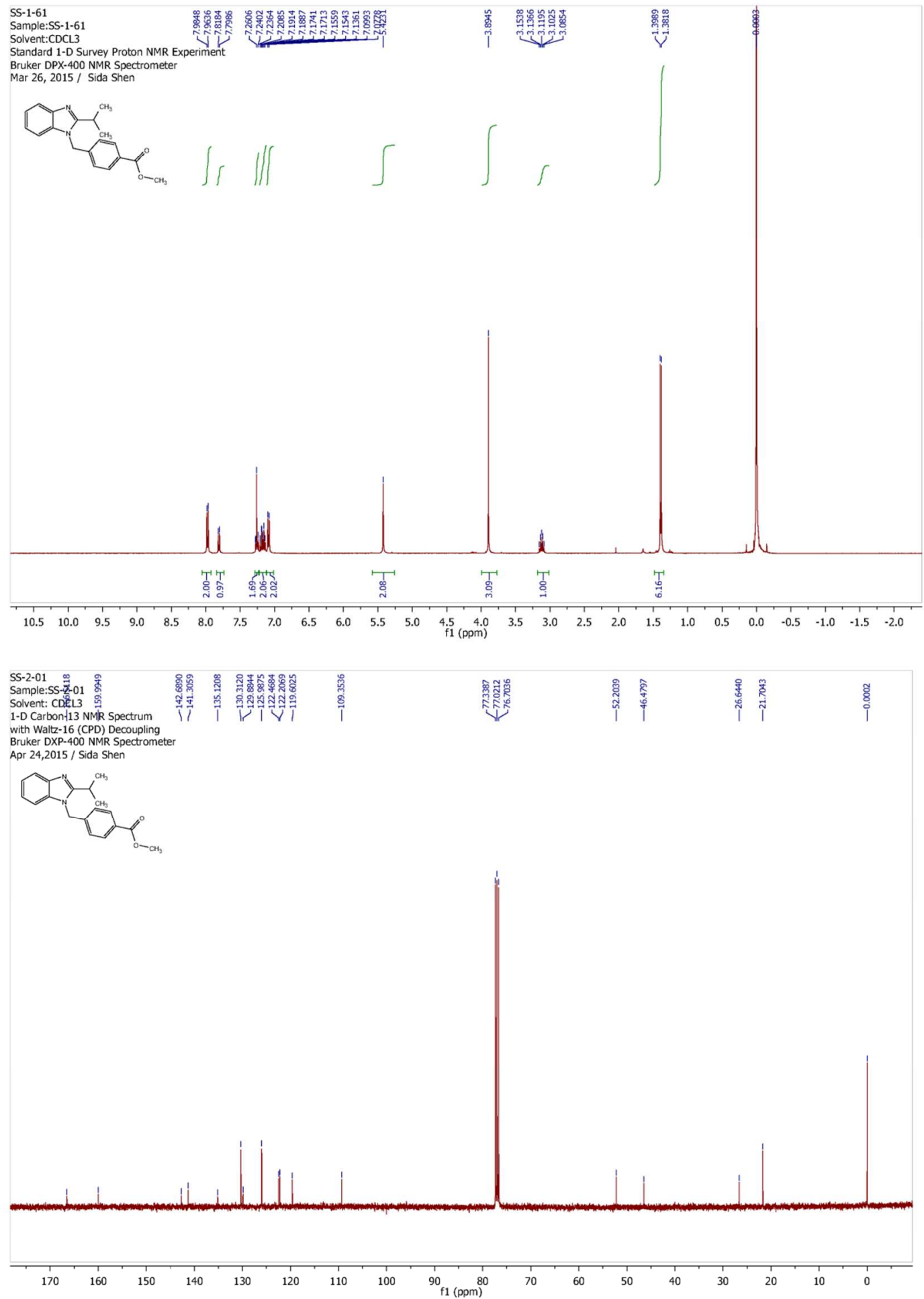
${ }^{1} \mathrm{H}$ NMR $\left(400 \mathrm{MHz}, \mathrm{CDCl}_{3}\right)$ and ${ }^{13} \mathrm{C} \mathrm{NMR}\left(100 \mathrm{MHz}, \mathrm{CDCl}_{3}\right)$ spectra for compound methyl 4-[[2-(Trifluoromethyl)-1-benzimidazolyl]methyl]benzoate (11c).
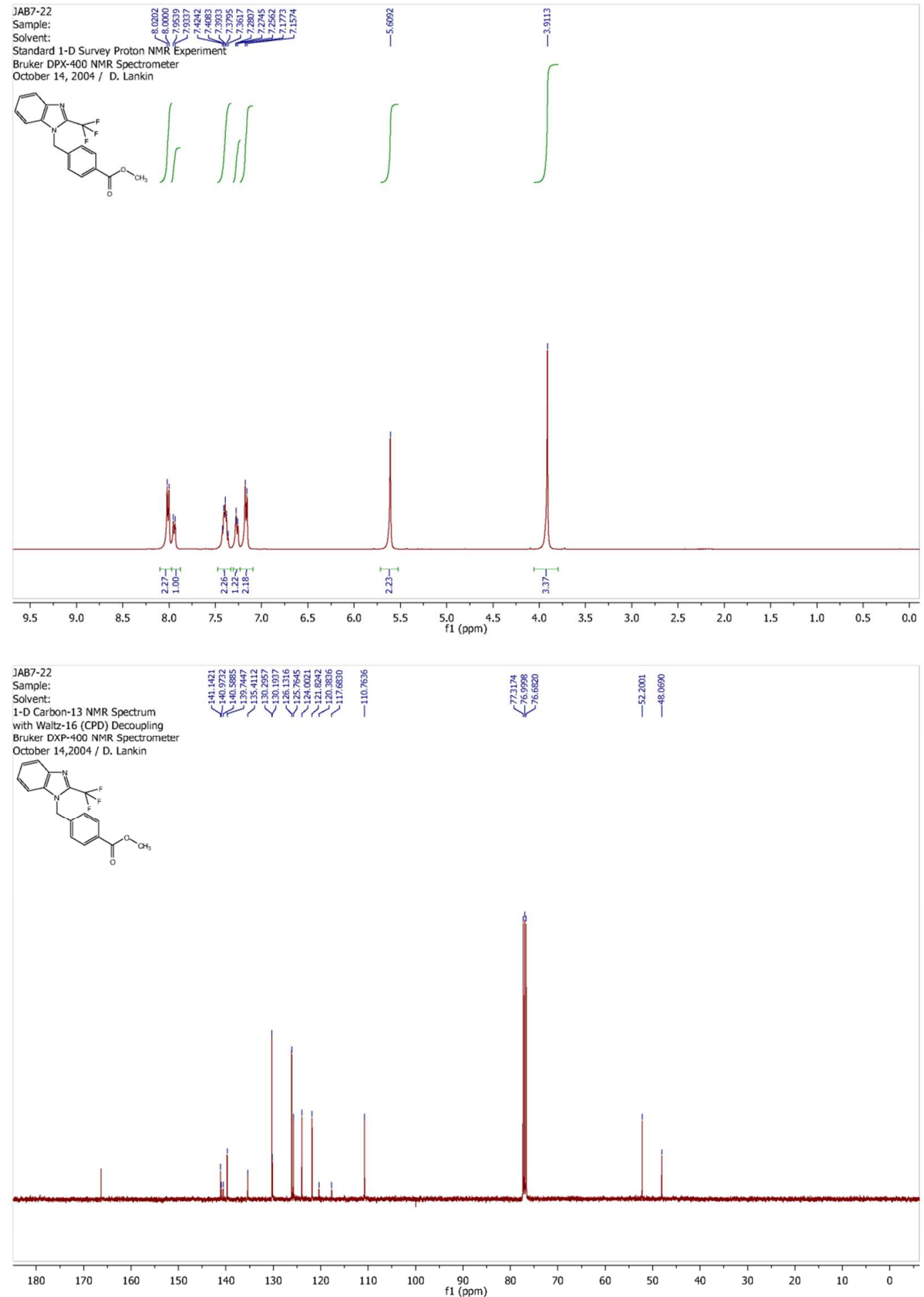
${ }^{1} \mathrm{H}$ NMR (400 MHz, $\mathrm{CD}_{3} \mathrm{OD}$ ) and ${ }^{13} \mathrm{C}$ NMR $\left(100 \mathrm{MHz}, \mathrm{CD}_{3} \mathrm{OD}\right)$ spectra for compound tert-butyl [3-(2-Benzimidazolyl)propyl]carbamate (14a).

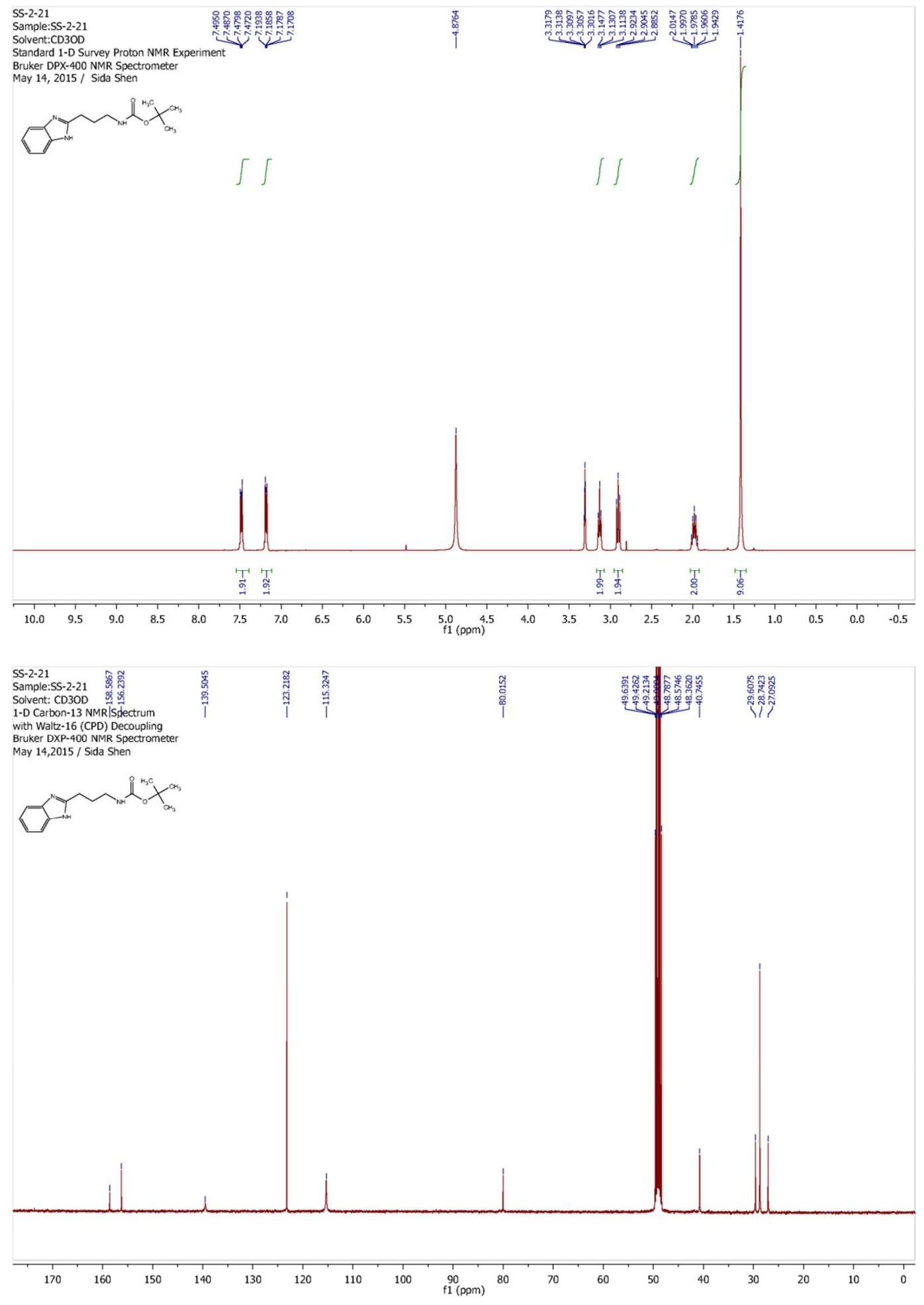


${ }^{1} \mathrm{H}$ NMR (400 MHz, DMSO- $d_{6}$ ) and ${ }^{13} \mathrm{C}$ NMR (100 MHz, DMSO- $d_{6}$ ) spectra for compound tert-butyl [2-(2-Benzimidazolyl)ethyl]carbamate (14b).

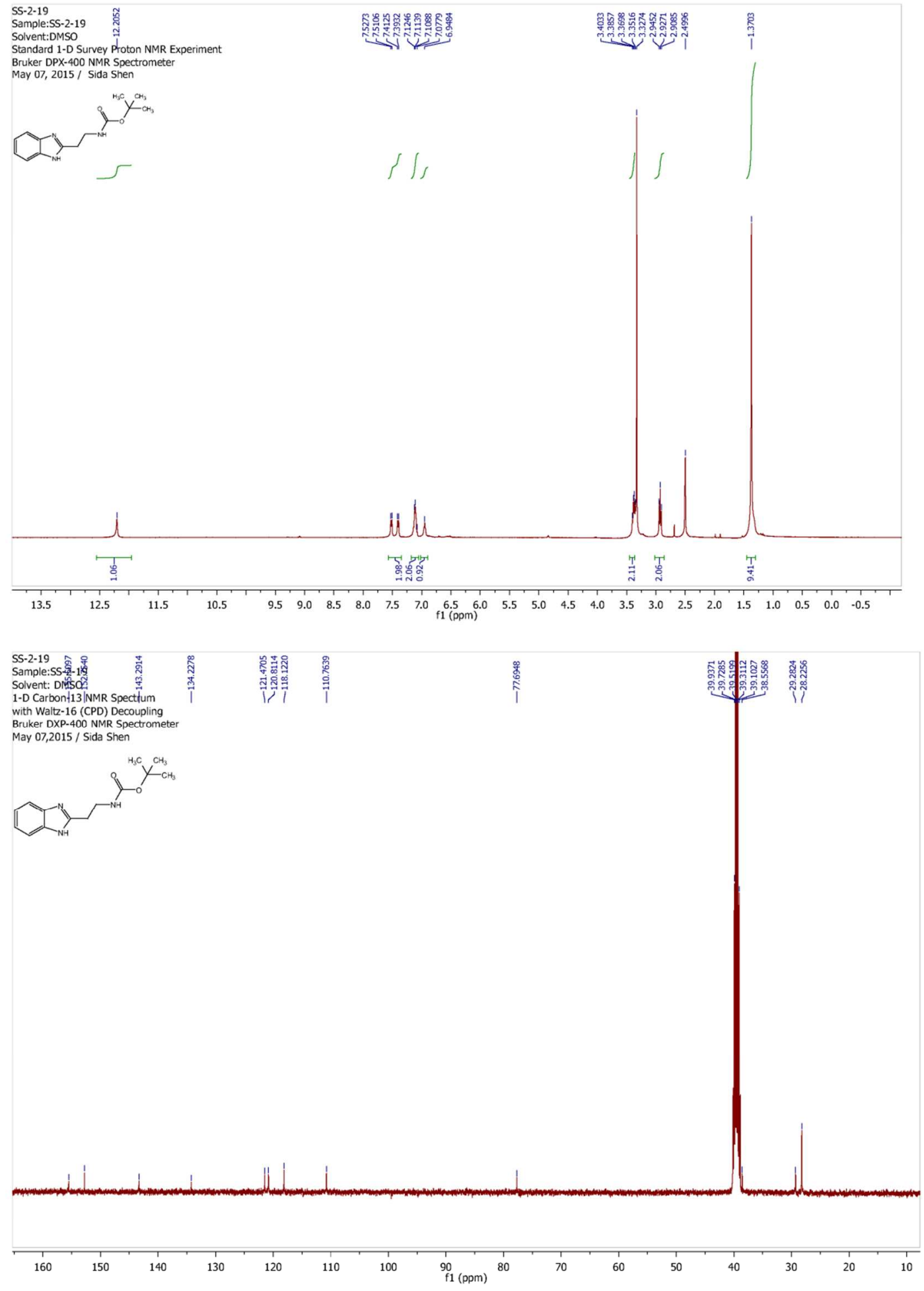


${ }^{1} \mathrm{H}$ NMR $\left(400 \mathrm{MHz}, \mathrm{CDCl}_{3}\right)$ and ${ }^{13} \mathrm{C} \mathrm{NMR}\left(100 \mathrm{MHz}, \mathrm{CDCl}_{3}\right)$ spectra for compound methyl 4-[[2-(3-Acetamidopropyl)-1-benzimidazolyl]methyl]benzoate (11d).
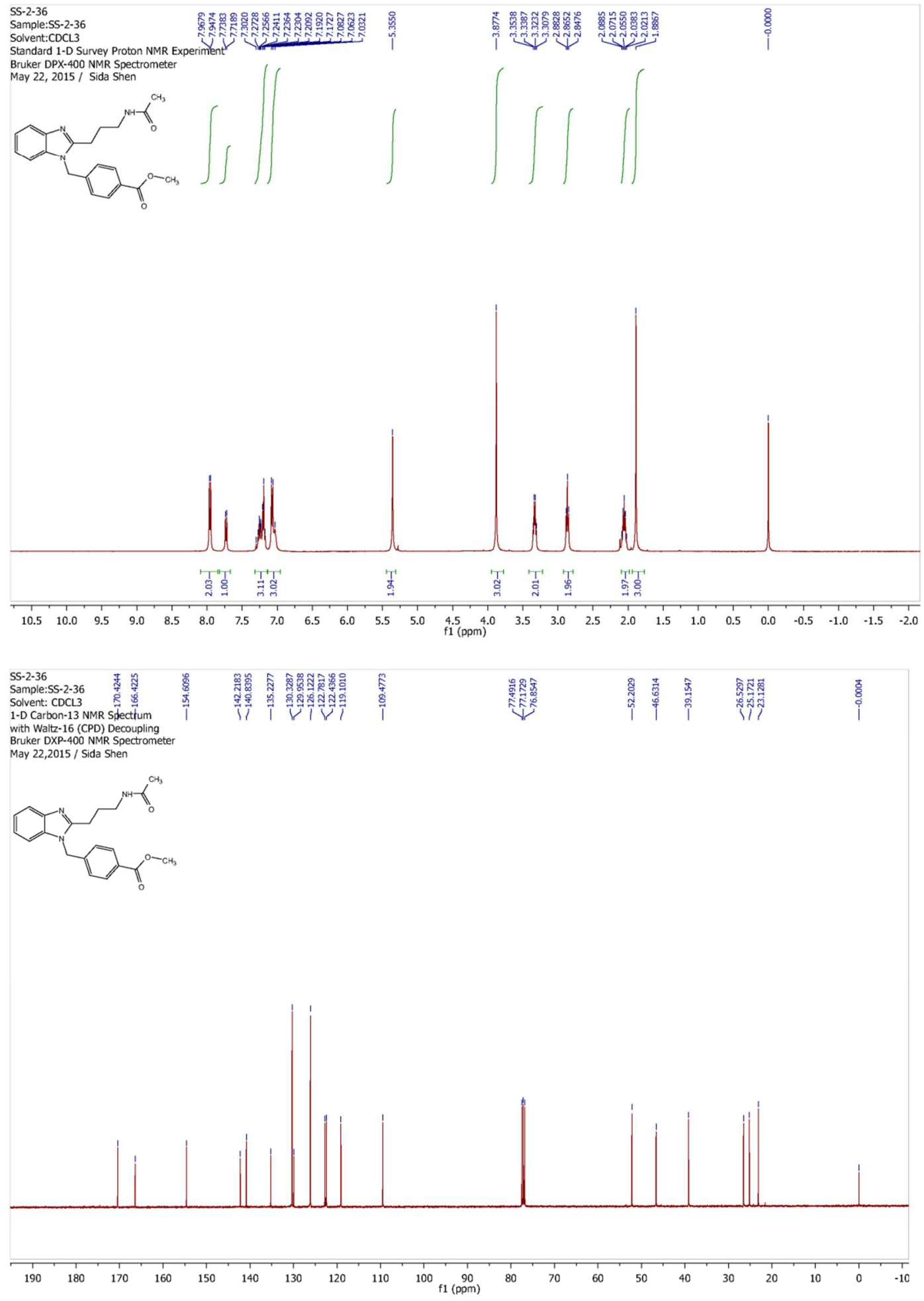
${ }^{1} \mathrm{H}$ NMR $\left(400 \mathrm{MHz}, \mathrm{CDCl}_{3}\right)$ and ${ }^{13} \mathrm{C} \mathrm{NMR}\left(100 \mathrm{MHz}, \mathrm{CDCl}_{3}\right)$ spectra for compound methyl 4-[[2-[2-(Dimethylamino)ethyl]-1-benzimidazolyl]methyl]benzoate (11e).

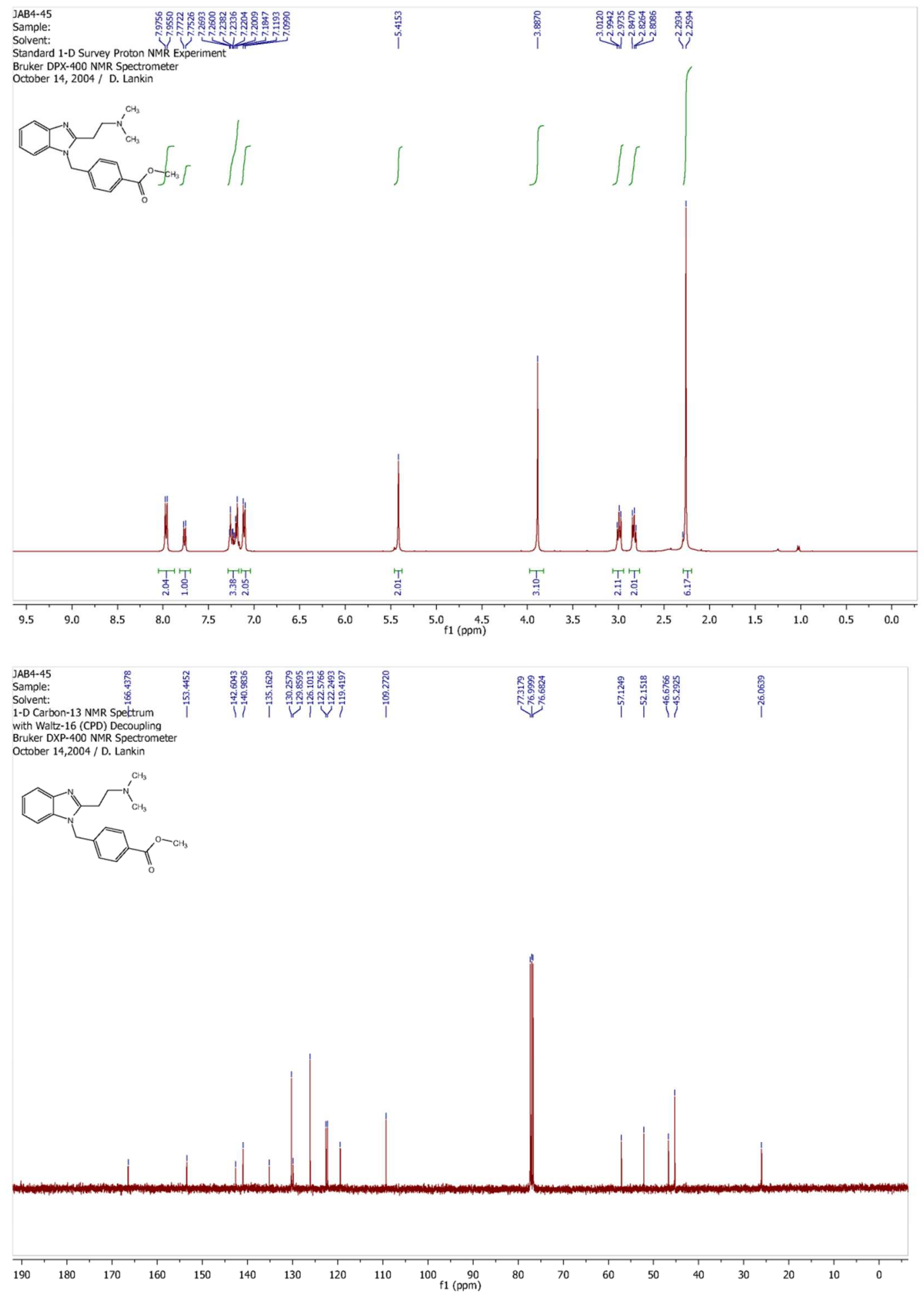


${ }^{1} \mathrm{H}$ NMR (400 MHz, DMSO- $d_{6}$ ) and ${ }^{13} \mathrm{C}$ NMR (100 MHz, DMSO- $d_{6}$ ) spectra for compound $N$-hydroxy-4-[2-methyl-1-benzimidazolyl)methyl]benzamide (12a).

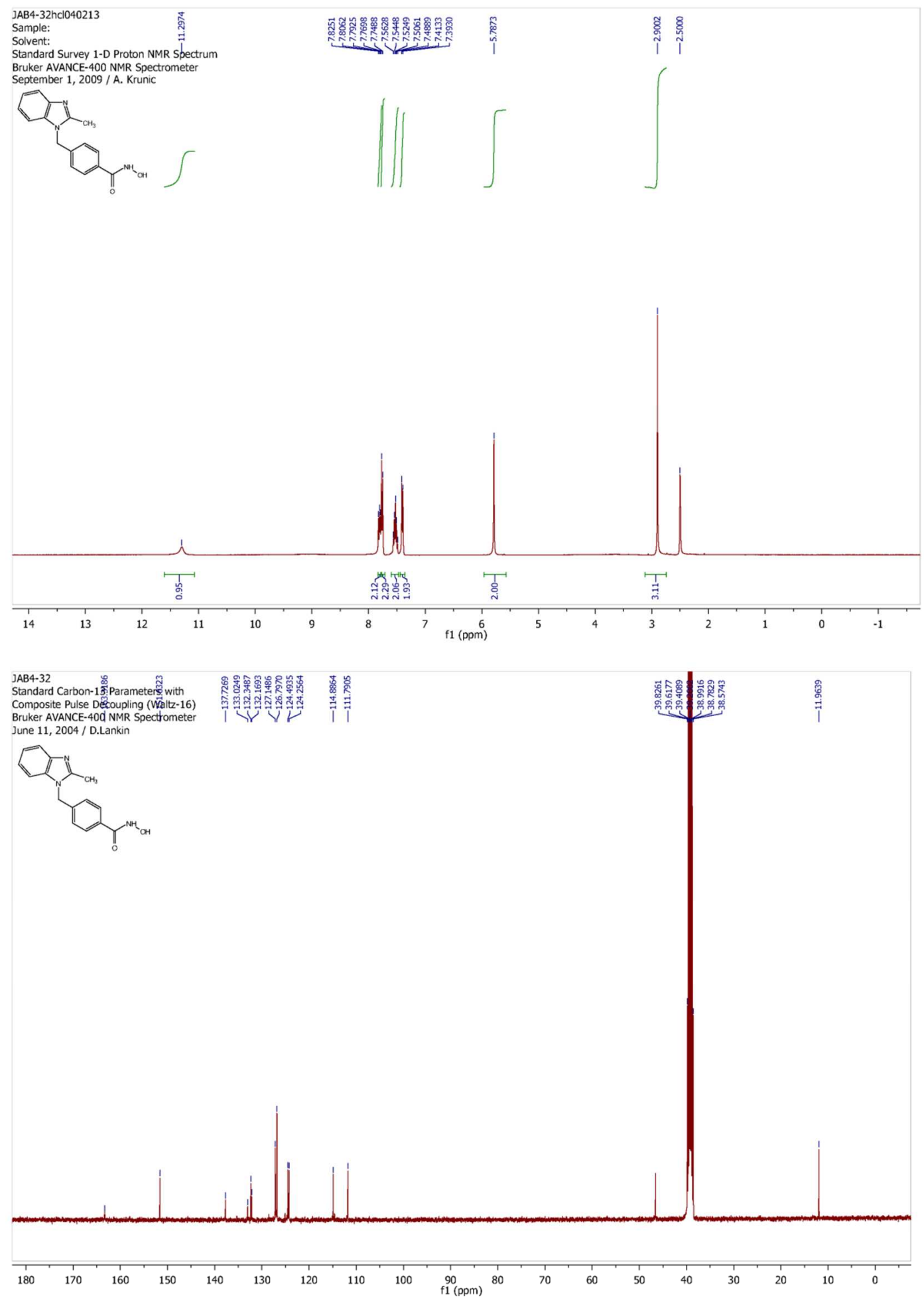


${ }^{1} \mathrm{H}$ NMR (400 MHz, DMSO- $d_{6}$ ) and ${ }^{13} \mathrm{C}$ NMR (100 MHz, DMSO- $d_{6}$ ) spectra for compound $\boldsymbol{N}$-hydroxy-4-[(2-isopropyl-1-benzimidazolyl)methyl]benzamide (12b).

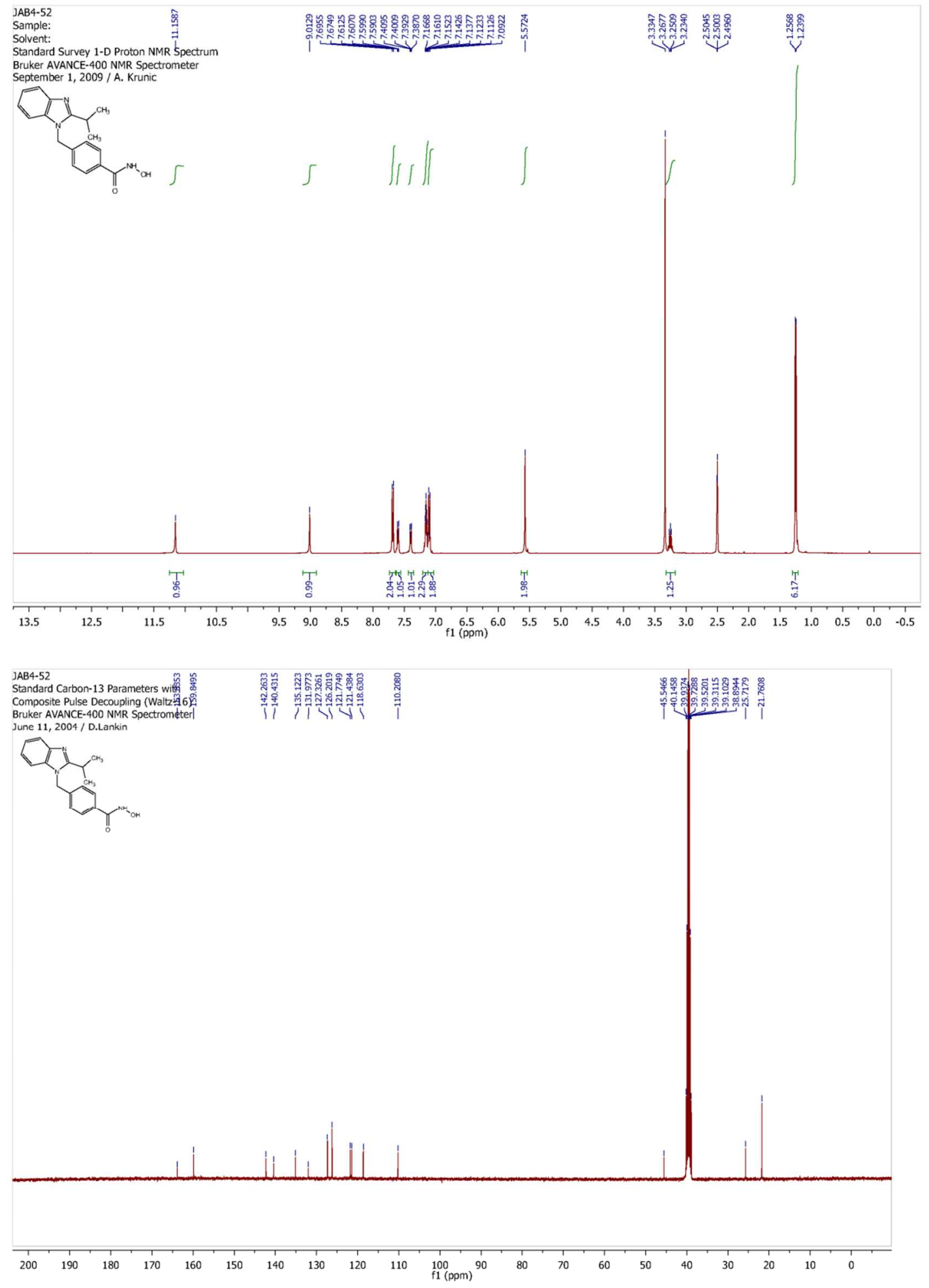


${ }^{1} \mathrm{H}$ NMR (400 MHz, DMSO- $d_{6}$ ) and ${ }^{13} \mathrm{C}$ NMR (100 MHz, DMSO- $d_{6}$ ) spectra for compound $\mathrm{N}$-hydroxy-4-[[2-(trifluoromethyl)-1-benzimidazolyl]methyl]benzamide (12c).
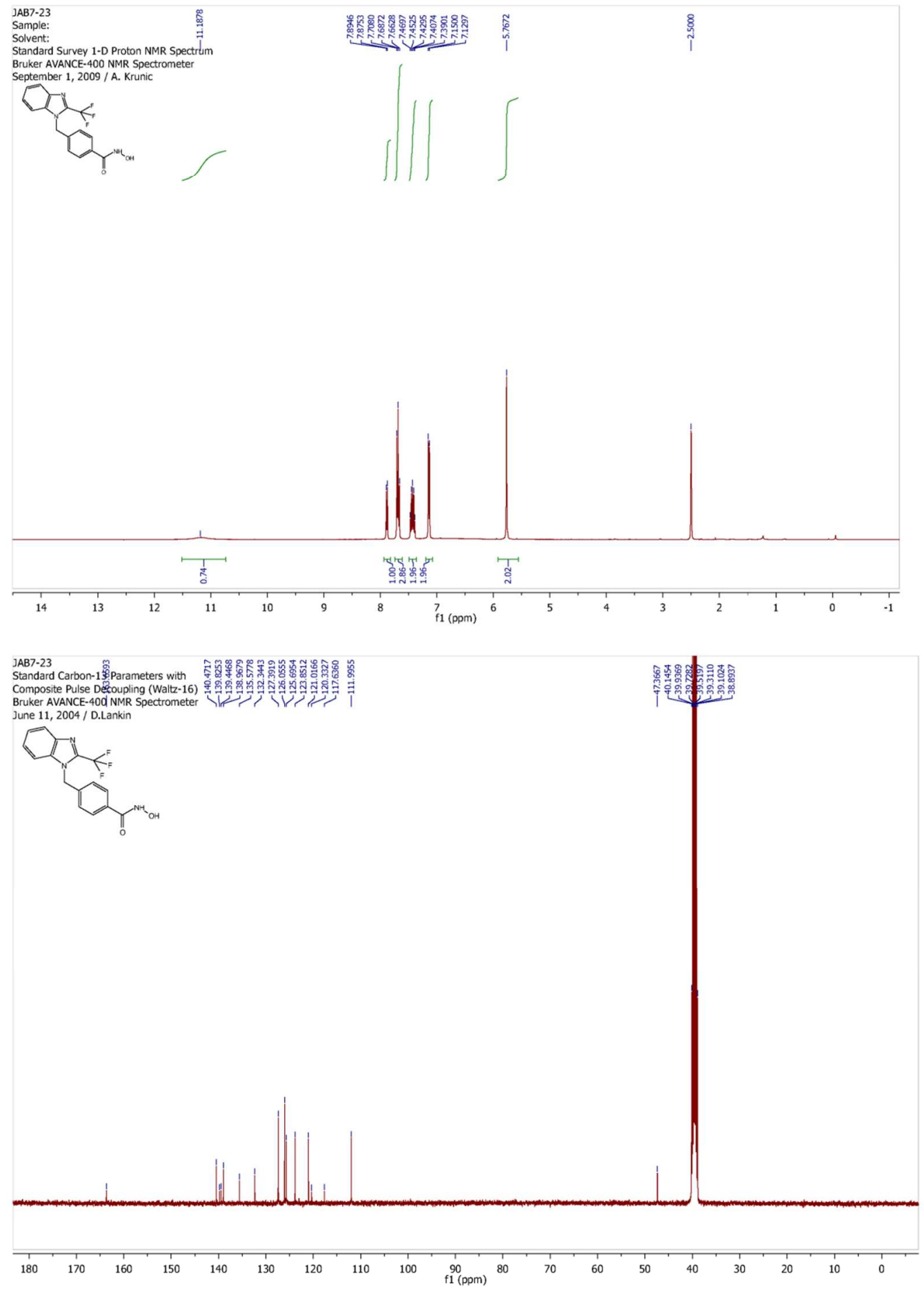
${ }^{1} \mathrm{H}$ NMR (400 MHz, $\mathrm{CD}_{3} \mathrm{OD}$ ) and ${ }^{13} \mathrm{C}$ NMR (100 MHz, $\mathrm{CD}_{3} \mathrm{OD}$ ) spectra for compound 4-[[2-(3-acetamidopropyl)-1-benzimidazolyl]methyl]- $N$-hydroxybenzamide (12d).

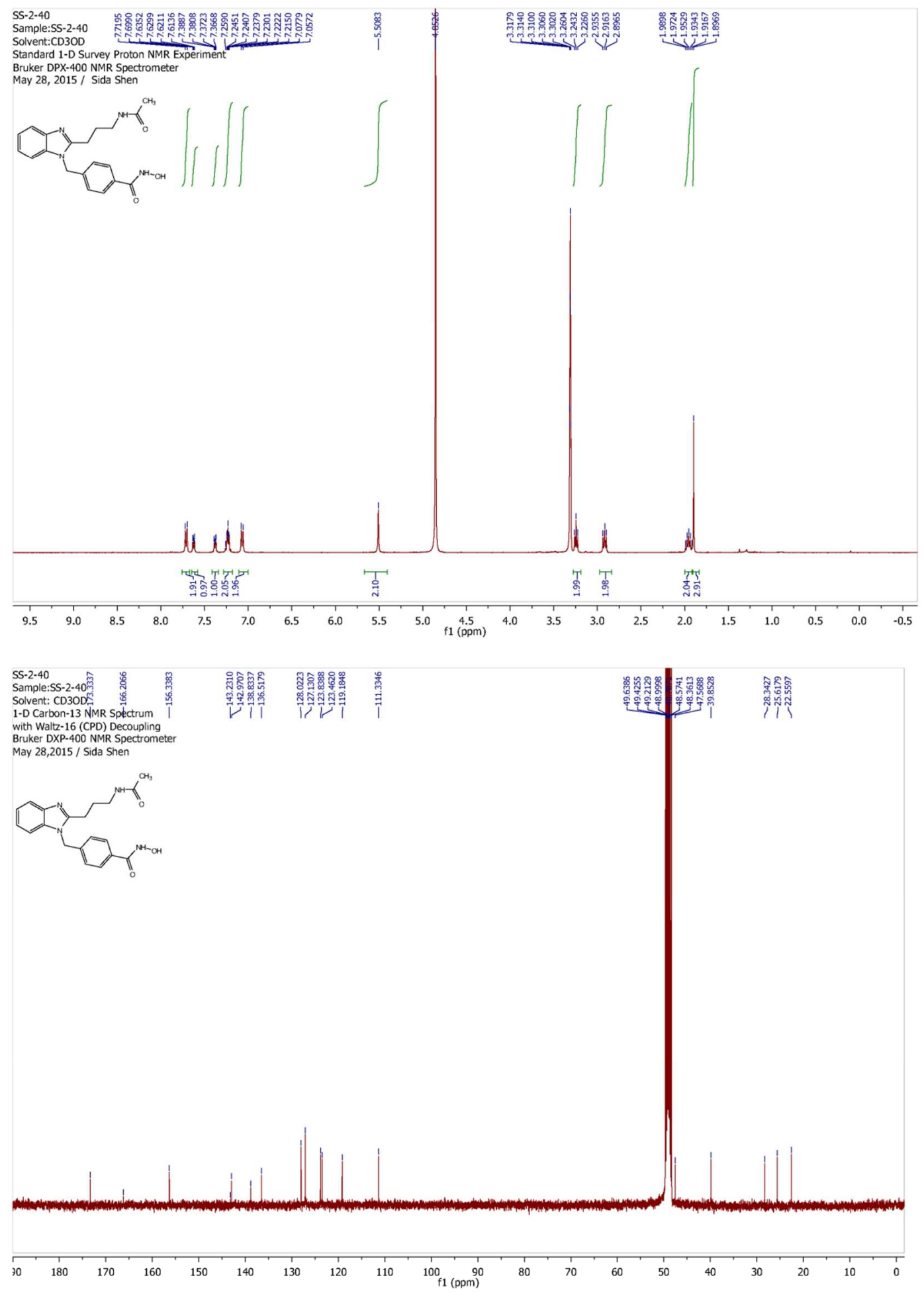


${ }^{1} \mathrm{H}$ NMR (400 MHz, DMSO- $d_{6}$ ) and ${ }^{13} \mathrm{C}$ NMR (100 MHz, DMSO- $d_{6}$ ) spectra for compound 4-[[2-[2-(dimethylamino)ethyl]-1-benzimidazolyl]methyl]- $N$ hydroxybenzamide (12e).
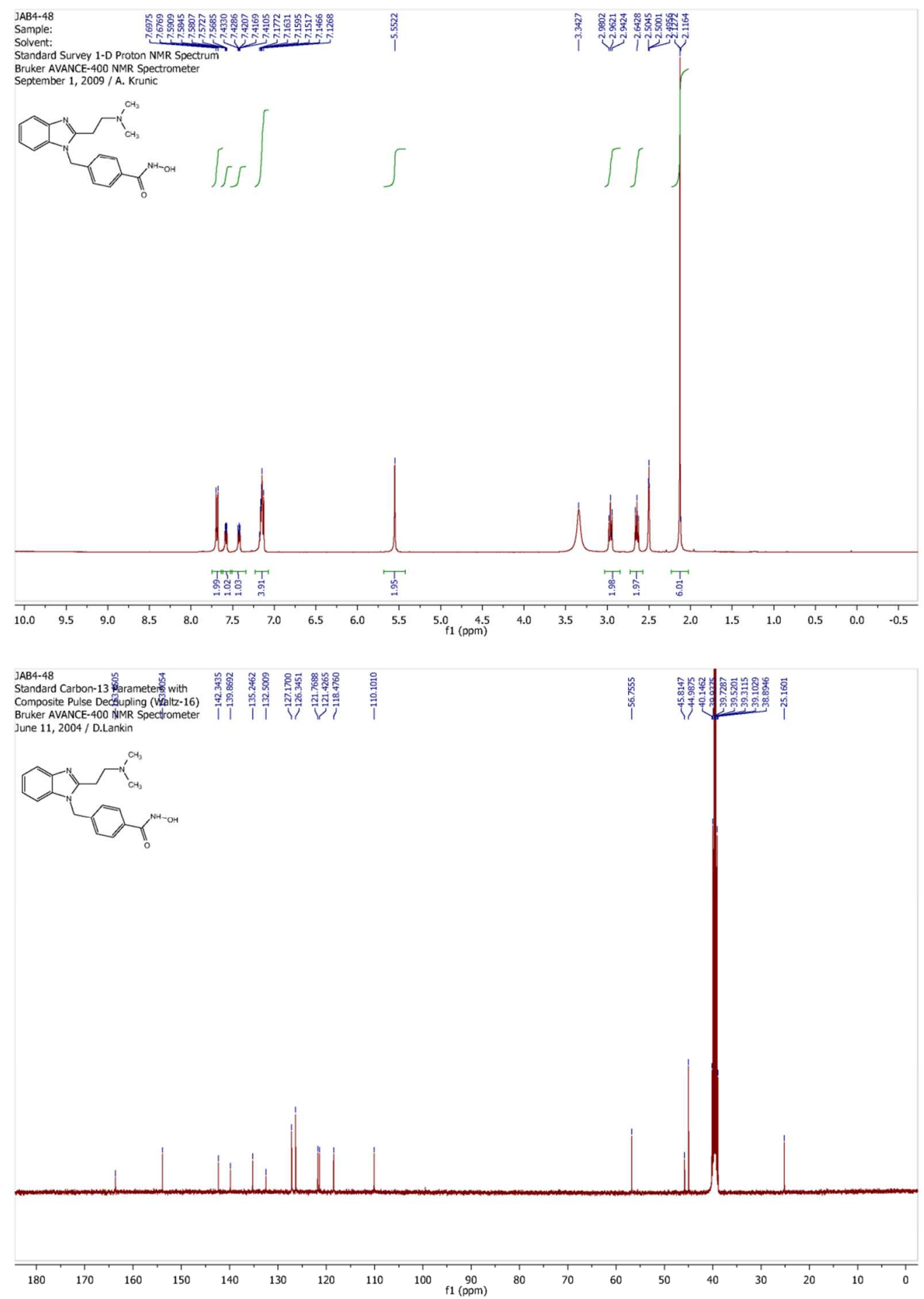
${ }^{1} \mathrm{H}$ NMR (400 MHz, $\mathrm{CDCl}_{3}$ ) and ${ }^{13} \mathrm{C}$ NMR $\left(100 \mathrm{MHz}\right.$, DMSO- $\left.d_{6}\right)$ spectra for compound tert-butyl 4-[4-(Methoxycarbonyl)benzyl]-3,4-dihydroquinoxaline-1(2H)-carboxylate (16a).
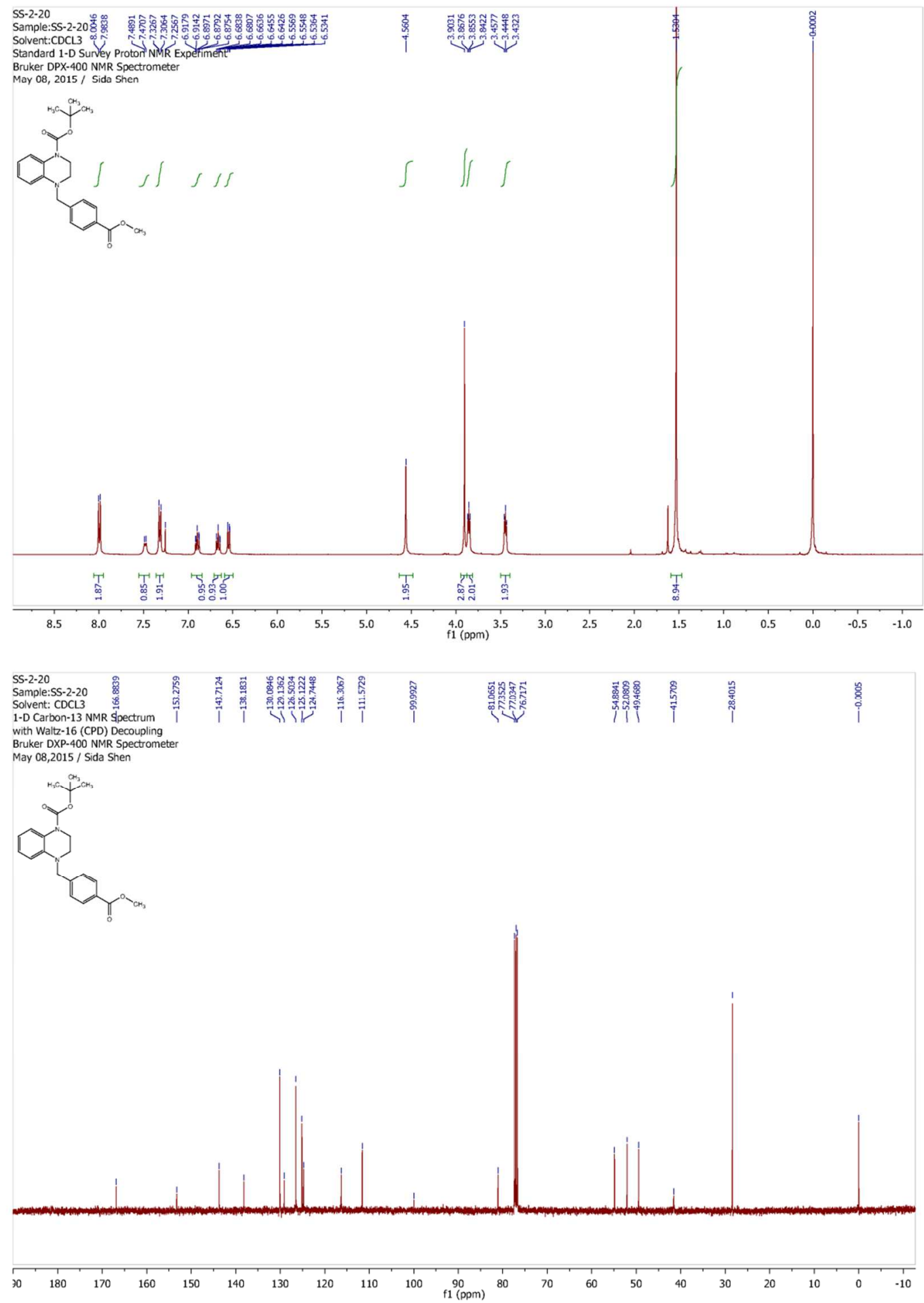
${ }^{1} \mathrm{H}$ NMR $\left(400 \mathrm{MHz}, \mathrm{CDCl}_{3}\right.$ ) and ${ }^{13} \mathrm{C} \mathrm{NMR}\left(400 \mathrm{MHz}, \mathrm{CDCl}_{3}\right.$ ) spectra for compound methyl 4-[[2,3-Dihydro-4H-benzo[b][1,4]thiazin-4-yl)]methyl]benzoate (16b).
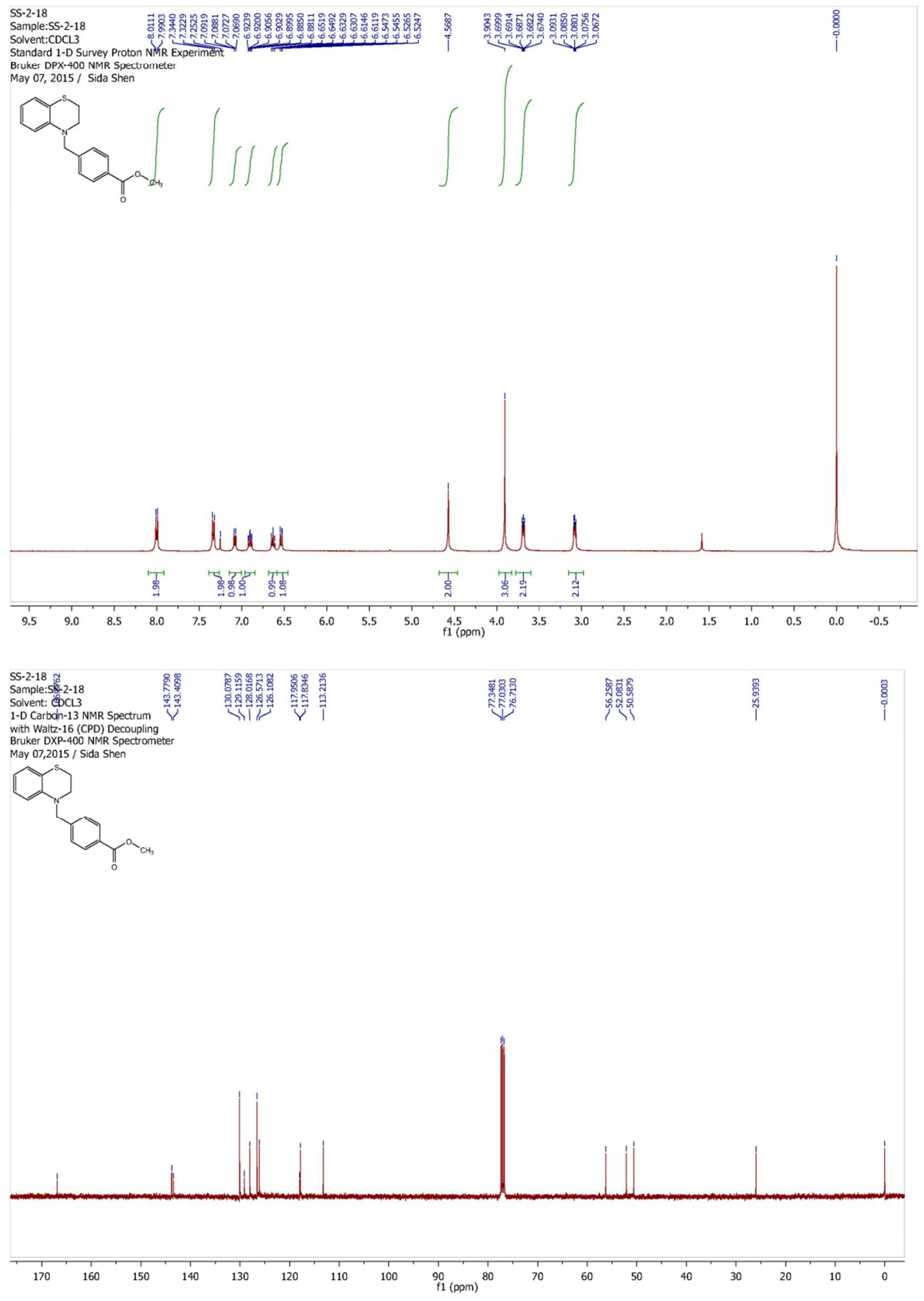
${ }^{1} \mathrm{H} \mathrm{NMR}\left(400 \mathrm{MHz}, \mathrm{CDCl}_{3}\right)$ and ${ }^{13} \mathrm{C} \mathrm{NMR}\left(100 \mathrm{MHz}, \mathrm{CDCl}_{3}\right)$ spectra for compound tert-butyl 4-[4-(Methoxycarbonyl)benzyl]-3-oxo-3,4-dihydroquinoxaline-1(2H)carboxylate (19).

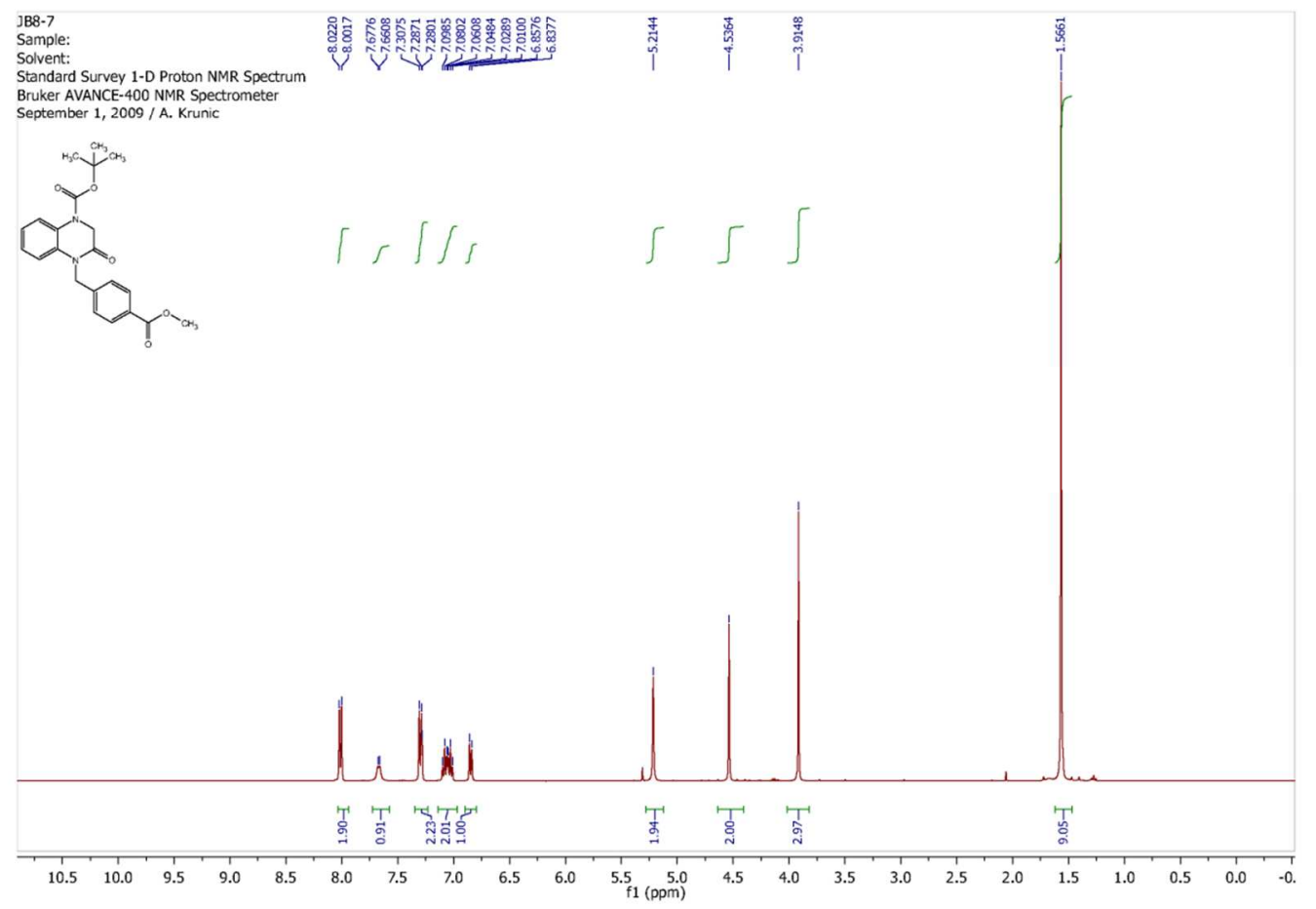

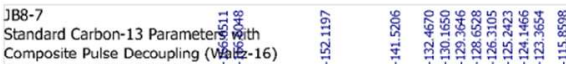

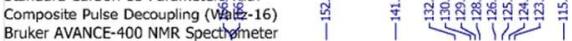

June 11,2004 / D.Lankin

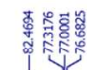

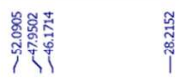
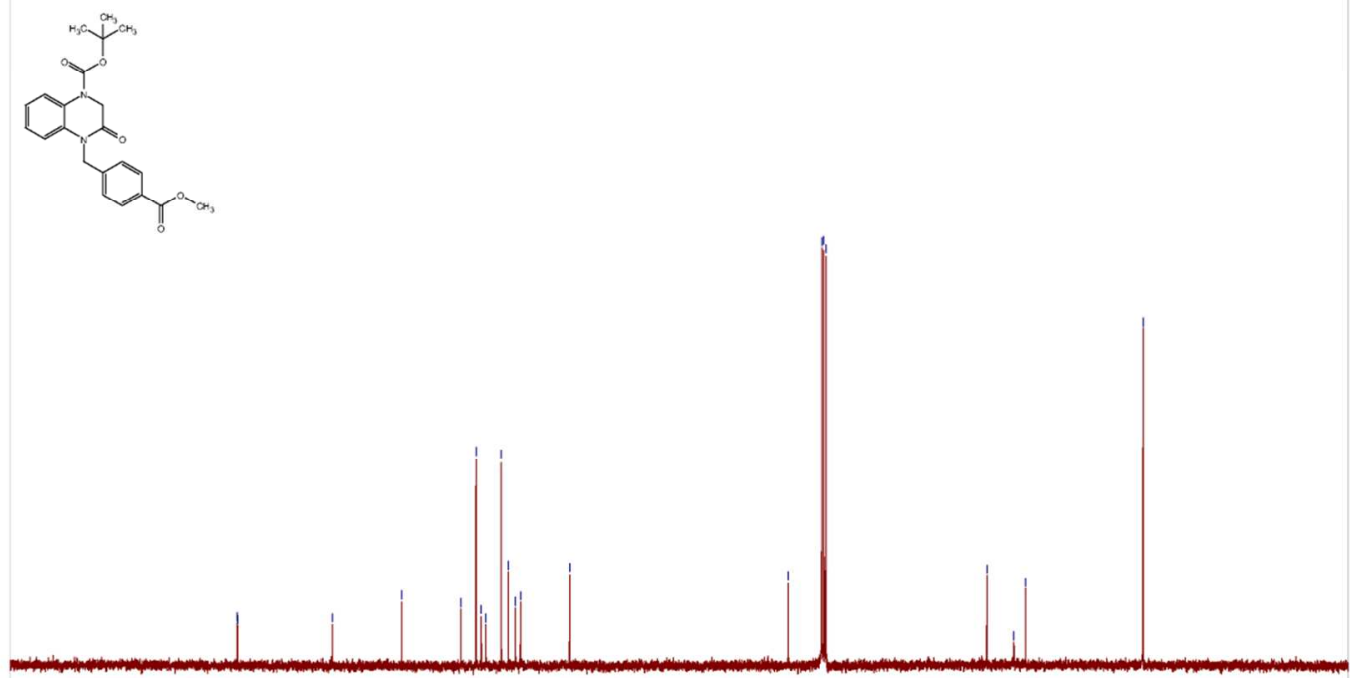$$
T
$$

200

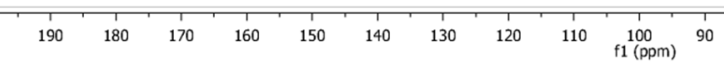


${ }^{1} \mathrm{H}$ NMR (400 MHz, DMSO- $d_{6}$ ) and ${ }^{13} \mathrm{C}$ NMR (400 MHz, DMSO- $d_{6}$ ) spectra for compound 4-[[1,2,3,4-tetrahydroquinoxalin-1-yl] methyl]- $N$-hydroxybenzamide (17a).
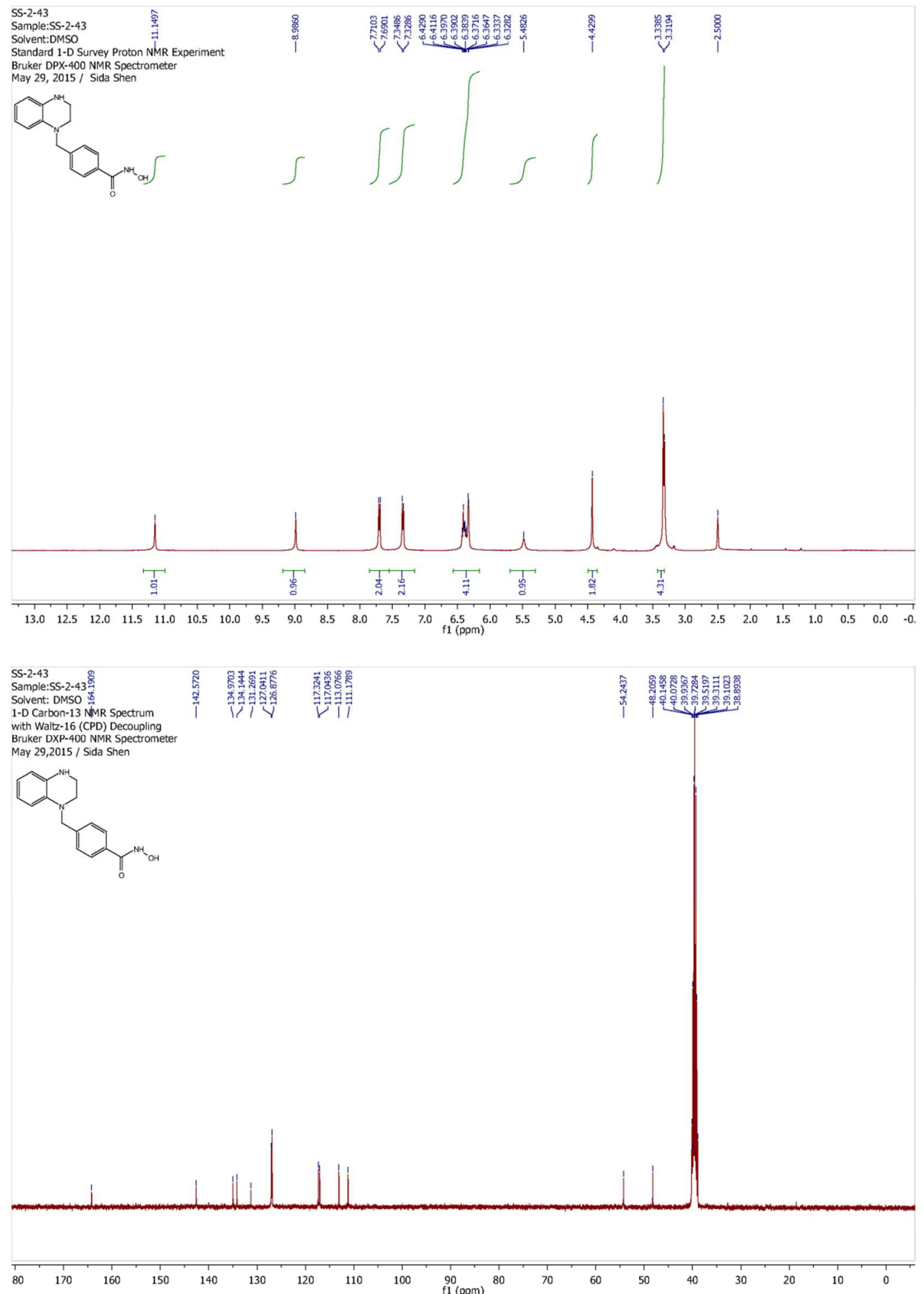
${ }^{1} \mathrm{H}$ NMR (400 MHz, DMSO- $d_{6}$ ) and ${ }^{13} \mathrm{C}$ NMR (100 MHz, DMSO- $d_{6}$ ) spectra for compound 4-[[4-(cyclopropylmethyl)-1,2,3,4-tetrahydroquinoxalin-1-yl]methyl]- $N$ hydroxybenzamide (17b).

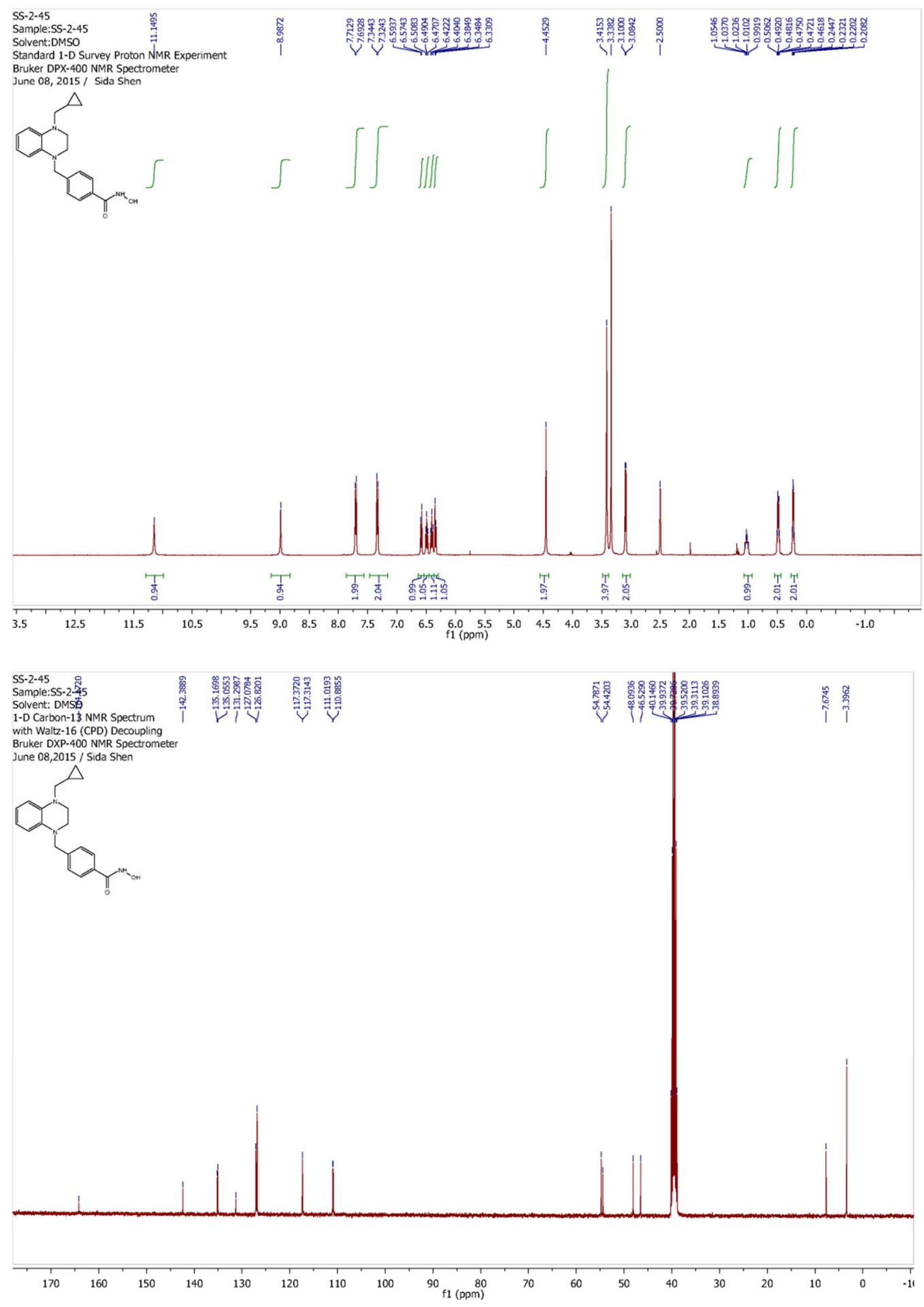


${ }^{1} \mathrm{H}$ NMR (400 MHz, DMSO- $d_{6}$ ) and ${ }^{13} \mathrm{C}$ NMR (100 MHz, DMSO- $d_{6}$ ) spectra for compound 4-[[2,3-dihydro-4H-benzo[b][1,4]thiazin-4-yl]methyl]- $N$ hydroxybenzamide $(17 \mathrm{c})$.

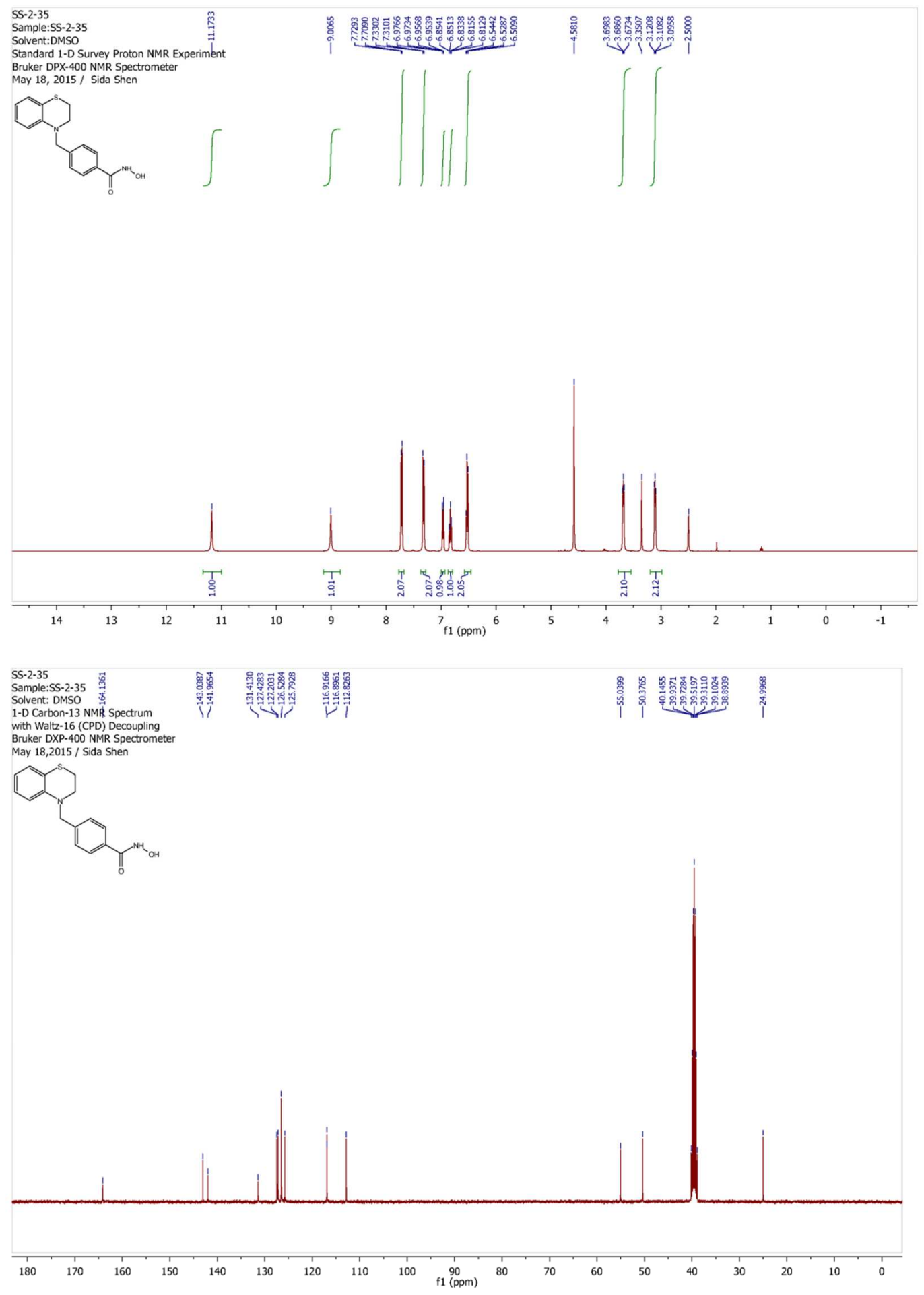


${ }^{1} \mathrm{H}$ NMR (400 MHz, DMSO- $d_{6}$ ) and ${ }^{13} \mathrm{C}$ NMR (100 MHz, CD $30 D$ ) spectra for compound $N$-hydroxy-4-[[1-oxido-2,3-dihydro-4H-benzo[b][1,4]thiazin-4yl]methyl]benzamide (17d).

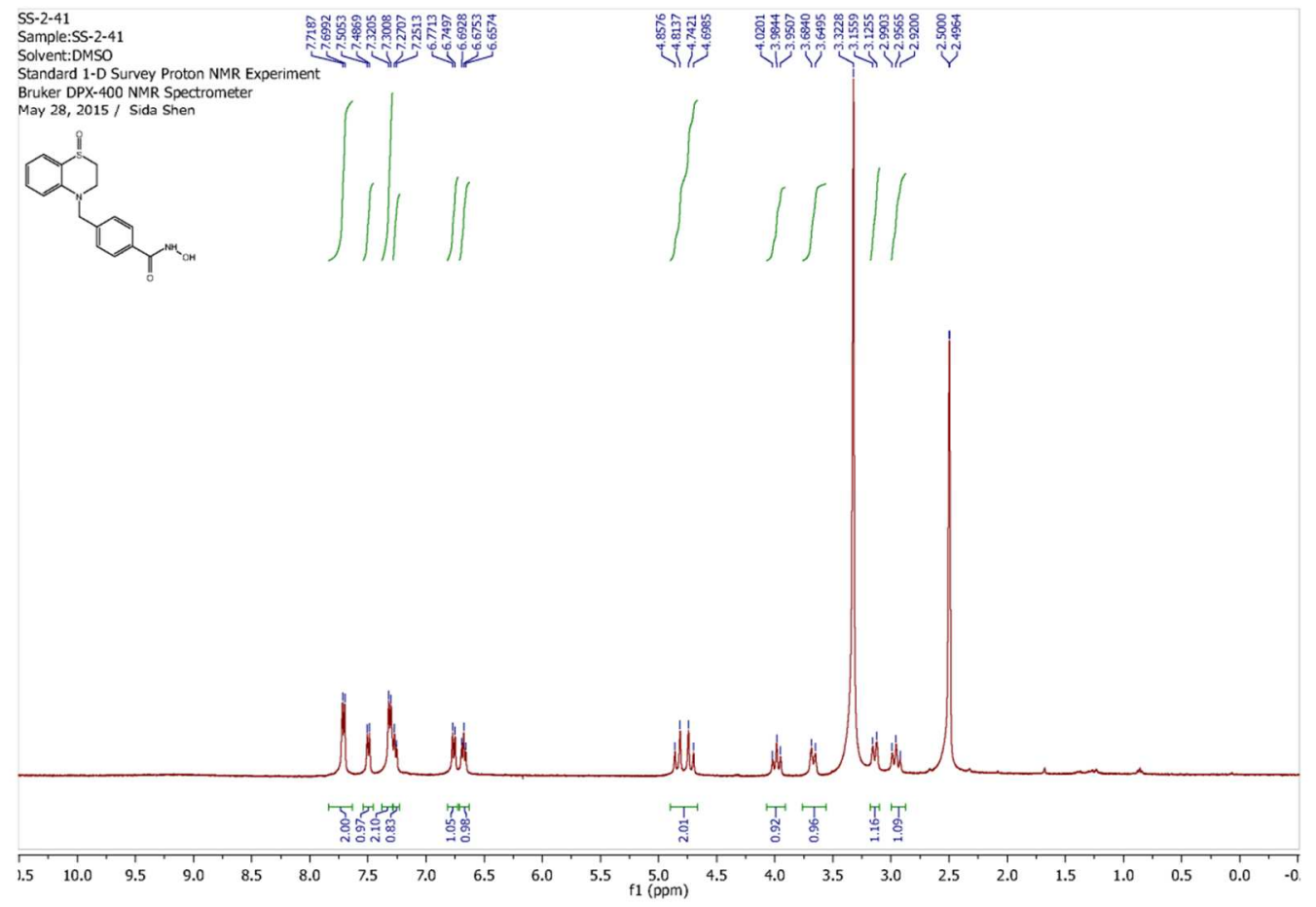

100

Standard Carbon-13 Pa

Composite Pulse Decouspling (Walt:-16)

June 11,2004 / D.Lankin

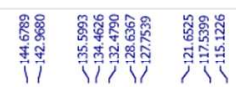

(1)

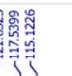


${ }^{1} \mathrm{H}$ NMR (400 MHz, $\left.\mathrm{CD}_{3} \mathrm{OD}\right)$ and ${ }^{13} \mathrm{C}$ NMR (100 MHz, DMSO- $d_{6}$ ) spectra for compound tert-butyl 4-[4-(Hydroxycarbamoyl)benzyl]-3-oxo-3,4dihydroquinoxaline-1(2H)-carboxylate (17e).
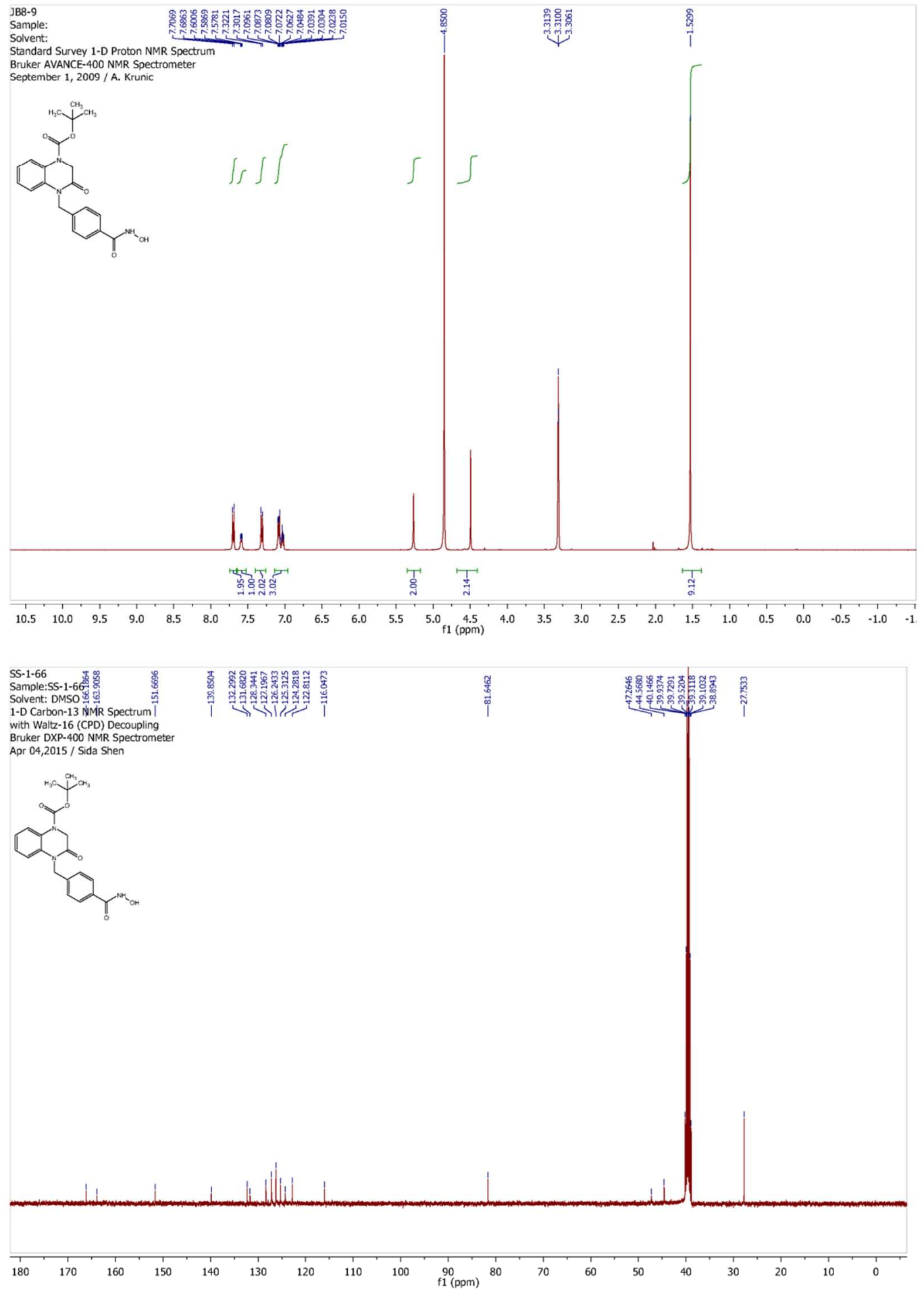

S37 
${ }^{1} \mathrm{H}$ NMR (400 MHz, DMSO- $d_{6}$ ) and ${ }^{13} \mathrm{C}$ NMR (100 MHz, $\left.\mathrm{CD}_{3} \mathrm{OD}\right)$ spectra for compound $\mathrm{N}$-hydroxy-4-[(2-oxoquinoxalin-1(2H)-yl)methyl]benzamide TFA Salt (17f).

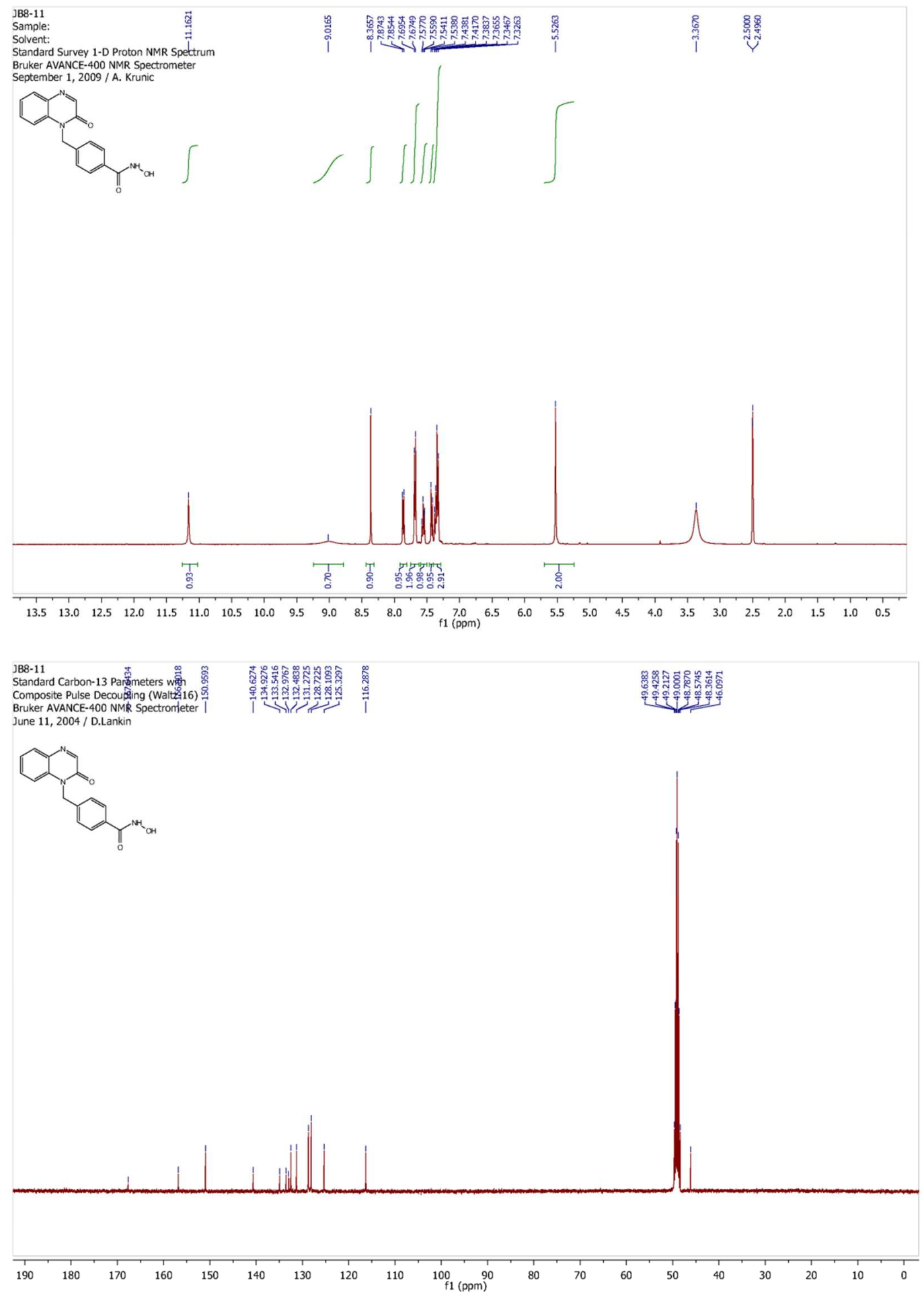


${ }^{1} \mathrm{H}$ NMR $\left(400 \mathrm{MHz}, \mathrm{CDCl}_{3}\right)$ and ${ }^{13} \mathrm{C} \mathrm{NMR}\left(100 \mathrm{MHz}, \mathrm{CDCl}_{3}\right)$ spectra for compound methyl 4-(Bromomethyl)-3-fluorobenzoate (21d).
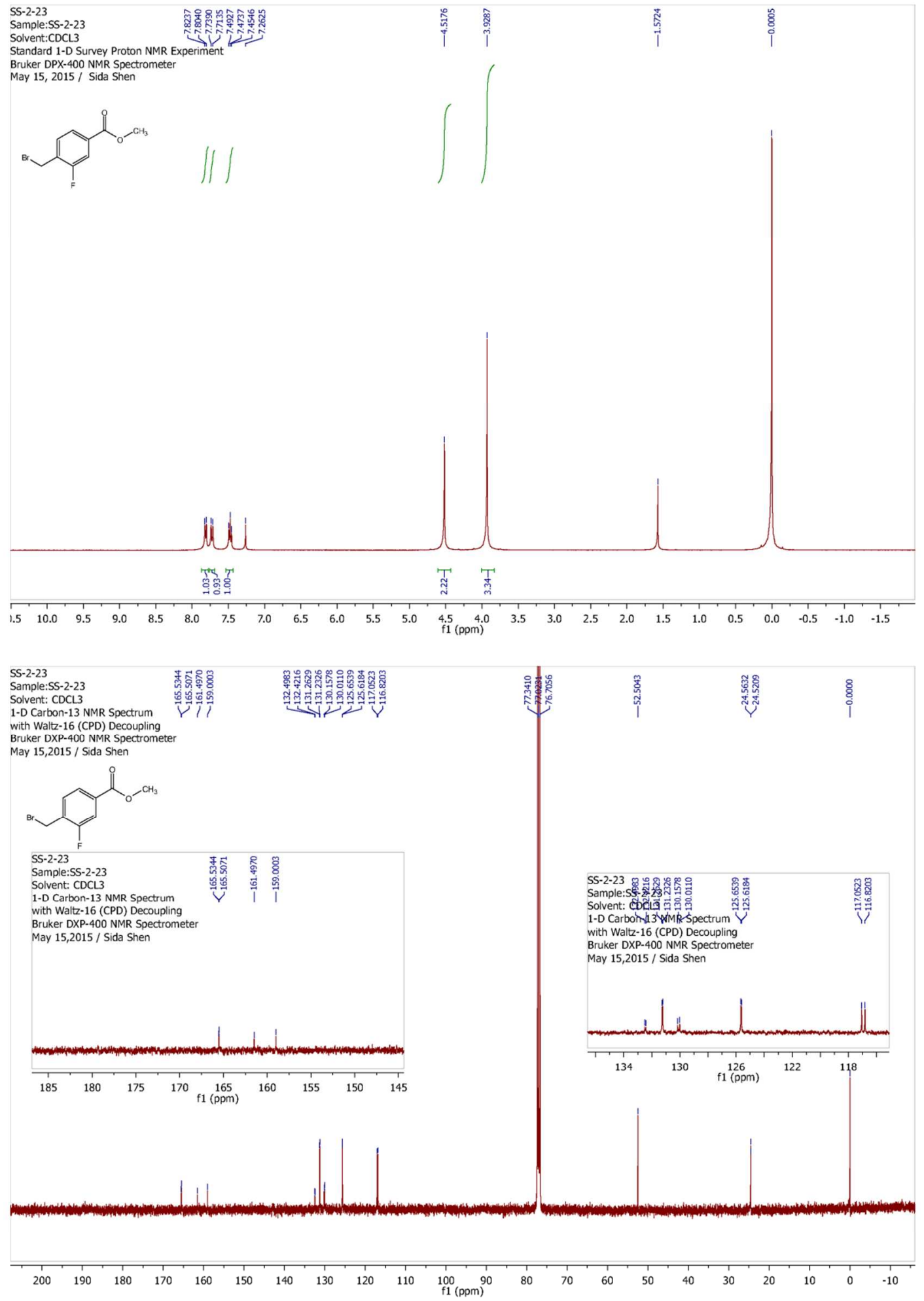
${ }^{1} \mathrm{H} \mathrm{NMR}\left(400 \mathrm{MHz}, \mathrm{CDCl}_{3}\right)$ and ${ }^{13} \mathrm{C} \mathrm{NMR}\left(100 \mathrm{MHz}, \mathrm{CDCl}_{3}\right)$ spectra for compound methyl 2-[(2-Methyl-1-benzimidazolyl)methyl]oxazole-4-carboxylate (22a).

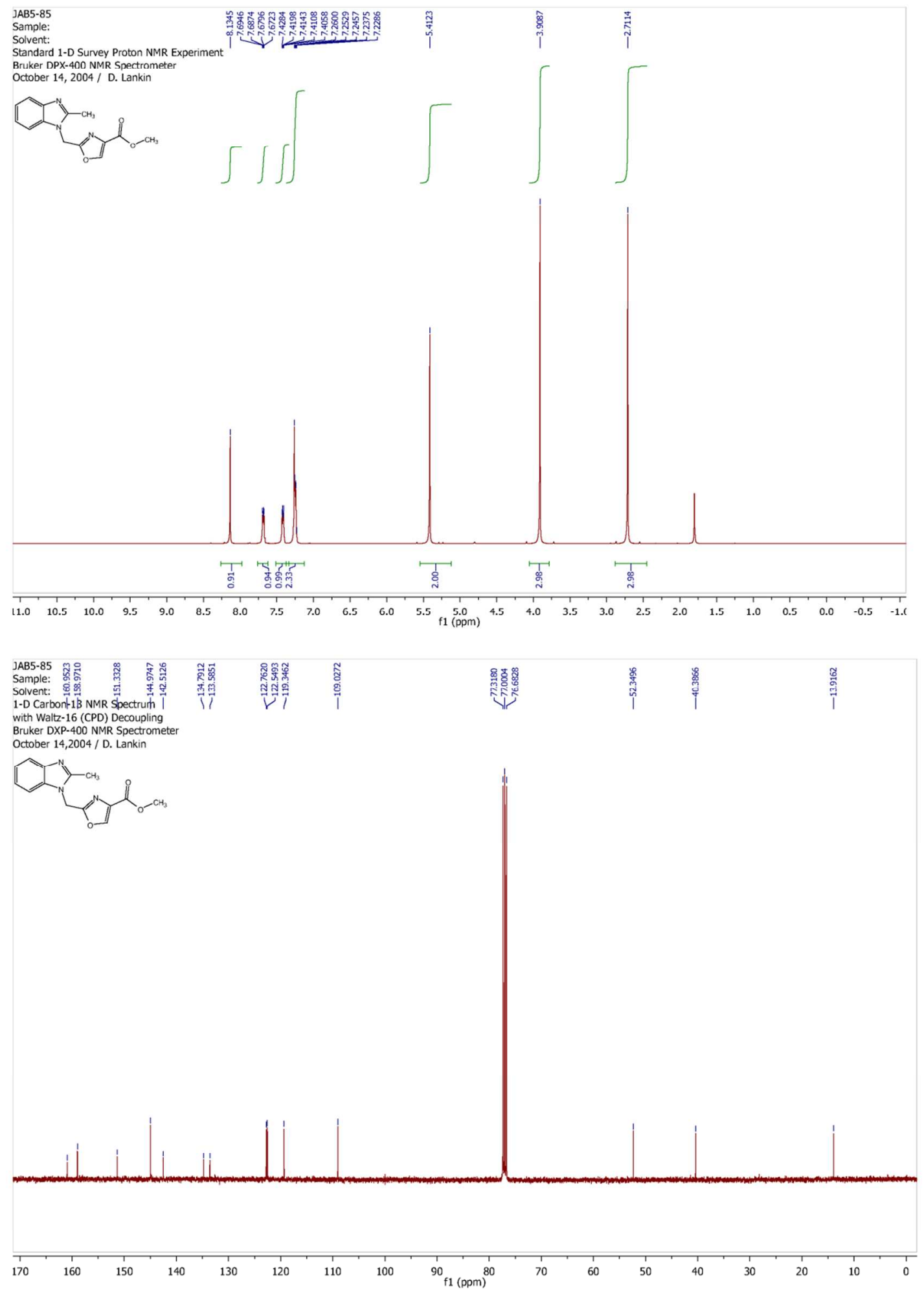


${ }^{1} \mathrm{H}$ NMR $\left(400 \mathrm{MHz}, \mathrm{CDCl}_{3}\right)$ and ${ }^{13} \mathrm{C} \mathrm{NMR}\left(100 \mathrm{MHz}, \mathrm{CDCl}_{3}\right)$ spectra for compound methyl 2-[(2-Methyl-1-benzimidazolyl)methyl]thiazole-4-carboxylate (22b).

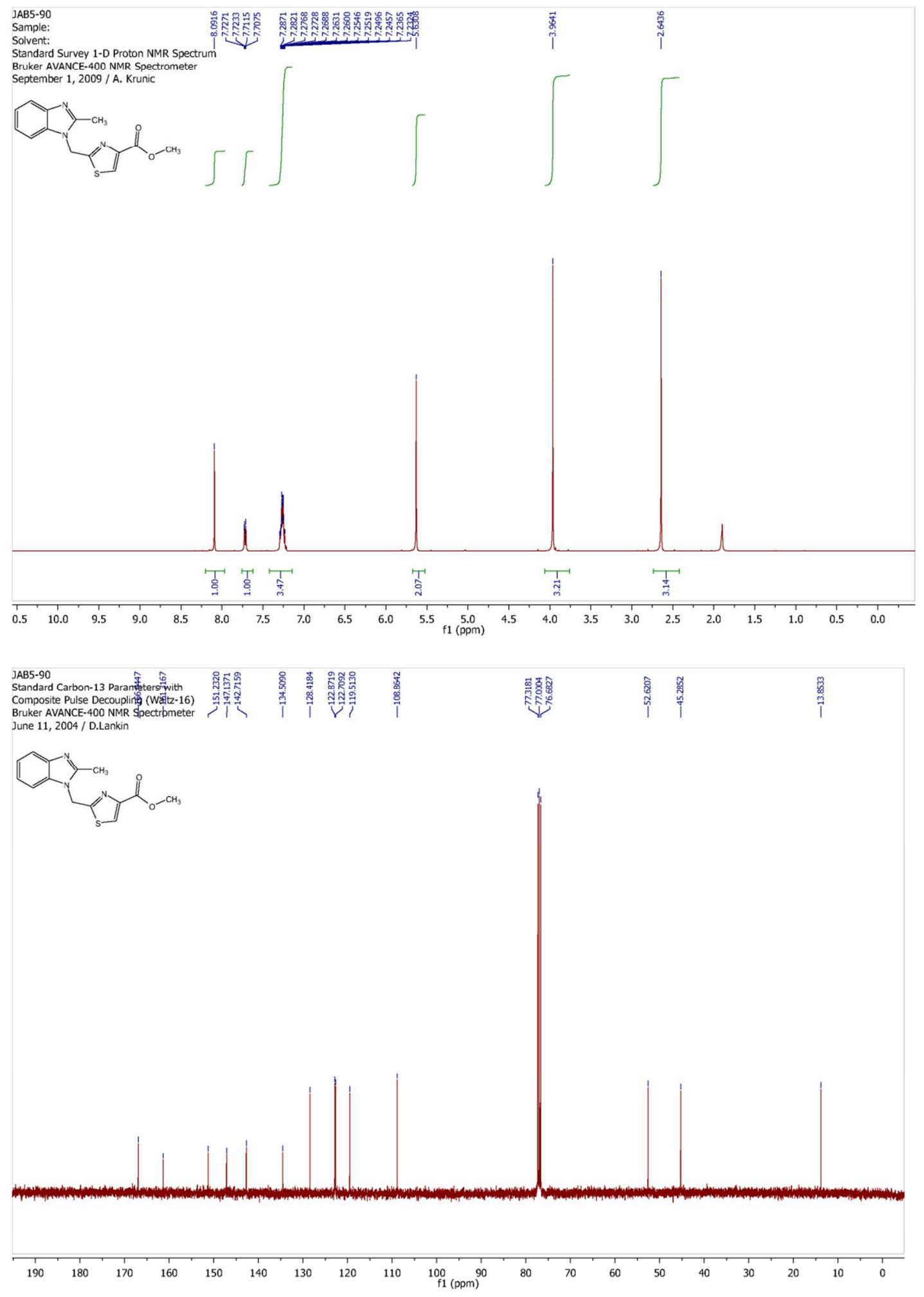


${ }^{1} \mathrm{H}$ NMR $\left(400 \mathrm{MHz}, \mathrm{CDCl}_{3}\right)$ and ${ }^{13} \mathrm{C} \mathrm{NMR}\left(100 \mathrm{MHz}, \mathrm{CDCl}_{3}\right)$ spectra for compound methyl 6-[(2-Methyl-1-benzimidazolyl)methyl]nicotinate (22c).
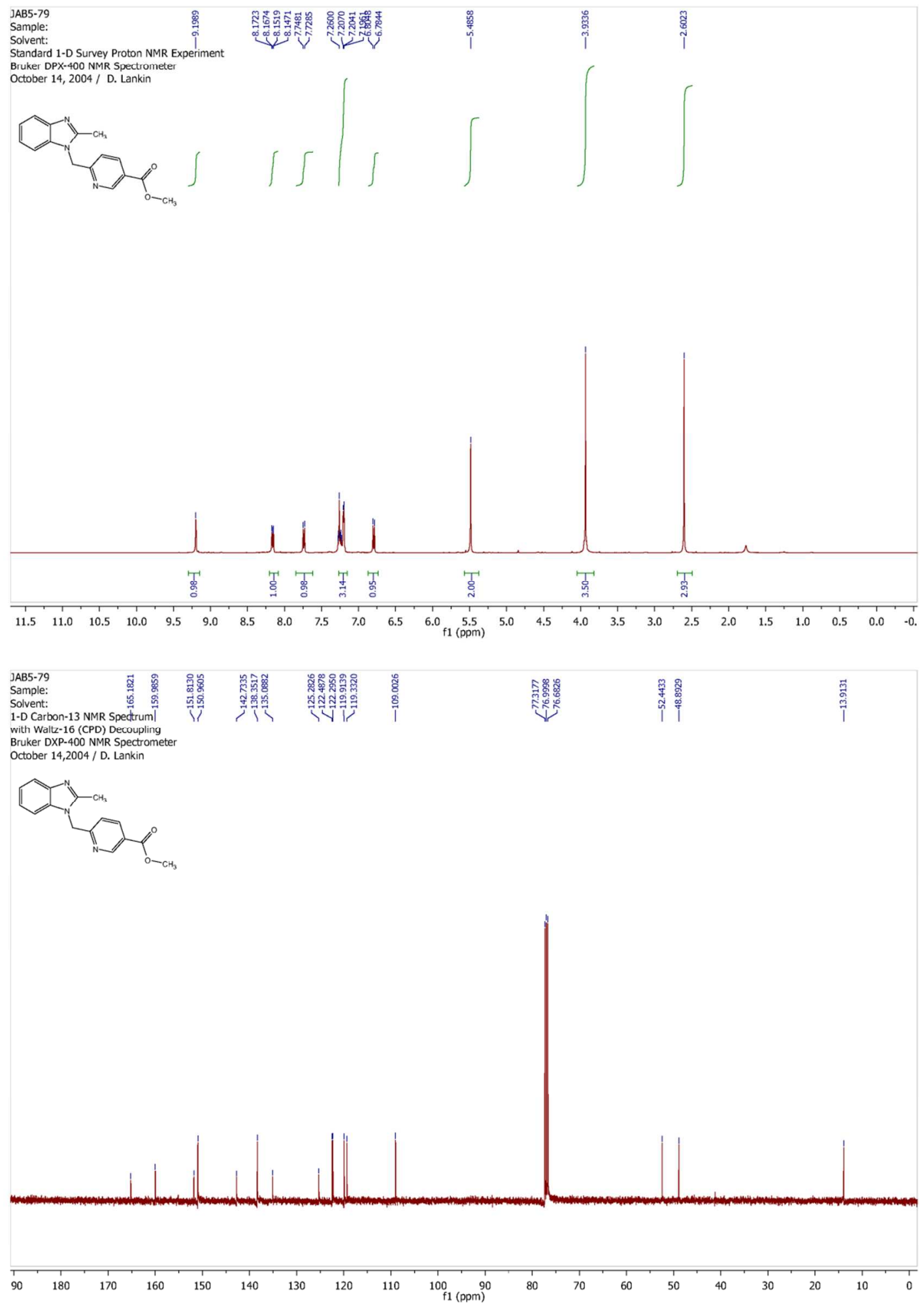
${ }^{1} \mathrm{H}$ NMR $\left(400 \mathrm{MHz}, \mathrm{CDCl}_{3}\right)$ and ${ }^{13} \mathrm{C}$ NMR $\left(100 \mathrm{MHz}, \mathrm{CDCl}_{3}\right)$ spectra for compound methyl 3-Fluoro-4-[(2-methyl-1-benzimidazolyl)methyl]benzoate (22d).

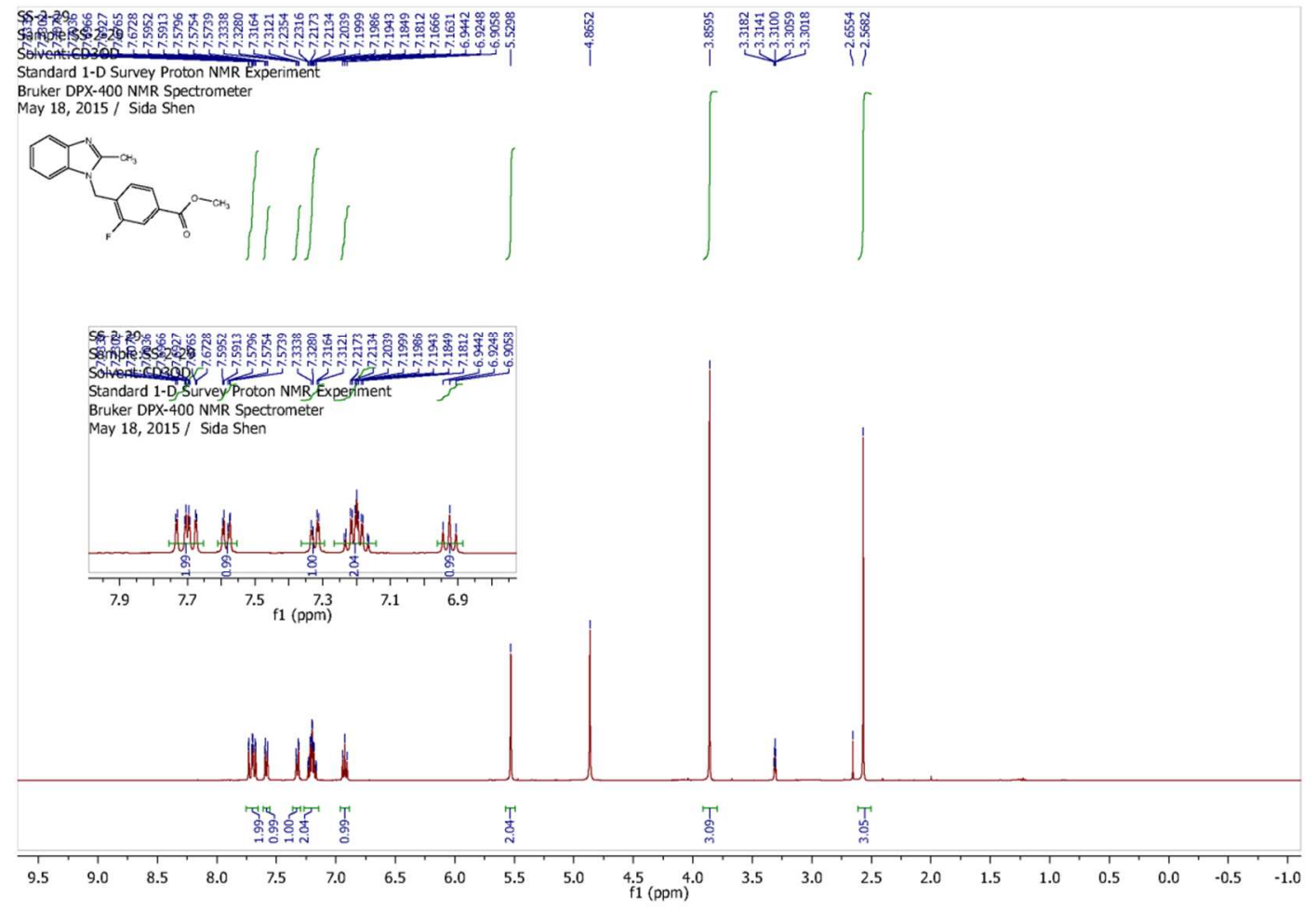

$\cos \cdot 2 \cdot 29$

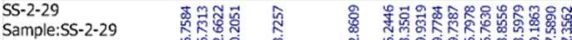

Solvent: CD30D 80

1-D Carbon-13 NMR Spectrund ।

with Waltz-16 (CPD) Decoupling

May 18,2015 / Sida Shen

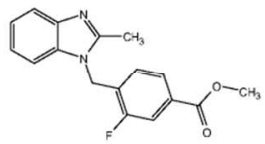

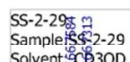

1-D Carbot-13 NMR Spectrum

with Walt-16 (CPD) Decoupling

Bruker DXP-400 NMR Spectrometer

May 18,2015 / Sida Shen

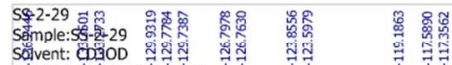

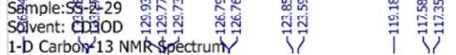

1-D Carbolyr 13 NMR Spectrumy

Bith Waltz-16 (CPD) Decoupling

May 18,2015 / Sida Shen
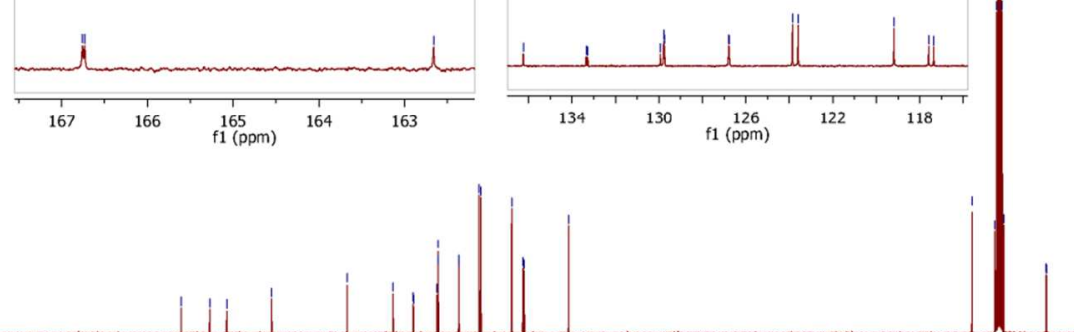

$\begin{array}{llllllllll}190 & 180 & 170 & 160 & 150 & 140 & 130 & 120 & 110 & 100 \begin{array}{c}90 \\ f 1(\mathrm{ppm})\end{array}\end{array}$ 
${ }^{1} \mathrm{H}$ NMR $\left(400 \mathrm{MHz}, \mathrm{CDCl}_{3}\right)$ and ${ }^{13} \mathrm{C} \mathrm{NMR}\left(100 \mathrm{MHz}, \mathrm{CDCl}_{3}\right)$ spectra for compound methyl 3-Fluoro-4-[(2-(trifluoromethyl)-1-benzimidazolyl)methyl]benzoate (22e).
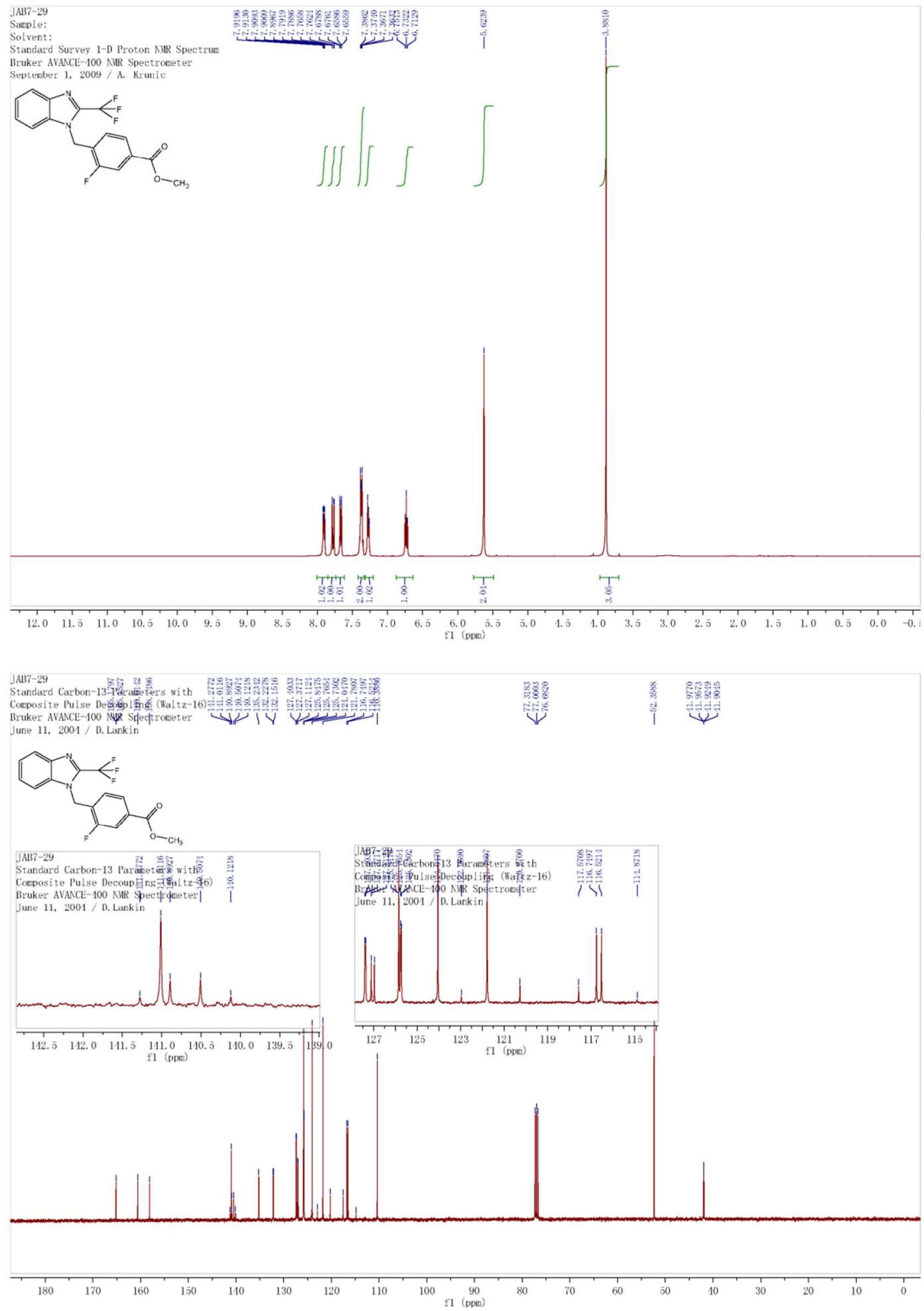
${ }^{1} \mathrm{H}$ NMR $\left(400 \mathrm{MHz}, \mathrm{CDCl}_{3}\right)$ and ${ }^{13} \mathrm{C} \mathrm{NMR}\left(100 \mathrm{MHz}, \mathrm{CDCl}_{3}\right)$ spectra for compound methyl 4-(Bromomethyl)-2,3,5,6-tetrafluorobenzoate (25).

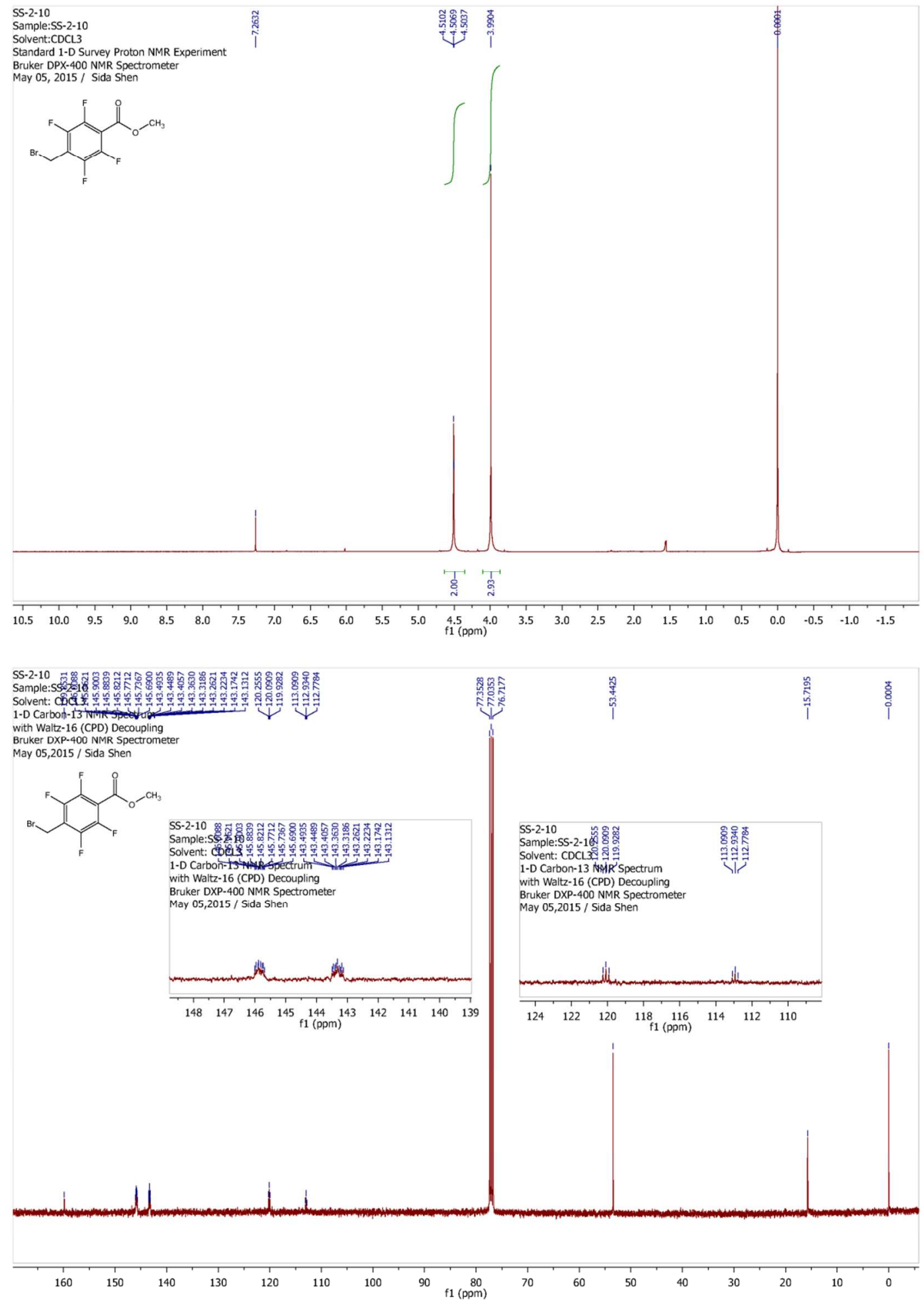


${ }^{1} \mathrm{H}$ NMR $\left(400 \mathrm{MHz}, \mathrm{CDCl}_{3}\right)$ and ${ }^{13} \mathrm{C} \mathrm{NMR}\left(100 \mathrm{MHz}, \mathrm{CDCl}_{3}\right)$ spectra for compound methyl 2,3,5,6-Tetrafluoro-4-[(2-methyl-1-benzimidazolyl)methyl]benzoate (22f).
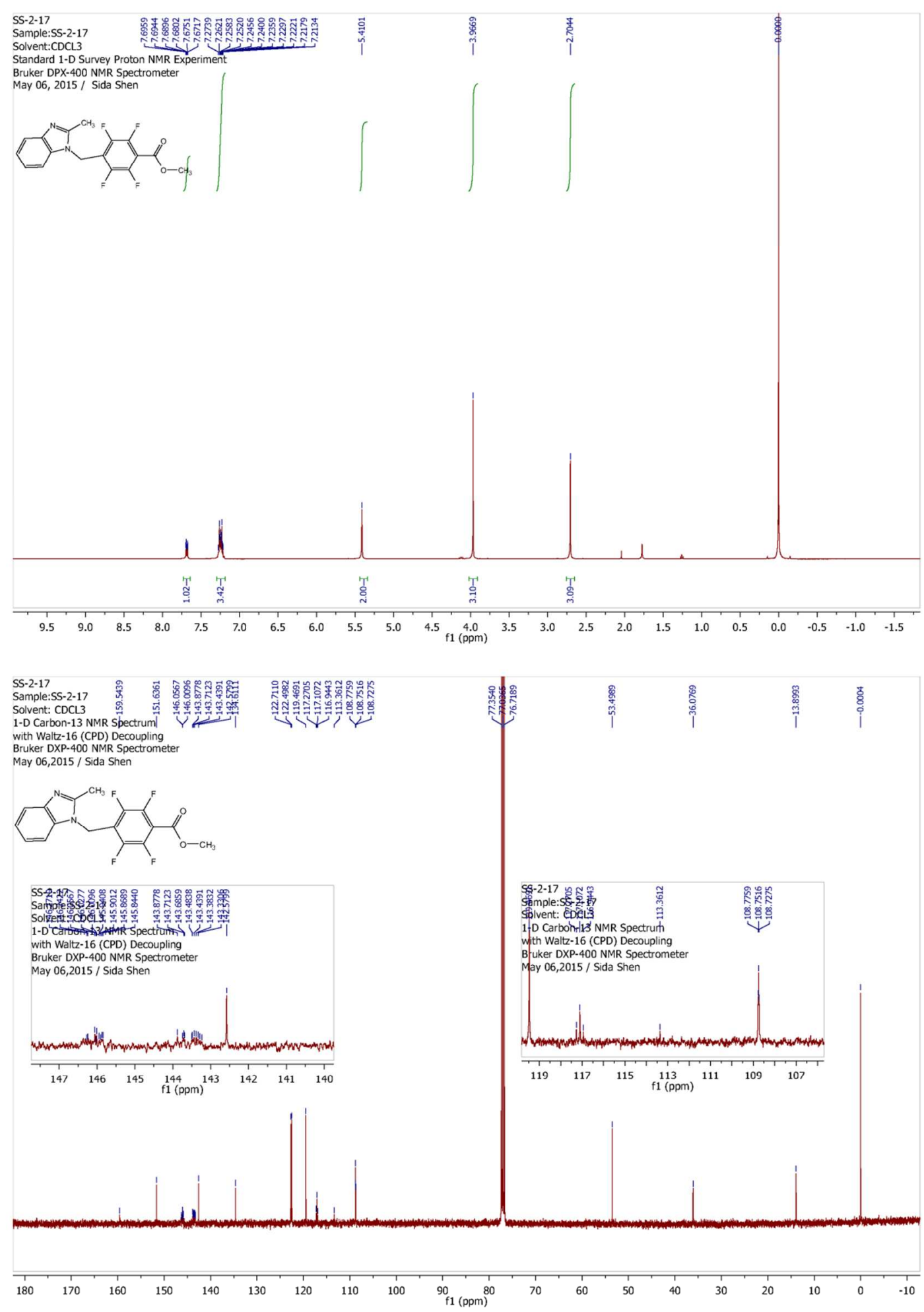
${ }^{1} \mathrm{H}$ NMR (400 MHz, $\mathrm{CDCl}_{3}$ ) and ${ }^{13} \mathrm{C}$ NMR $\left(100 \mathrm{MHz}, \mathrm{CDCl}_{3}\right.$ ) spectra for compound ethyl 2,6-Difluoro-4-[[(tetrahydropyran-2-yl)oxy]methyl]benzoate (27).

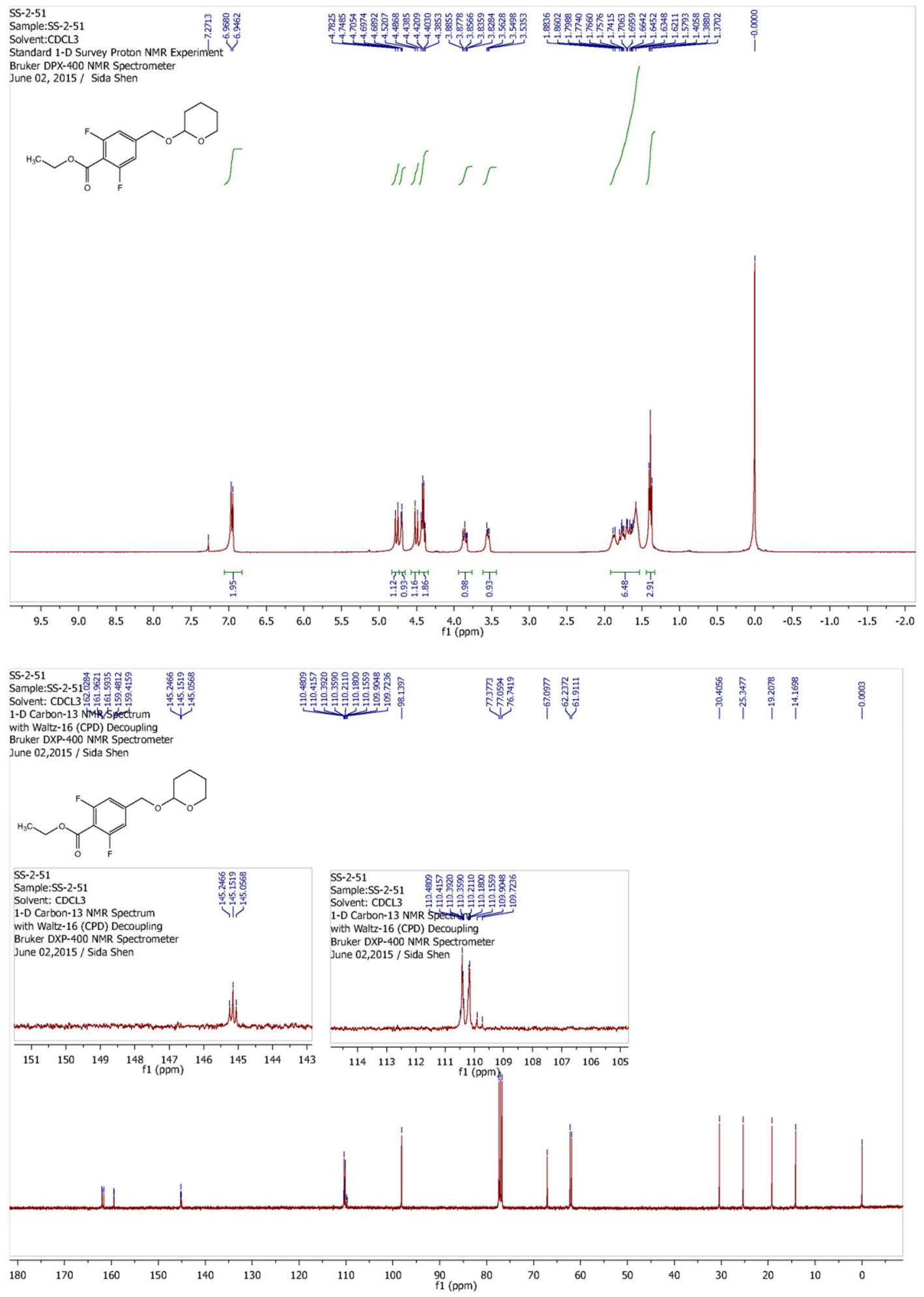


${ }^{1} \mathrm{H}$ NMR $\left(400 \mathrm{MHz}, \mathrm{CDCl}_{3}\right)$ and ${ }^{13} \mathrm{C}$ NMR $\left(100 \mathrm{MHz}, \mathrm{CDCl}_{3}\right.$ ) spectra for compound ethyl 2,6-Difluoro-4-[(2-methyl-1-benzimidazolyl)methyl]benzoate (22g).

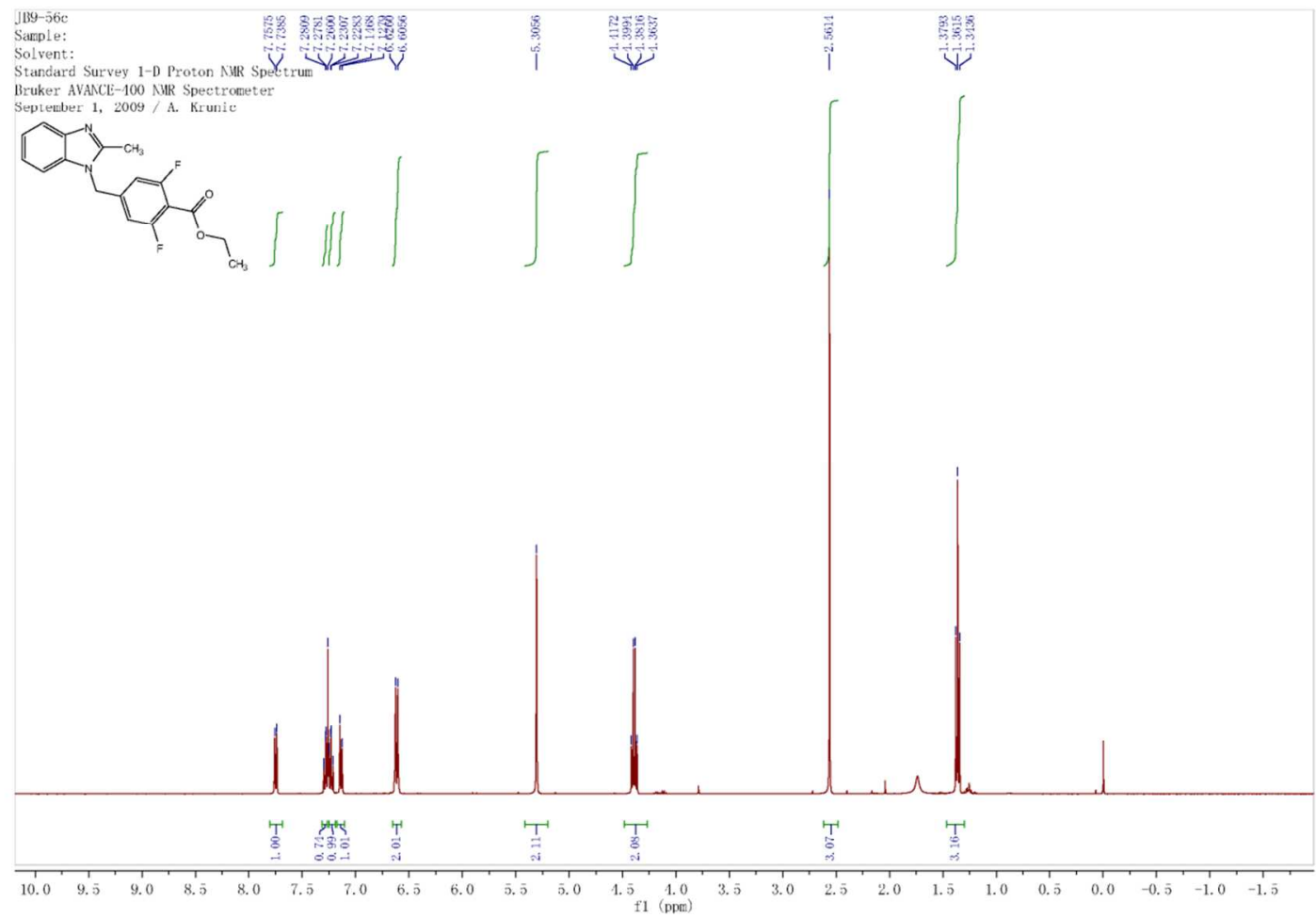

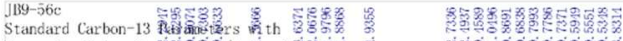

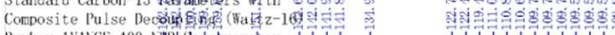

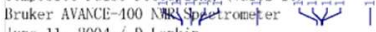

(-

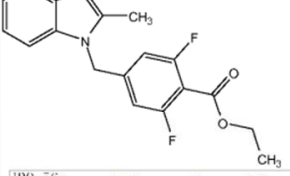

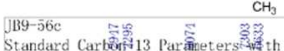

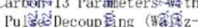

Bruker AVANCBLtpo NMR Speetrongter

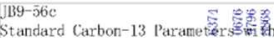

Composite Pulse Decoupling (lifite

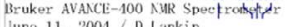

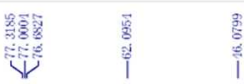

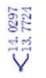
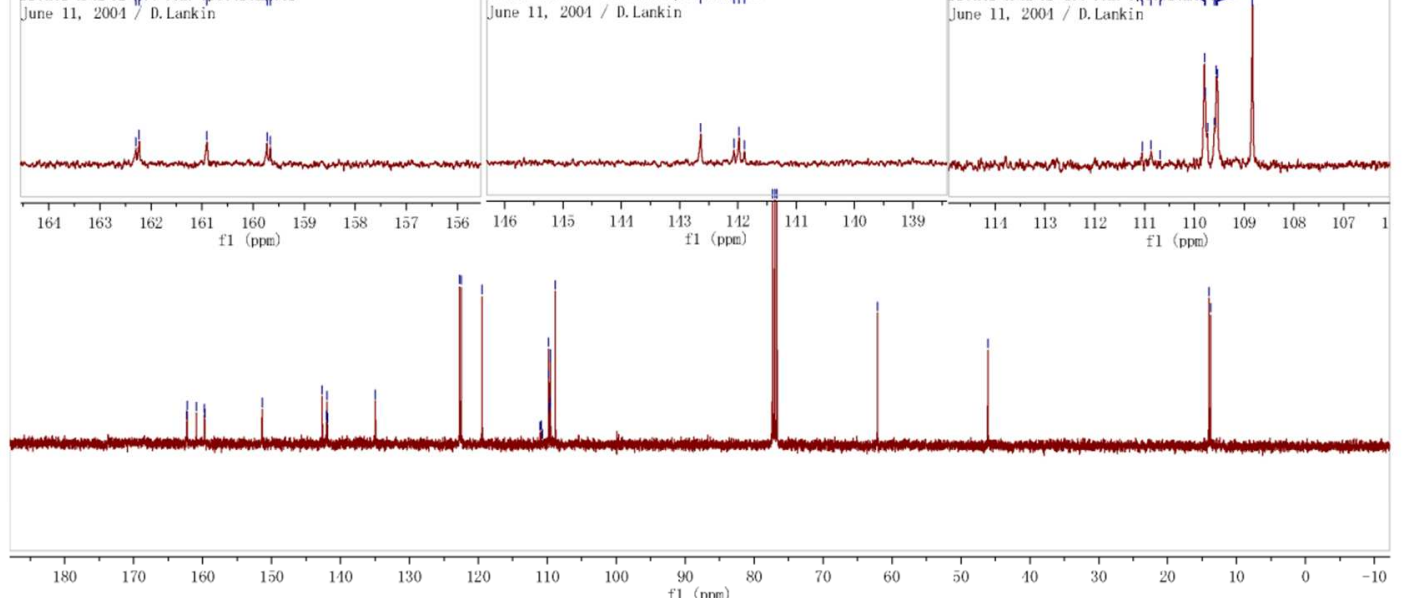
${ }^{1} \mathrm{H}$ NMR (400 MHz, DMSO- $d_{6}$ ) and ${ }^{13} \mathrm{C}$ NMR (100 MHz, DMSO- $d_{6}$ ) spectra for compound $\mathrm{N}$-Hydroxy-2-[(2-methyl-1-benzimidazolyl)methyl]oxazole-4carboxamide (23a).

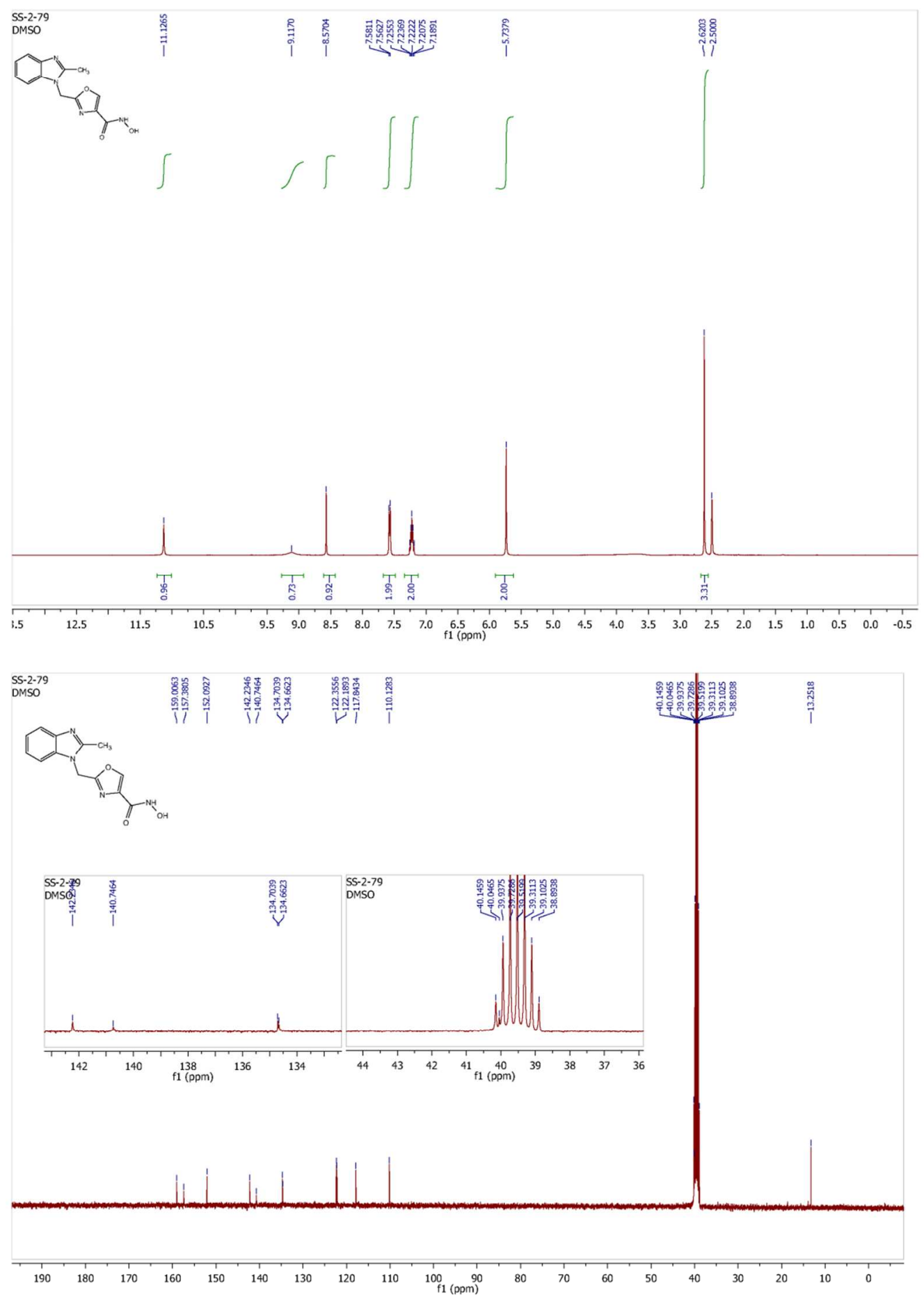


${ }^{1} \mathrm{H}$ NMR (400 MHz, DMSO- $d_{6}$ ) and ${ }^{13} \mathrm{C}$ NMR (100 MHz, DMSO- $d_{6}$ ) spectra for compound $\boldsymbol{N}$-hydroxy-2-[(2-methyl-1-benzimidazolyl)methyl]thiazole-4carboxamide (23b).

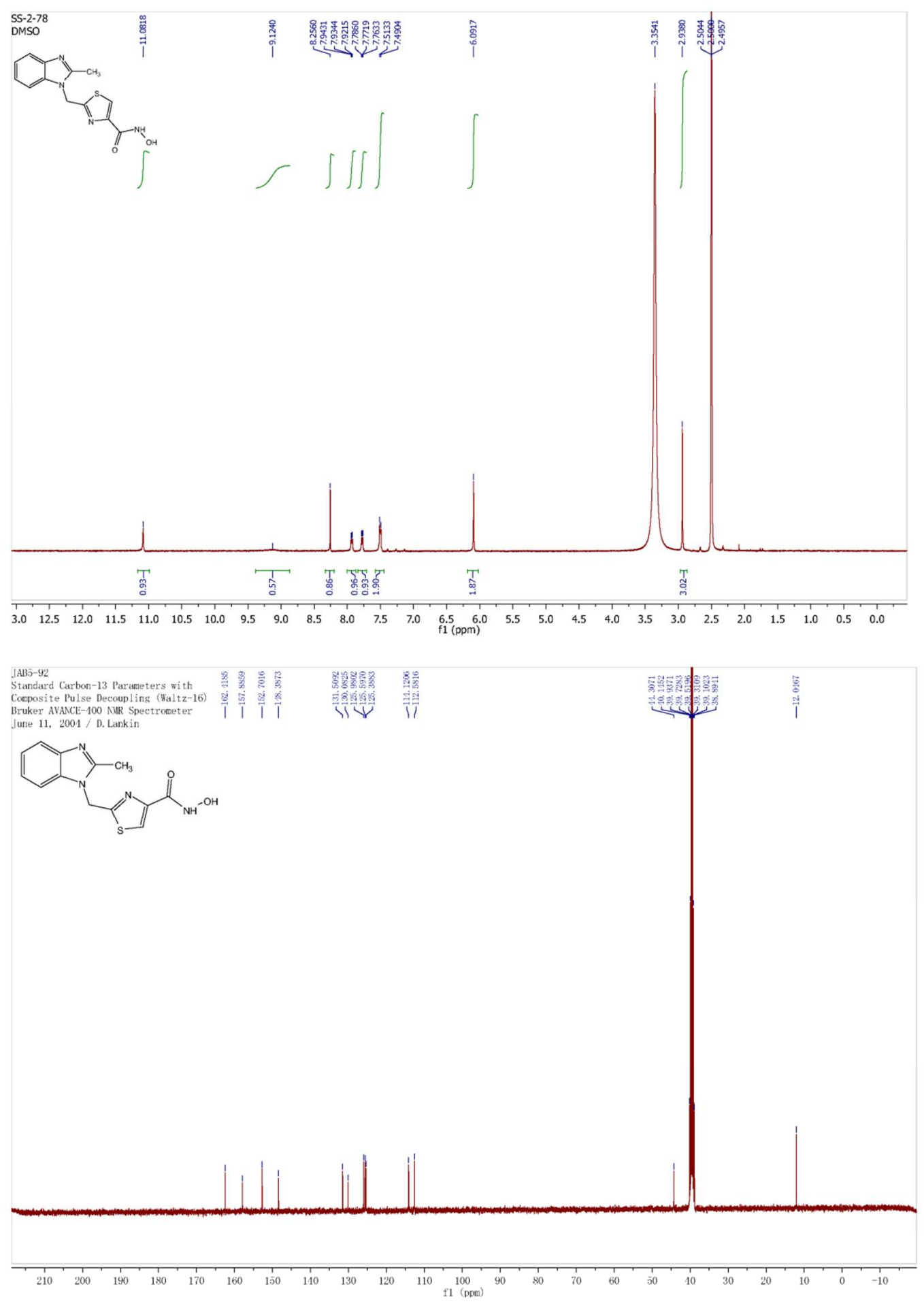


${ }^{1} \mathrm{H}$ NMR (400 MHz, DMSO- $d_{6}$ ) and ${ }^{13} \mathrm{C}$ NMR (100 MHz, DMSO- $d_{6}$ ) spectra for compound $N$-hydroxy-6-[(2-methyl-1-benzimidazolyl)methyl]nicotinamide (23c).
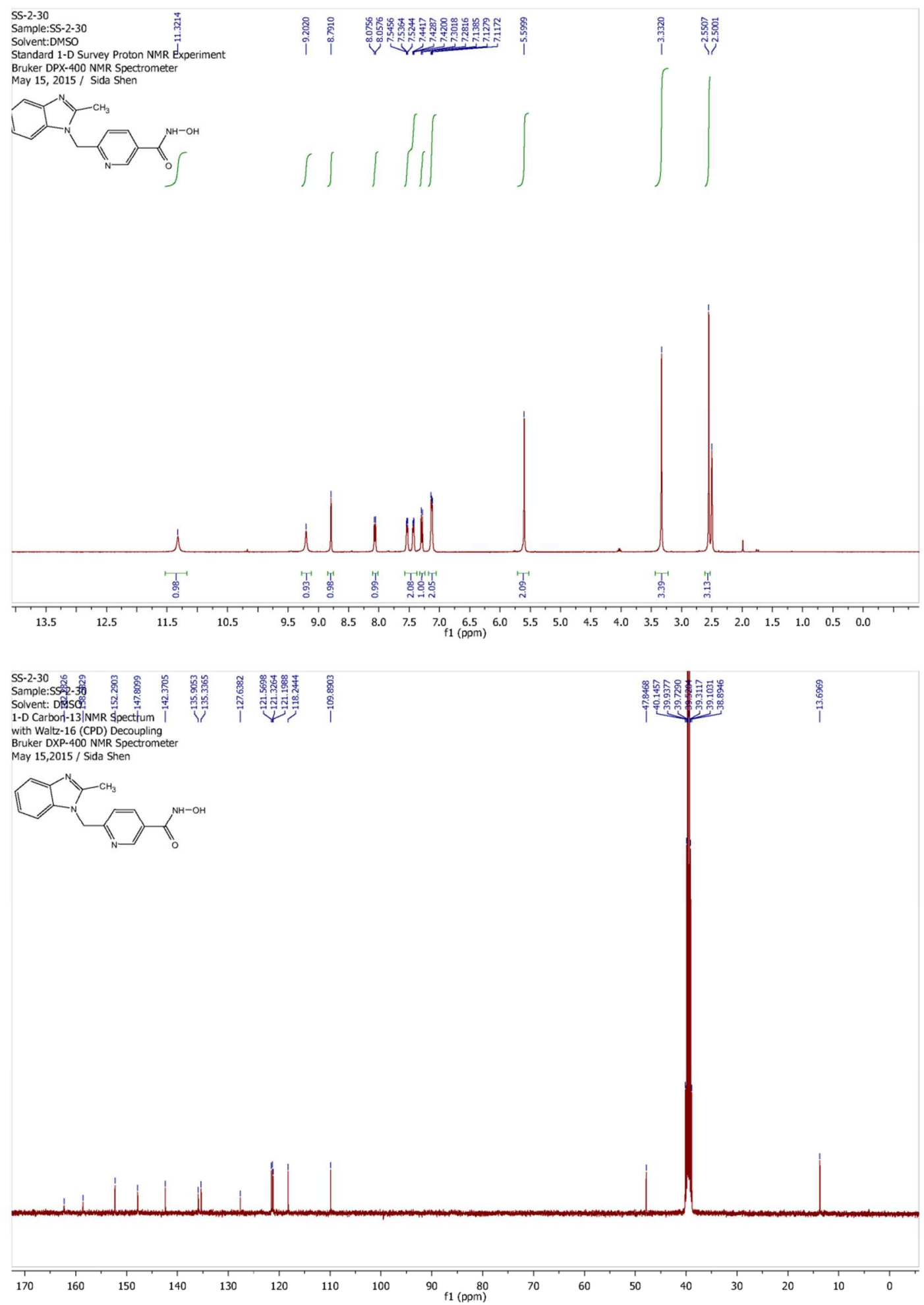
${ }^{1} \mathrm{H}$ NMR (400 MHz, DMSO- $d_{6}$ ) and ${ }^{13} \mathrm{C}$ NMR (100 MHz, DMSO- $d_{6}$ ) spectra for compound 3-fluoro- $N$-hydroxy-4-[(2-methyl-1-benzimidazolyl)methyl]benzamide (23d).

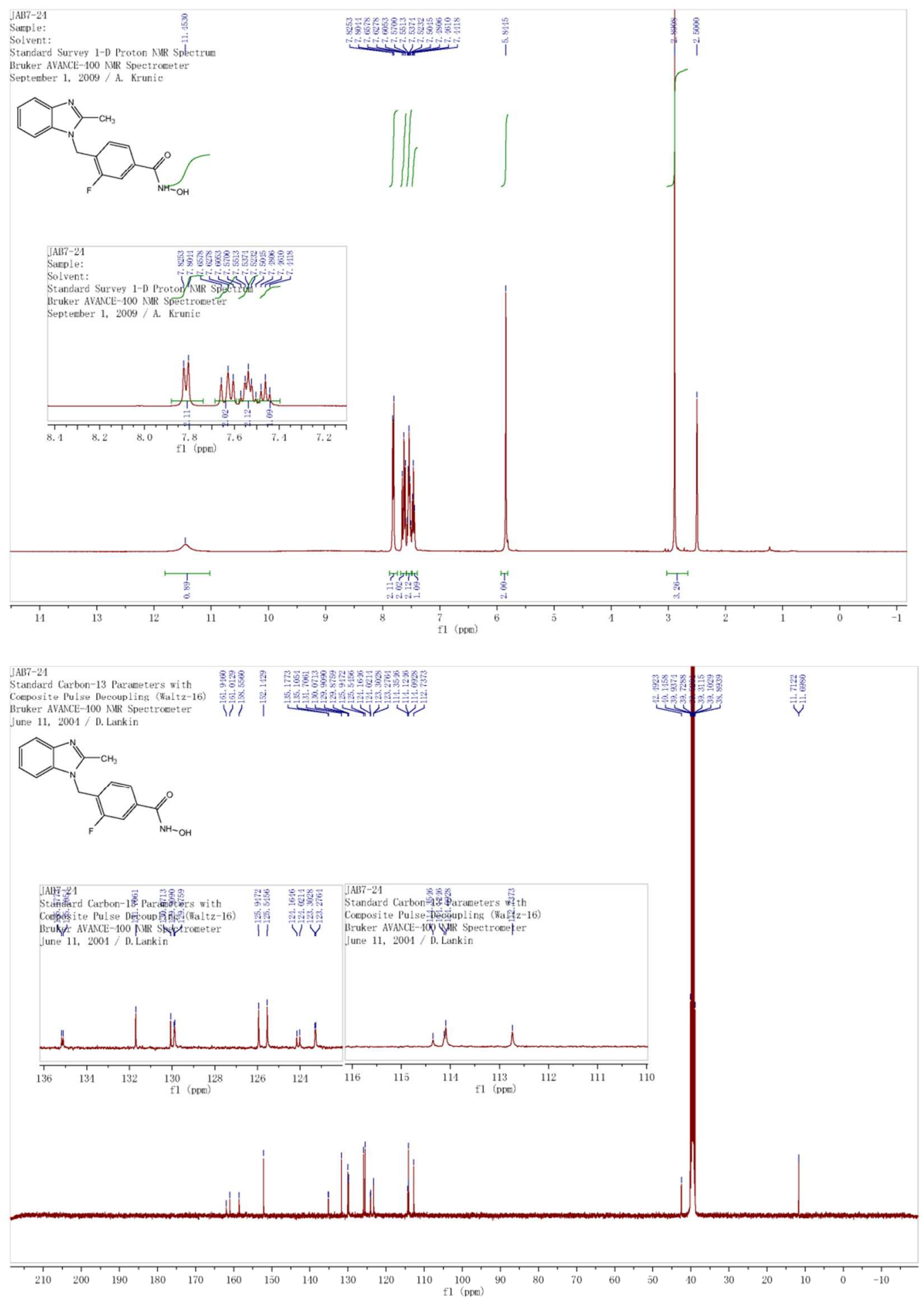


${ }^{1} \mathrm{H}$ NMR (400 MHz, DMSO- $d_{6}$ ) and ${ }^{13} \mathrm{C}$ NMR (100 MHz, DMSO- $d_{6}$ ) spectra for compound 3-fluoro- $N$-hydroxy-4-[(2-(trifluoromethyl)-1-

benzimidazolyl)methyl]benzamide (23e).
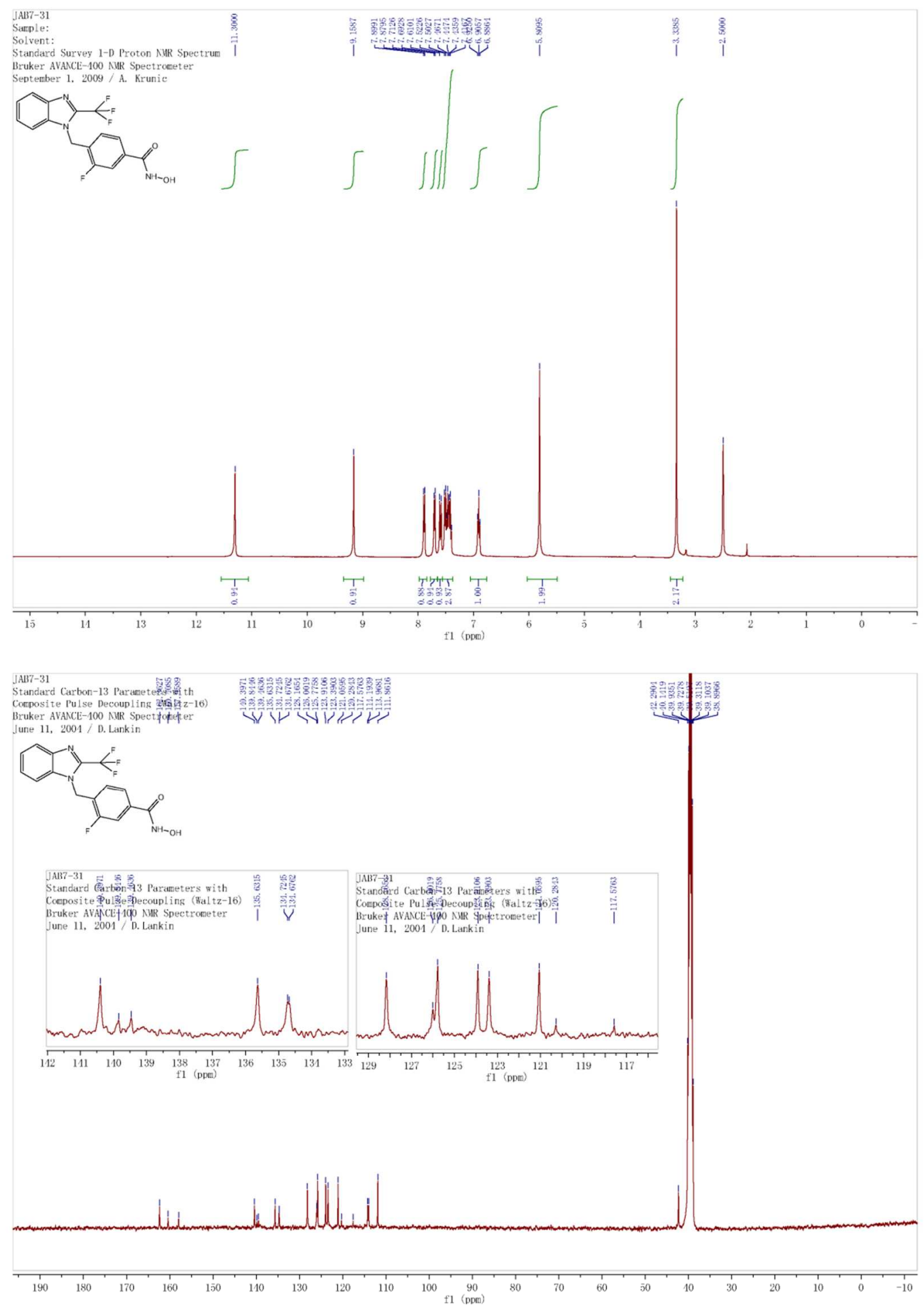
${ }^{1} \mathrm{H}$ NMR (400 MHz, DMSO- $d_{6}$ ) and ${ }^{13} \mathrm{C}$ NMR (100 MHz, DMSO- $d_{6}$ ) spectra for compound 2,3,5,6-tetrafluoro- $N$-hydroxy-4-[(2-methyl-1-

benzimidazolyl)methyl]benzamide (23f).

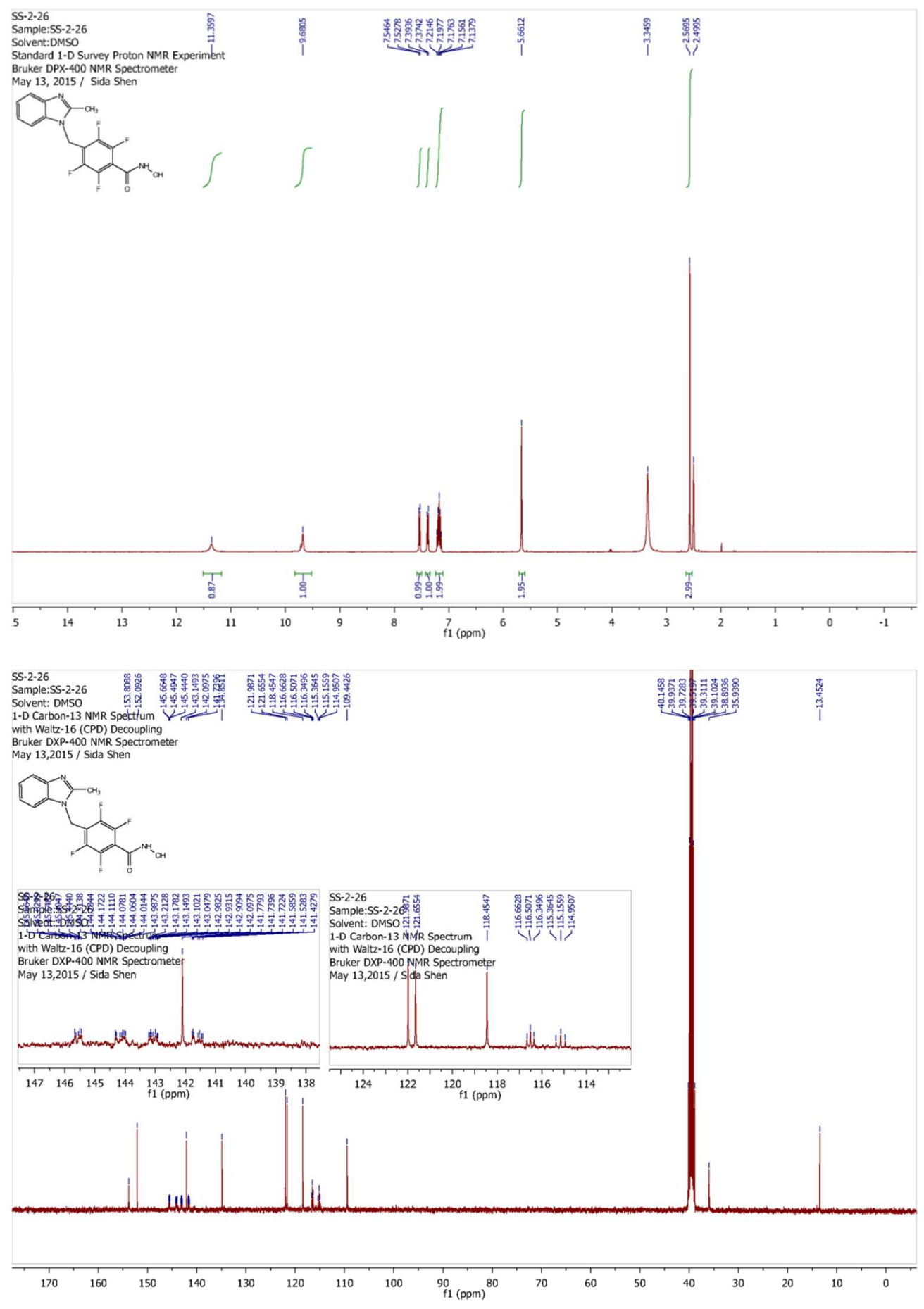


${ }^{1} \mathrm{H}$ NMR (400 MHz, DMSO- $d_{6}$ ) and ${ }^{13} \mathrm{C}$ NMR (100 MHz, DMSO- $d_{6}$ ) spectra for 2,6difluoro- $N$-hydroxy-4-[(2-methyl-1-benzimidazolyl)methyl]benzamide (23g).
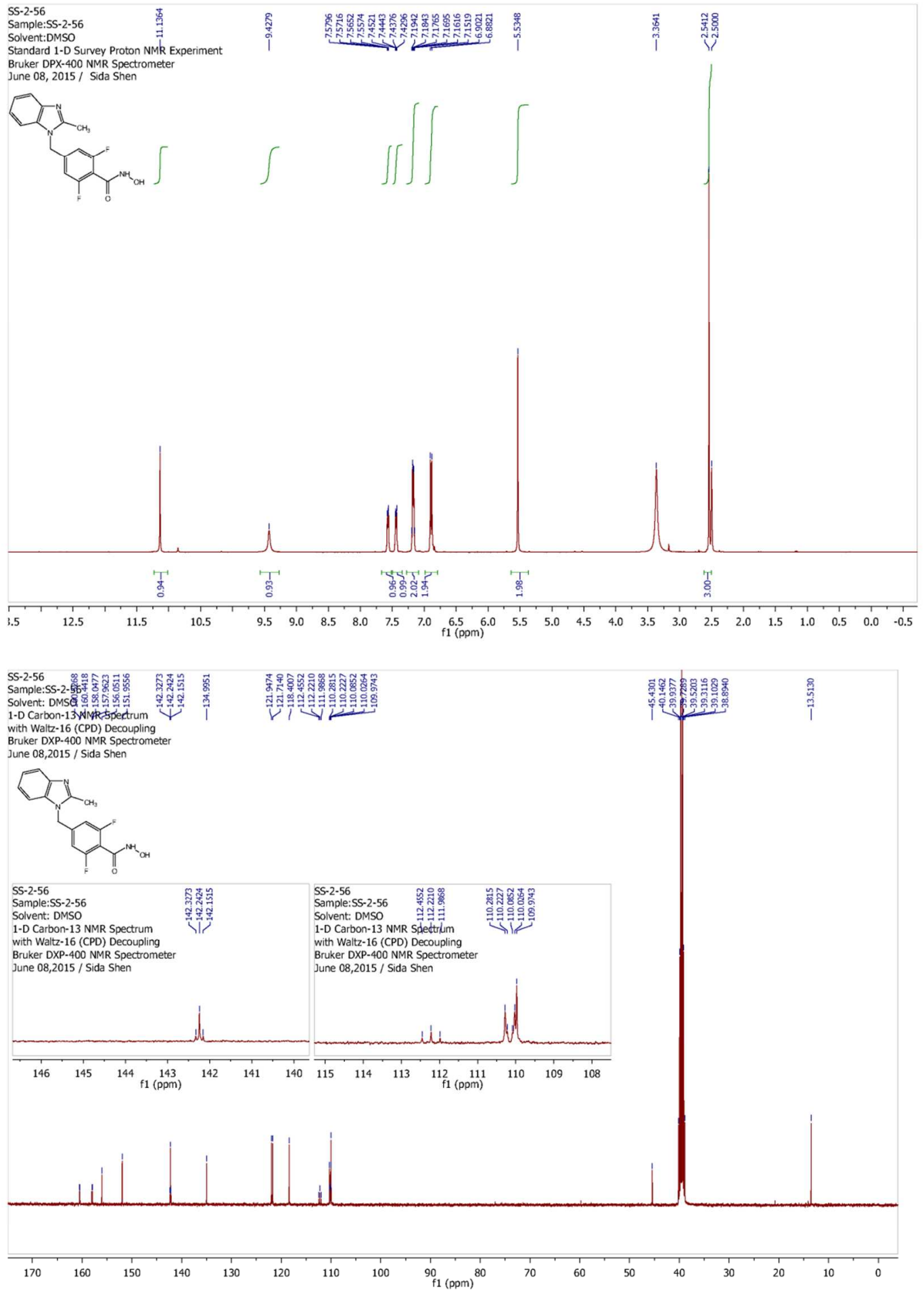
${ }^{1} \mathrm{H}$ NMR $\left(400 \mathrm{MHz}, \mathrm{CDCl}_{3}\right)$ and ${ }^{13} \mathrm{C} \mathrm{NMR}\left(100 \mathrm{MHz}, \mathrm{CDCl}_{3}\right)$ spectra for compound methyl 4-[(6-Fluoro-2-methyl-1-benzimidazolyl)methyl]benzoate (29a).

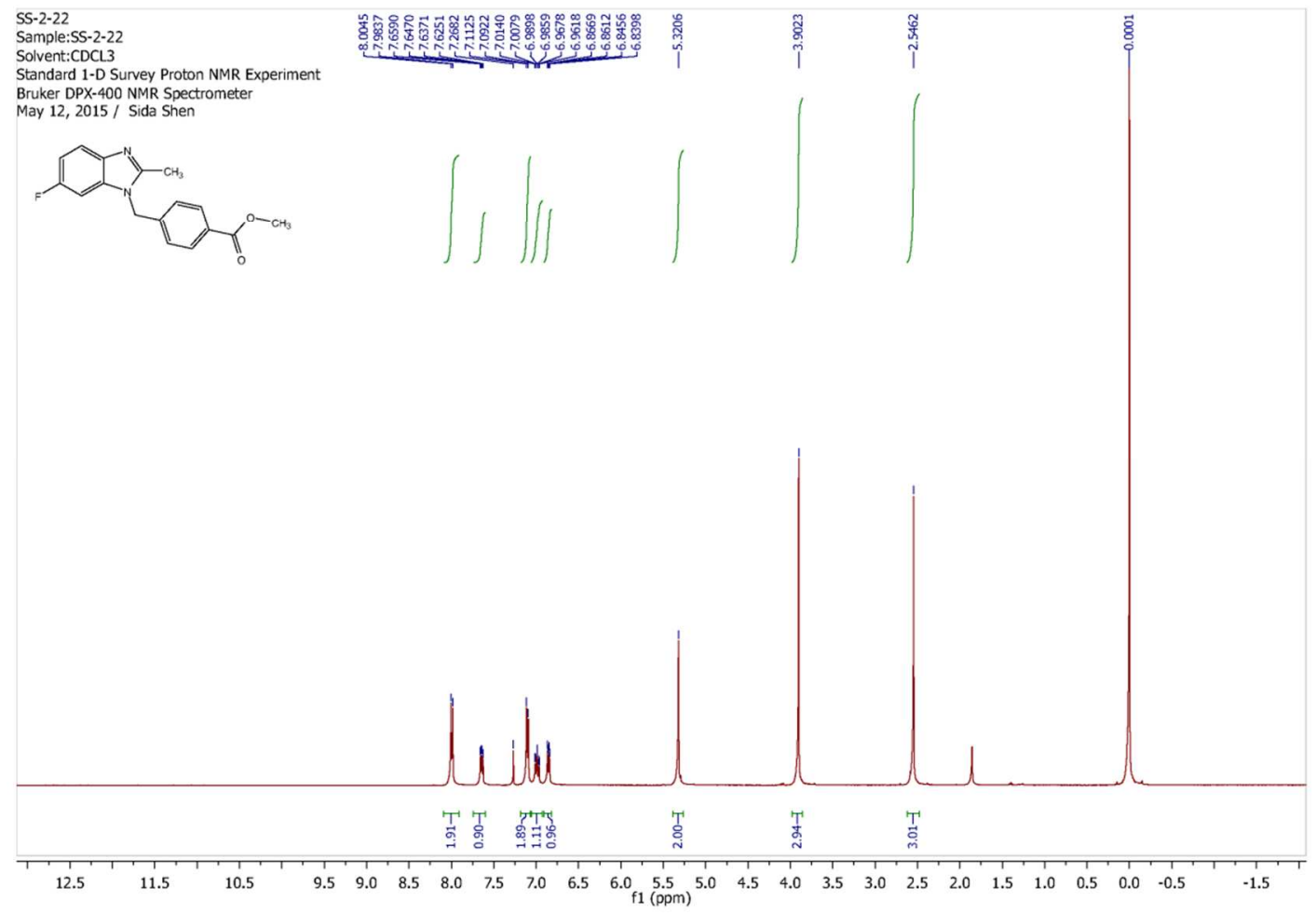

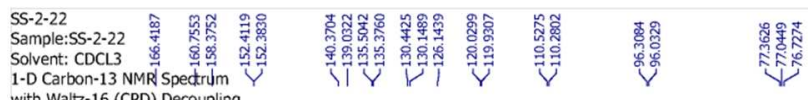

with Waltz-16 (CPD) Decoupling

May 12,2015 / Sida Shen

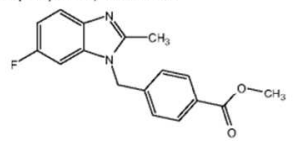$$
\text { SS-2-22 }
$$

Sample:SS-2-22

1-D Carbon-13 NMR Spectrum

with Waltz-16 (CPD) Dectrum

Bruker DXP-400 NMR Spectrometer

May 12,2015 / Sida Shen

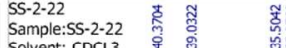

Sample:SS-2-22
Solvent: CDCL2
1-D Carbon-13 NMR ISpectrum

with Waltz-16 (CPD) Decoupling

Bruker DXP-400 NMR Spectrometer

May 12,2015 / Sida Shen
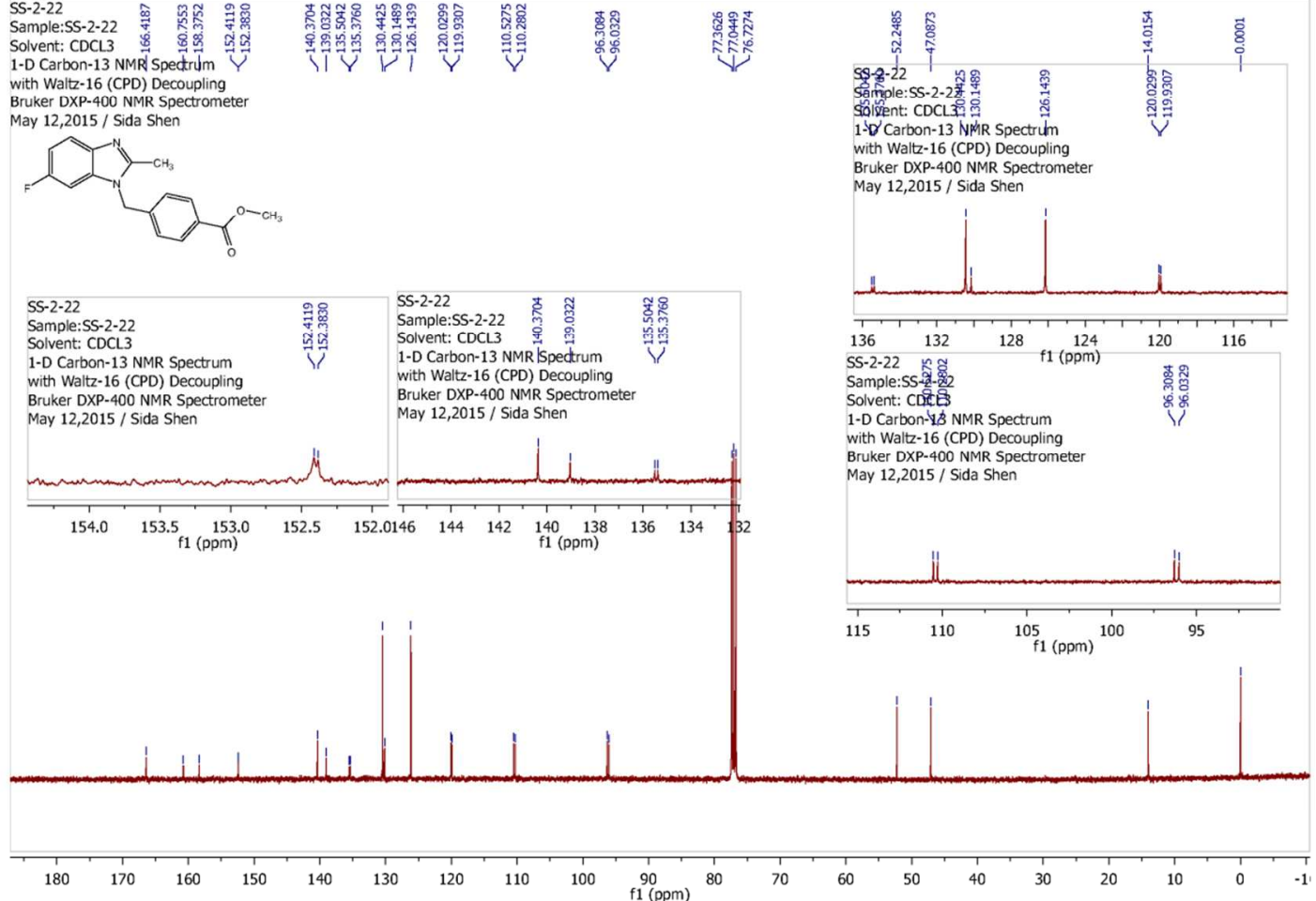
${ }^{1} \mathrm{H}$ NMR $\left(400 \mathrm{MHz}, \mathrm{CDCl}_{3}\right)$ and ${ }^{13} \mathrm{C} \mathrm{NMR}\left(100 \mathrm{MHz}, \mathrm{CDCl}_{3}\right)$ spectra for compound methyl 4-[(5-Fluoro-2-methyl-1-benzimidazolyl)methyl]benzoate (29b).
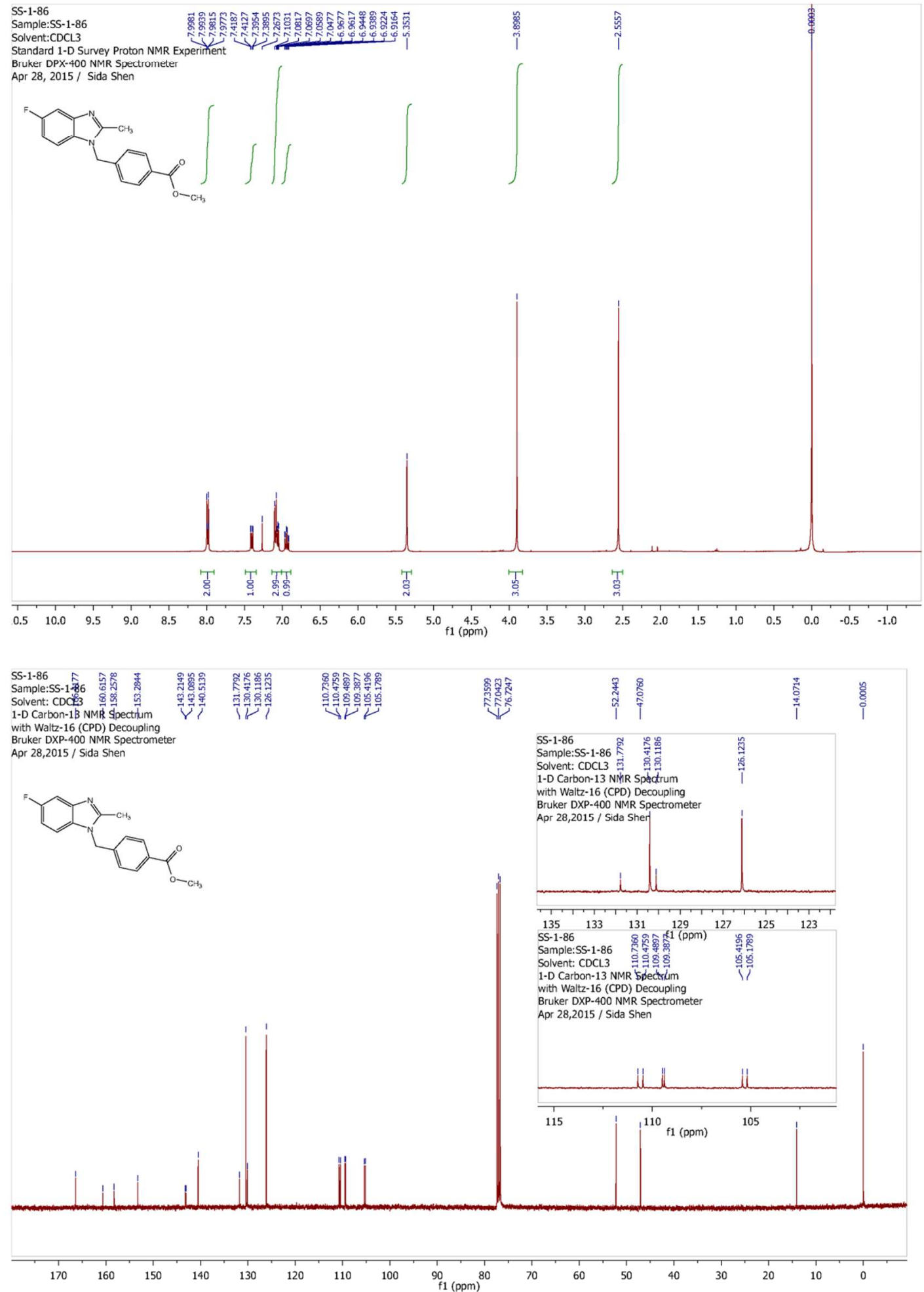
${ }^{1} \mathrm{H}$ NMR (400 MHz, DMSO- $d_{6}$ ) and ${ }^{13} \mathrm{C}$ NMR (100 MHz, DMSO- $d_{6}$ ) spectra for compound 4-[(6-fluoro-2-methyl-1-benzimidazolyl)methyl]- $N$-hydroxybenzamide (30a).
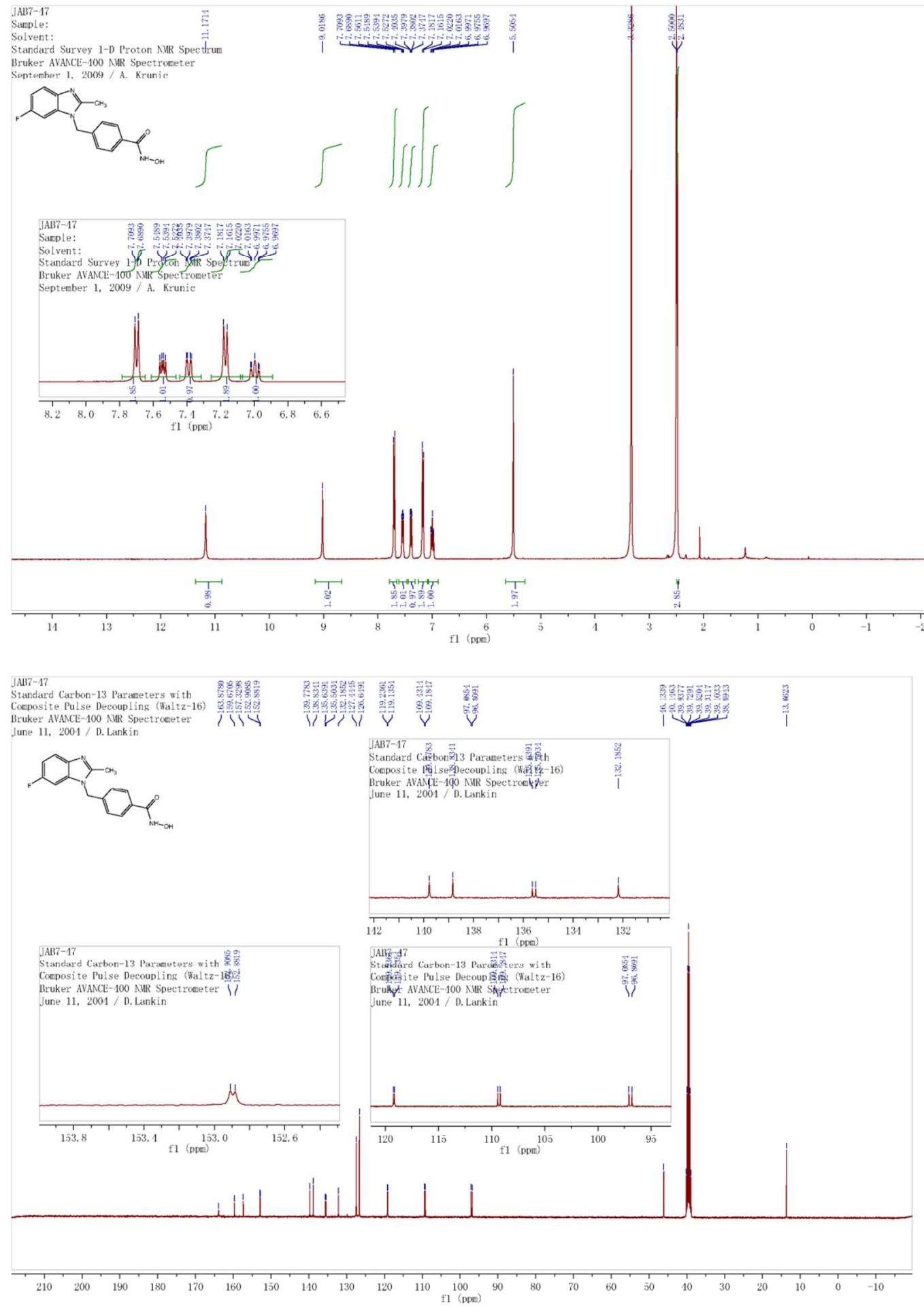
${ }^{1} \mathrm{H}$ NMR (400 MHz, DMSO- $d_{6}$ ) and ${ }^{13} \mathrm{C}$ NMR (100 MHz, DMSO- $d_{6}$ ) spectra for compound 4-[(5-fluoro-2-methyl-1-benzimidazolyl)methyl]- $N$-hydroxybenzamide (30b).

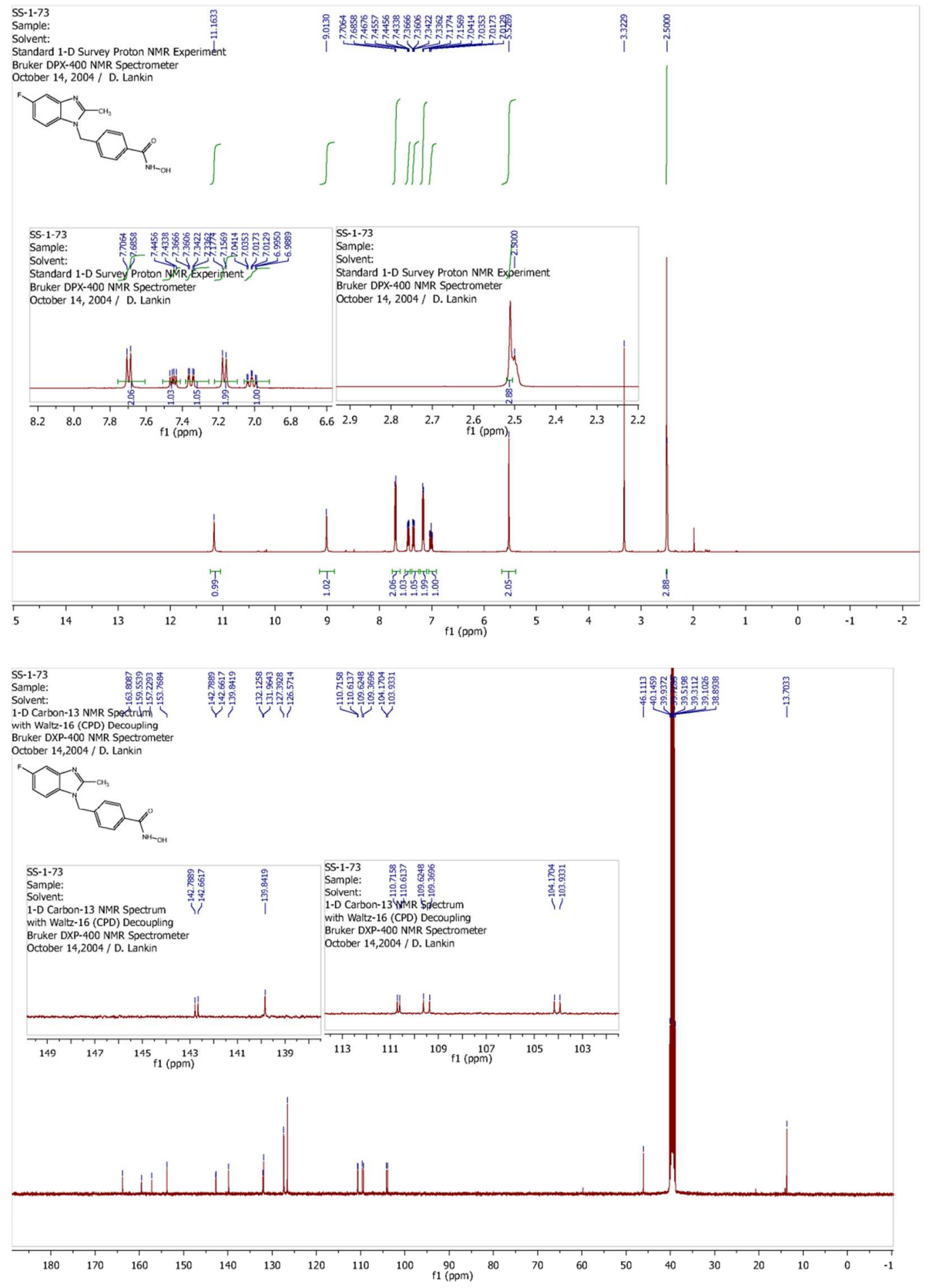




\section{Supplementary figure S1}

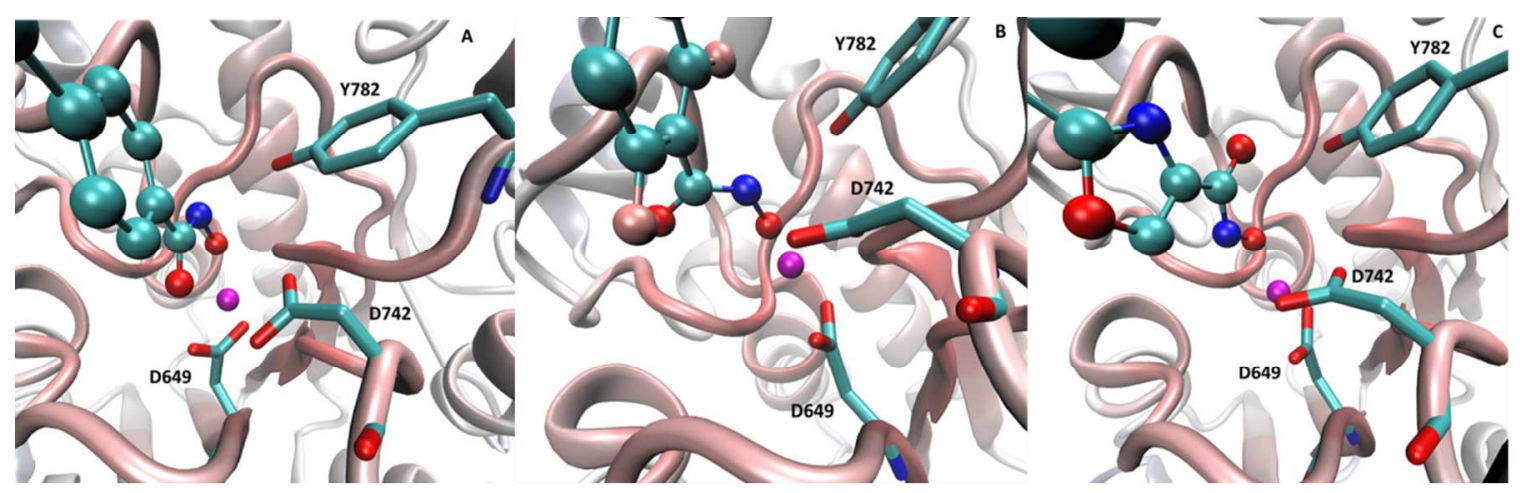

Figure S1. Main interactions between the ligand hydroxamic acid and the metal ion as seen in three representative complexes. S1A refers to $\mathbf{1 7 f}$ taken as an example of a very potent inhibitor in which the hydroxamic acid and phenyl ring are coplanar and both oxygen atoms contact the zinc ion. S1B shows the arrangement for $\mathbf{2 3 g}$, chosen as example of a weakly potent inhibitor, in which the hydroxamic acid and the phenyl ring are roughly perpendicular and only one oxygen atom properly approaches the metal ion. $\mathrm{S} 1 \mathrm{C}$ displays the complex for $\mathbf{2 3 a}$, which is completely inactive due to the incorporation of a 5-membered ring in the linker which prevents the hydroxamic acid from properly approaching the metal ion. 


\section{Supplementary figure S2}
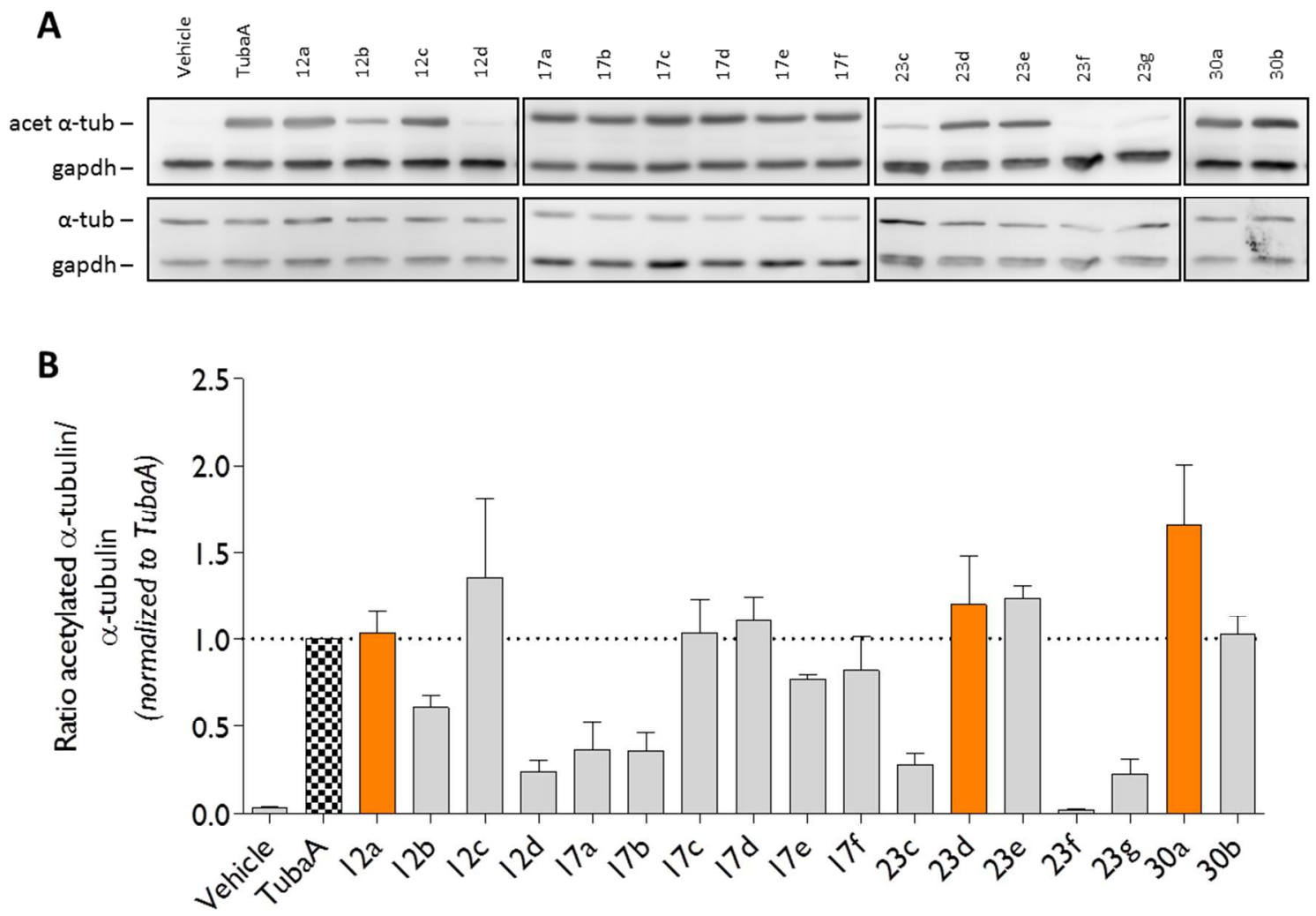

Figure S2. All potential HDAC6 inhibitors were tested in N2a cells at $1 \mu \mathrm{M}$ to quantify their ability to inhibit HDAC6 by WB. A. Antibodies against the acetylated form and the total amount of $\alpha$-tubulin were used on WB. Tubastatin A (TubaA) was used as a positive control. B. Quantification using densitometry of acetylated $\alpha$-tubulin and the total amount of $\alpha$-tubulin shows that several compounds that are able to inhibit HDAC6 while others fail to increase the acetylation of tubulin in a more complex cellular environment. 


\section{Supplementary figure S3}
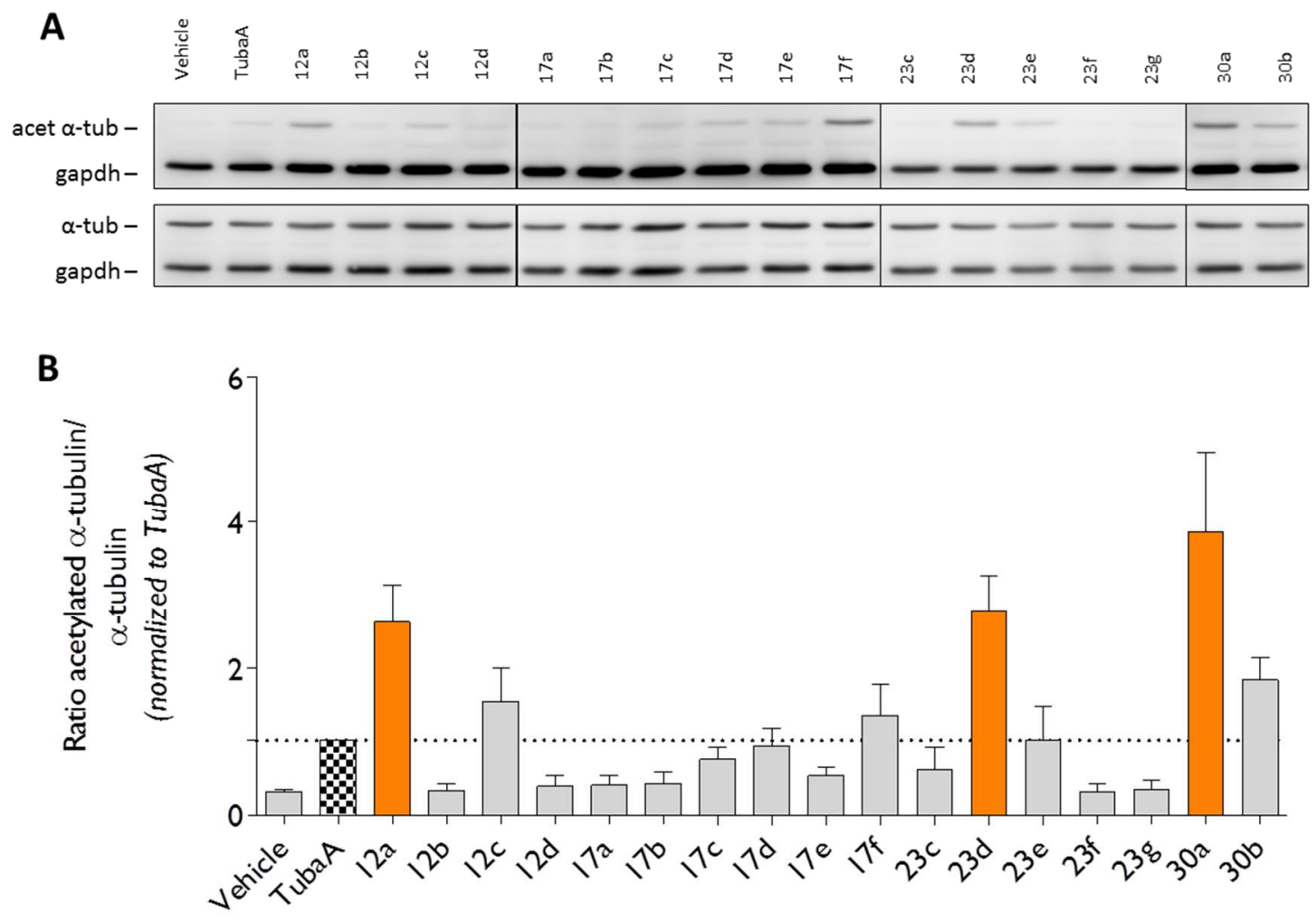

Figure S3. All potential HDAC6 inhibitors were tested in N2a cells at $10 \mathrm{nM}$ to quantify their ability to inhibit HDAC6 by WB. A. Antibodies against the acetylated form and the total amount of $\alpha$-tubulin were used on WB to determine if the compounds were able to inhibit HDAC6. Tubastatin A (TubaA) was used as a positive control. B. Quantification using densitometry of the acetylated $\alpha$-tubulin and the total amount of $\alpha$-tubulin shows that several compounds that are able to inhibit HDAC6 while others fail to increase the acetylation of tubulin in a more complex cellular environment. 


\section{Supplementary figure S4}

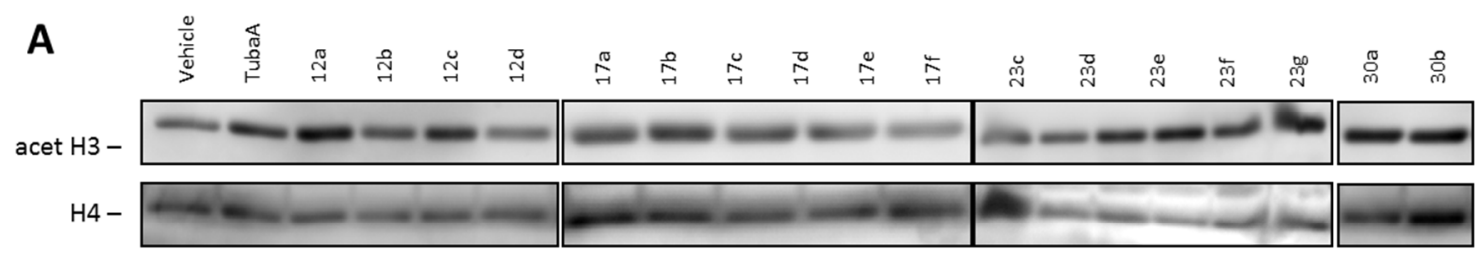

B

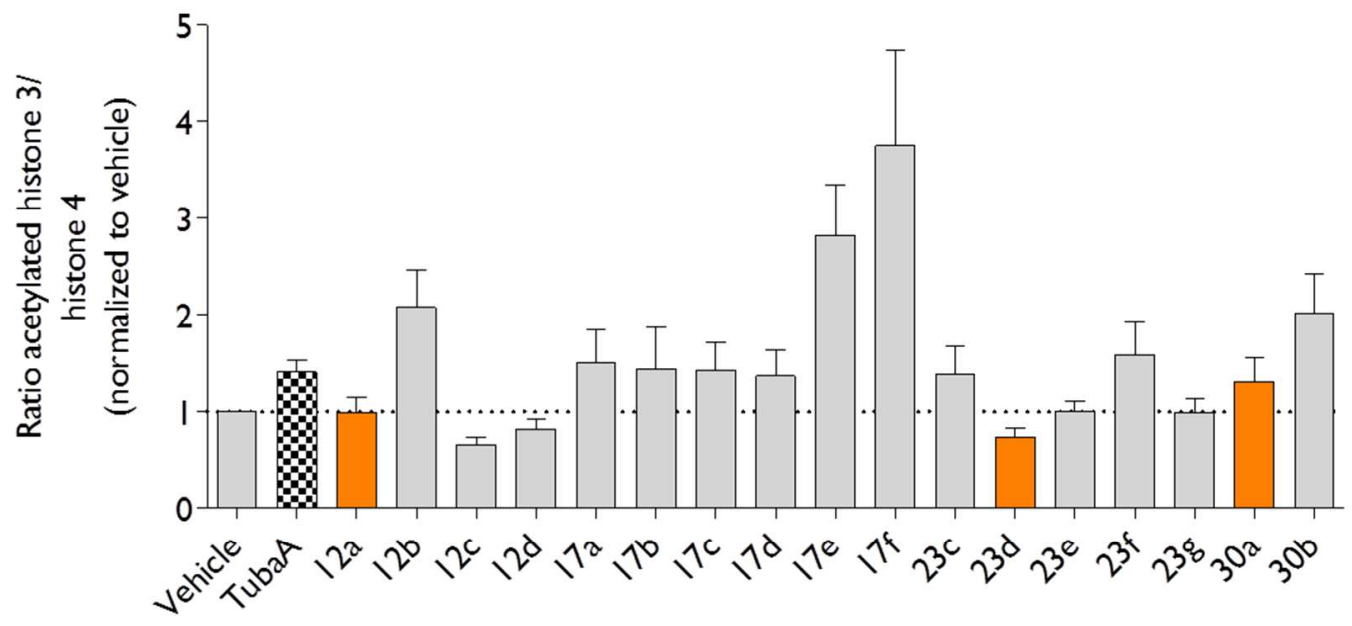

Figure S4. All potential HDAC6 inhibitors were tested in $\mathrm{N} 2$ a cells at $1 \mu \mathrm{M}$ to quantify their selectivity towards by WB. A. Antibodies against the acetylated form of $\mathrm{H} 3$ and the total amount of $\mathrm{H} 4$ were used on WB to determine if the compounds were able to inhibit HDAC6. B. Quantification using densitometry of acetylated $\mathrm{H} 3$ and the total amount of H4 shows that several compounds that are selective toward HDAC6 while some molecules also show affinity for other HDACs. 